\title{
Investigation of bovine conceptus galectins and the effect of bovine conceptus secretory proteins on the endometrial epithelial transcriptome
}

Heather Lynn Baldwin

West Virginia University, hebaldwin@mix.wvu.edu

Follow this and additional works at: https://researchrepository.wvu.edu/etd

Part of the Beef Science Commons, and the Reproductive and Urinary Physiology Commons

\section{Recommended Citation}

Baldwin, Heather Lynn, "Investigation of bovine conceptus galectins and the effect of bovine conceptus secretory proteins on the endometrial epithelial transcriptome" (2019). Graduate Theses, Dissertations, and Problem Reports. 4080.

https://researchrepository.wvu.edu/etd/4080

This Thesis is protected by copyright and/or related rights. It has been brought to you by the The Research Repository @ WVU with permission from the rights-holder(s). You are free to use this Thesis in any way that is permitted by the copyright and related rights legislation that applies to your use. For other uses you must obtain permission from the rights-holder(s) directly, unless additional rights are indicated by a Creative Commons license in the record and/ or on the work itself. This Thesis has been accepted for inclusion in WVU Graduate Theses, Dissertations, and Problem Reports collection by an authorized administrator of The Research Repository @ WVU. For more information, please contact researchrepository@mail.wvu.edu. 
2019

Investigation of bovine conceptus galectins and the effect of bovine conceptus secretory proteins on the endometrial epithelial transcriptome

Heather Lynn Baldwin

Follow this and additional works at: https://researchrepository.wvu.edu/etd 


\title{
INVESTIGATION OF BOVINE CONCEPTUS GALECTINS AND THE EFFECT OF BOVINE CONCEPTUS SECRETORY PROTEINS ON THE ENDOMETRIAL EPITHELIAL TRANSCRIPTOME
}

\author{
HEATHER L. BALDWIN
}

Thesis submitted

to the Davis College of Agriculture, Natural Resources and Design at West Virginia University

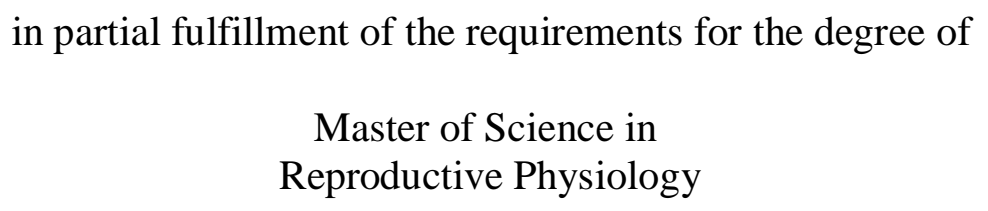

Daniel J. Mathew, Ph.D., Chair Jianbo Yao, Ph.D. Robert A. Dailey, Ph.D.

Division of Animal and Nutritional Sciences

$$
\text { Morgantown, WV }
$$

2019

KEYWORDS: Cattle, elongation, endometrium, conceptus, interferon tau, galectin Copyright 2019 Heather Baldwin 
ABSTRACT

INVESTIGATION OF BOVINE CONCEPTUS GALECTINS AND THE EFFECT OF

BOVINE CONCEPTUS SECRETORY PROTEINS ON THE ENDOMETRIAL EPITHELIAL

\title{
TRANSCRIPTOME
}

\author{
Heather L. Baldwin
}

Pregnancy loss in cattle is greatest in the first 30 days of gestation. Near d15 of gestation, bovine conceptuses elongate and express LGALS1, an immunosuppressive glycan-binding protein believed to be essential for implantation. However, other members of the bovine galectin family, including LGALS3, LGALS4, LGALS7, LGALS8, LGALS9 and a galectin-13-like gene (LGALS13L), also may be expressed by the elongating conceptus. Therefore, galectin expression in elongating, d16 bovine conceptuses and intercaruncular endometrium as well as elongating, d14 ovine conceptuses and intercaruncular endometrium was assessed by RT-qPCR. Angus heifer and Texel ewes underwent estrous cycle synchronization and either inseminated or not bred. On d16 (heifers) or d14 (ewes) after synchronized estrus (d0), reproductive tracts of pregnant (heifers, $\mathrm{n}=4$; ewes, $\mathrm{n}=3$ ) and cyclic (heifers, $\mathrm{n}=4$; ewes, $\mathrm{n}=3$ ) animals were removed. Conceptuses and intercaruncular endometrial samples were then collected. Conceptuses and intercaruncular endometrium samples were individually snap frozen and stored at $-80^{\circ} \mathrm{C}$ until RT-qPCR. Bovine and ovine conceptus gene expression was normalized to control genes GAPDH and YWHAZ, and endometrial gene expression was normalized to control genes H3F3A and RNF11. A general linear model procedure (PROC GLM) in SAS was used to test for differences. For the conceptus data, alpha was set at 0.05 , and a Tukey's test was included in the analysis. Conceptus data are presented as non-transformed means \pm standard deviation (SD) of the mean. Endometrial data are presented as non-transformed least square means (LSM) \pm standard error of the mean (SEM) and P $\leq 0.05$ was considered significant. In bovine conceptuses, expression of LGALS3 $(24.47 \pm 6.41)$ and LGALS1 $(21.80 \pm 2.07)$ was similar, yet, greater than all other galectins measured $(\alpha=0.05)$. Expression of LGALS8 $(1.73 \pm 0.27)$ was 12 -fold less than LGALS1, however, LGALS8 expression was greater than LGALS9 $(0.77 \pm 0.77)$, LGALS13L $(0.30 \pm 0.10)$, LGALS4 (0.08 \pm $0.01)$ and LGALS7 $(0.02 \pm 0.01)(\alpha=0.05)$. In bovine intercaruncular endometrium, expression of LGALS1, LGALS8, and LGALS9 were greatest. Compared to cyclic heifers, endometrial expression of LGALS7 was less (5.80 \pm 2.35 and $2.62 \pm 2.35$; cyclic and pregnant, respectively; $\mathrm{P} \leq 0.05)$, while expression of LGALS9 (9.26 \pm 2.25 and $24.56 \pm 2.25$; cyclic and pregnant, respectively; $\mathrm{P} \leq 0.001)$ and LGALS3 were greater $(2.62 \pm 0.52$ and $4.40 \pm 0.52$; cyclic and pregnant, respectively; $\mathrm{P} \leq 0.05)$ during pregnancy. In sheep conceptuses, expression of LGALS3 (4.30 \pm 0.78$)$, LGALS1 $(1.90 \pm 0.25)$ and LGALS8 $(1.68 \pm 0.25)$ were similar. Compared to all other galectins measured, LGALS4 $(0.20 \pm 0.10)$ had the lowest level of expression $(\alpha=0.05)$. In ovine intercaruncular endometrium, expression of LGALS3, LGALS8, and LGALS15 were greatest. Compared to cyclic ewes, expression of LGALS7 was greater in pregnant ewes $(0.81 \pm$ 0.24 and $2.25 \pm 0.24$; cyclic and pregnant, respectively; $\mathrm{P} \leq 0.05)$ while LGALS4 (3.10 \pm 0.38 and $1.78 \pm 0.38$; cyclic and pregnant, respectively; $\mathrm{P}=0.06)$ tended to be less during pregnancy and 
LGALS15 tended to be greater during pregnancy $(104.30 \pm 234.20$ and $591.35 \pm 234.20, \mathrm{P}=0.07$; cyclic and pregnant, respectively). In conclusion, elongating bovine and ovine conceptuses express various members of the galectin gene family, and select galectin genes are differentially expressed in the endometrium during pregnancy. The galectins may have important functions during early pregnancy in ruminants.

Interferon-tau (IFNT), secreted by the elongating bovine conceptus, is the maternal recognition of pregnancy signal that suppresses the endometrial luteolytic mechanism by modifying expression of genes in specific cell types within the endometrium. The conceptus also secretes galectin proteins, specifically galectin-3. This study assessed the effect of IFNT (Experiment 1) and LGALS3 (Experiment 2) on bovine endometrial epithelial and fibroblast cell transcriptomes when the mid-luteal phase endometrial cells were cultured in a 3D environment. In Experiment one, epithelial cells, cultured in Transwell inserts above the fibroblast cells, were treated with RPMI media alone (control; $\mathrm{n}=4$ ) or treatment media (RPMI with 5\% FBS and 1\% ABAM) containing $100 \mathrm{ng}$ of recombinant ovine IFNT $(n=3)$ for $6 \mathrm{~h}$. In Experiment two, cells were treated with either RPMI media alone (Control; $n=5)$, pregnant ovine uterine flush fluid, theoretically containing INFT, diluted with treatment media 1:1 $(\mathrm{n}=4)$, or treatment media (RPMI with 5\% FBS and $1 \%$ ABAM) containing either 100 or 1000 ng of recombinant mouse LGALS3 $(\mathrm{n}=5)$ for $6 \mathrm{~h}$. Total RNA was extracted from both cell types and the transcriptomes were assayed by RNA Sequencing and RT-qPCR. Interferon-tau regulated 673 and 83 genes (differentially expressed genes or DEGs) in epithelial and fibroblast cells, respectively $(\mathrm{P} \leq 0.001 ; \mathrm{FDR} \mathrm{P} \leq 0.05)$. Many of the DEGs identified in the epithelial (205) and fibroblast cells (64) were previously reported as IFNT and bovine conceptus-induced DEGs in intact bovine endometrium, including well-known ISGs such as ISG15, MX1, MX2, OAS1, and OAS2. Surprisingly, the ZC3HAV1 gene, which was recently found to be up-regulated in intact bovine endometrium in response to the conceptus, was only up-regulated in fibroblast cells despite applying IFNT to the apical surface of the epithelial cells in 3D culture. The RNA-Seq analysis of the bovine endometrial cells treated with mouse LGALS3 protein resulted in the identification of a single gene, RPL23A, that was upregulated in epithelial cells treated with $100 \mathrm{ng}$ of LGALS3 $(\mathrm{P} \leq 0.001$; FDR $\mathrm{P} \leq 0.05)$. This study supports the idea that the 3D culture of bovine endometrial cells may be utilized to study early conceptus-maternal crosstalk and identify endometrial cell type-specific responses to the conceptus. 


\section{ACKNOWLEDGMENTS}

I would like to thank my advisor, Dr. Daniel Mathew for the opportunities you have granted me during my time as a M.S. student. I will be forever grateful for your encouragement and motivated by your passion for science. Thank you for being a great mentor, educator, and friend. I also would like to thank my committee members, Dr. Dailey and Dr. Yao for their time, wisdom, and encouragement as well as Dr. Inskeep and Dr. Holásková. I am grateful for their constant support, insight, and dedication to the field of reproductive physiology.

I greatly appreciate the support I have received from my lab mate, Lindsay Grose, and fellow graduate students, Malia Berg, Mingxiang Zhang, and Jaelynn Current. Thank you for always being willing to help in whatever way necessary. I would also like to thank them for their friendship as I will always cherish the memories and relationships made in the past two years. I would especially like to thank Dr. Wilson and Dr. Bowdridge for assisting with the sheep for my study. The numerous undergraduate students that have worked in our lab have been a tremendous help and I am greatly appreciative of their motivation and willingness to help. Our research would have not been possible without the help of various local slaughterhouses and their cooperation.

Lastly, I would like to thank my family and friends for always being understanding and supportive. I am thankful to my parents for the motivation and constant encouragement of my education. Without their support, I would not have been as successful. 


\section{TABLE OF CONTENTS}

\section{CHAPTER}

I. LITERATURE REVIEW .......................................... 1

Introduction.........................................................

The bovine estrous cycle........................................2

Early bovine pregnancy.........................................4

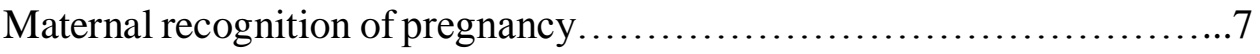

Bovine embryonic attachment................................. 10

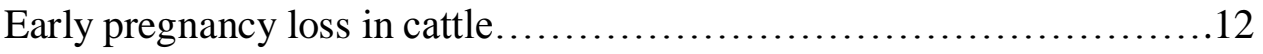

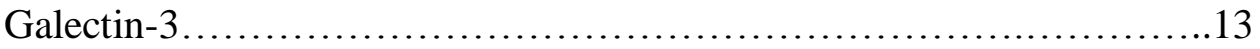

Galectin-3 in reproduction....................................... 16

The role of galectin-3 in apoptosis................................17

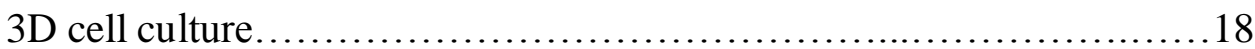

II. GALECTIN GENE EXPRESSION IN BOVINE AND OVINE ELONGATING CONCEPTUSES AND PREGNANT AND CYCLIC

\section{ENDOMETRIUM}

Abstract........................................................20

Introduction...................................................22

Materials and Methods................................................24

Results.......................................................29

Discussion....................................................... 32 
Conclusions.

III. EFFECT OF INTERFERON TAU AND GALECTIN-3 ON BOVINE ENDOMETRIAL EPITHELIAL AND FIBROBLAST CELL TRANSCRIPTOMES IN 3D CELL CULTURE

Abstract.......................................................... 44

Introduction................................................45

Materials and Methods..........................................48

Results..........................................................55

Discussion................................................61

Conclusions...................................................67

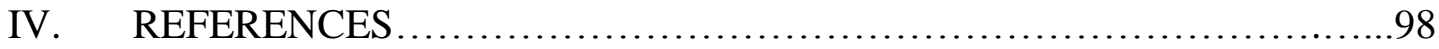




\section{LIST OF TABLES}

Table 2.1. GenBank accession number, gene name, primer direction, primer sequence, product size and percent amplification efficiency of cDNAs amplified during real-time quantitative-polymerase chain reaction (RT-qPCR)

Table 3.1 GenBank accession number, gene name, primer direction, primer sequence, product size, percent amplification efficiency, and source of primer of cDNAs amplified during real-time quantitative-polymerase chain reaction (RT-qPCR)

Table 3.2. Genes up- or down-regulated in the venn diagram (Figure 2.1) ...................72

Table 3.3. The $\log F C$ of the top 20 genes up-regulated in epithelial cells and explants (I and II of

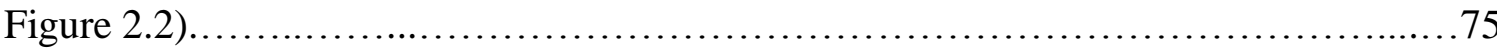

Table 3.4. GO Biological Process Direct for genes up-regulated in epithelial cells treated with $100 \mathrm{ng}$ of oIFNT in 3D culture (I and II of Figure 2.2.) .......................76

Table 3.5. GO Biological Process Direct for genes up-regulated in fibroblast cells treated with $100 \mathrm{ng}$ of oIFNT in 3D culture (II and III of Figure 2.2.) ......................82

Table 3.6. Quantitative real-time PCR analysis of the effect of 100 or $1000 \mathrm{ng}$ of LGALS3 protein on $3 \mathrm{D}$ cultured epithelial and fibroblast cells.............................. 96 


\section{LIST OF FIGURES}

Figure 2.1. Images of bovine and ovine conceptuses collected on d16 and d14 of gestation,

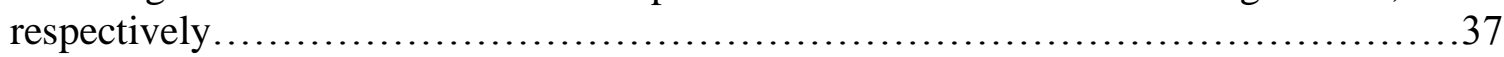

Figure 2.2. Galectin RT-qPCR products visualized on a $0.8 \%$ agarose gel and a 50 bp DNA

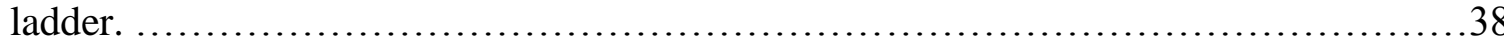

Figure 2.3. Quantitative real-time PCR analysis of galectins in the d16 bovine conceptus.......39

Figure 2.4. Quantitative real-time PCR analysis of galectins in pregnant and cyclic d16 bovine intercaruncular endometrium. ................................................. 40

Figure 2.5. Quantitative real-time PCR analysis of galectins in the d14 ovine conceptus

Figure 2.6. Quantitative real-time PCR analysis of galectins in pregnant and cyclic d14 ovine intercaruncular endometrium................................................ 42

Figure 2.7. Galectin-3 (LGALS3) protein in an elongating d15 bovine conceptus

Figure 3.1. The 3D cell culture system used to coculture bovine endometrial epithelial and fibroblast cells.

Figure 3.2. A Venn diagram (Venny 2.1 BioinfoGP) categorizing differentially expressed genes (DEGs) in response to oIFNT between bovine endometrial intercaruncular explants, bovine endometrial epithelial cells and bovine endometrial fibroblast cells cultured in a 3D system.

Figure 3.3. Quantitative real-time PCR analysis of $M X 1$ gene expression in bovine endometrial epithelial and fibroblast cells cultured in 3D treated with either $100 \mathrm{ng}$ of oIFNT or treatment media only.

Figure 3.4. Quantitative real-time PCR analysis of $M X 2$ gene expression in bovine endometrial epithelial and fibroblast cells cultured in 3D treated with either $100 \mathrm{ng}$ of oIFNT or treatment media only.

Figure 3.5. Quantitative real-time PCR analysis of OAS1 gene expression in bovine endometrial epithelial and fibroblast cells cultured in 3D treated with either $100 \mathrm{ng}$ of oIFNT or treatment media only.

Figure 3.6. Quantitative real-time PCR analysis of $L G A L S 3 B P$ gene expression in bovine endometrial epithelial and fibroblast cells cultured in 3D treated with either $100 \mathrm{ng}$ of oIFNT or treatment media only 
Figure 3.7. Quantitative real-time PCR analysis of $L G A L S 9$ gene expression in bovine endometrial epithelial and fibroblast cells cultured in 3D treated with either $100 \mathrm{ng}$ oIFNT or treatment media only.

Figure 3.8. Quantitative real-time PCR analysis of OAS2 gene expression in bovine endometrial epithelial and fibroblast cells cultured in 3D treated with either $100 \mathrm{ng}$ of oIFNT or treatment media only...

Figure 3.9. Quantitative real-time PCR analysis of BATF2 gene expression in bovine endometrial epithelial and fibroblast cells cultured in 3D treated with either $100 \mathrm{ng}$ of oIFNT or treatment media only. ...

Figure 3.10. Quantitative real-time PCR analysis of IDO1 gene expression in bovine endometrial epithelial and fibroblast cells cultured in 3D treated with either $100 \mathrm{ng}$ of oIFNT or treatment media only....

Figure 3.11. Quantitative real-time PCR analysis of MAP6 gene expression in bovine endometrial epithelial and fibroblast cells cultured in 3D treated with either $100 \mathrm{ng}$ of oIFNT or treatment media only.............................................

Figure 3.12. Quantitative real-time PCR analysis of TNFSF13B gene expression in bovine endometrial epithelial and fibroblast cells cultured in 3D treated with either $100 \mathrm{ng}$ of oIFNT or treatment media only.............................................94

Figure 3.13. Quantitative real-time PCR analysis of ZC3HAVI gene expression in bovine endometrial epithelial and fibroblast cells cultured in 3D treated with either $100 \mathrm{ng}$ of

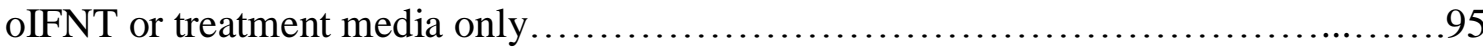

Figure 3.14. Model for IFNT regulation of classical and non-classical up-regulated ISGs in the bovine endometrium during early pregnancy.... 


\section{LIST OF ABBREVIATIONS}

$\begin{array}{ll}\mu \mathrm{g} & \text { microgram } \\ \mu \mathrm{L} & \text { microliter } \\ \text { 2D } & \text { two-dimensional } \\ \text { 3D } & \text { three-dimensional } \\ \text { ABAM } & \text { antibiotic-antimycotic } \\ \text { AIJ } & \text { ampulla-isthmic junction } \\ \text { AKT } & \text { protein kinase B } \\ \text { APOL3 } & \text { apolipoprotein L3 } \\ \text { ATP8B4 } & \text { ATPase phospholipid transporting 8B4 } \\ \text { BATF2 } & \text { basic leucine zipper ATF-like transcription factor 2 } \\ \text { BCL2A1 } & \text { Bcl-2-related protein A1 } \\ \text { BNC } & \text { binucleate cells } \\ \text { bp } & \text { base pair } \\ \text { BP } & \text { biological processes } \\ \text { BSA } & \text { bovine serum albumin } \\ \text { BTM } & \text { beta-2 microglobulin } \\ \text { C } & \text { celcius } \\ \text { CH } & \text { corpus hemorrhagicum } \\ \text { CIDR } & \text { controlled intravaginal drug releasing device } \\ \text { CL } & \text { corpus luteum } \\ \text { cm } & \text { centimeter } \\ \text { CRD } & \text { carbohydrate recognition domain } \\ \text { CSF } & \text { colony-stimulating factors } \\ \text { CST3 } & \text { cystatin-3 } \\ \text { CTSL } & \text { cathepsin-L } \\ \text { CXCR4 } & \text { C-X-C motif chemokine receptor 4 } \\ \text { d } & \text { day } \\ \text { DEG } & \text { differentially expressed gene } \\ \text { dGE } & \text { deep glandular epithelium } \\ \text { DMRTA1 } & \text { doublesex- and mab-3-related transcription factor A1 } \\ & \end{array}$




\begin{tabular}{|c|c|}
\hline $\mathrm{E}$ & primer efficiency \\
\hline $\mathrm{E} 2$ & estradiol \\
\hline ESR1 & estrogen receptor alpha \\
\hline $\mathrm{EtOH}$ & ethyl alcohol \\
\hline FBS & fetal bovine serum \\
\hline FF & flush fluid \\
\hline FOXS1 & forkhead box S1 \\
\hline FSH & follicle stimulating hormone \\
\hline GAPDH & glyceraldehyde 3-phosphate dehydrogenase \\
\hline GBP2 & guanylate-binding protein 2 \\
\hline GHSR & growth hormone secretagogue receptor \\
\hline GLM & eneralized linear model \\
\hline GnRH & gonadotropin releasing hormone \\
\hline GO & gene ontology \\
\hline GSK-3 $\beta$ & glycogen synthase kinase $-3 \beta$ \\
\hline $\mathrm{H}$ & hour \\
\hline H3F3A & H3 histone family member $3 \mathrm{~A}$ \\
\hline HBSS & hank's balanced salt solution \\
\hline $\mathrm{HSH} 2 \mathrm{D}$ & hematopoietic SH2 domain containing \\
\hline IACUC & Institutional Animal Care and Use Committee \\
\hline IDO1 & indoleamine 2,3-dioxygenase \\
\hline IFGBP1 & insulin-like growth factor-binding protein 1 \\
\hline IFGR & interferon gamma receptor \\
\hline IFI44 & interferon induced protein 44 \\
\hline IFI44L & interferon induced protein 44 like \\
\hline IFI6 & interferon alpha-inducible protein 6 \\
\hline IFIT3 & interferon induced protein with tetratricopeptide repeats 3 \\
\hline IFNAR & interferon alpha receptor \\
\hline IFNG & interferon gamma \\
\hline IFNT & interferon-tau \\
\hline IGF-1 & insulin-like growth factor 1 \\
\hline
\end{tabular}




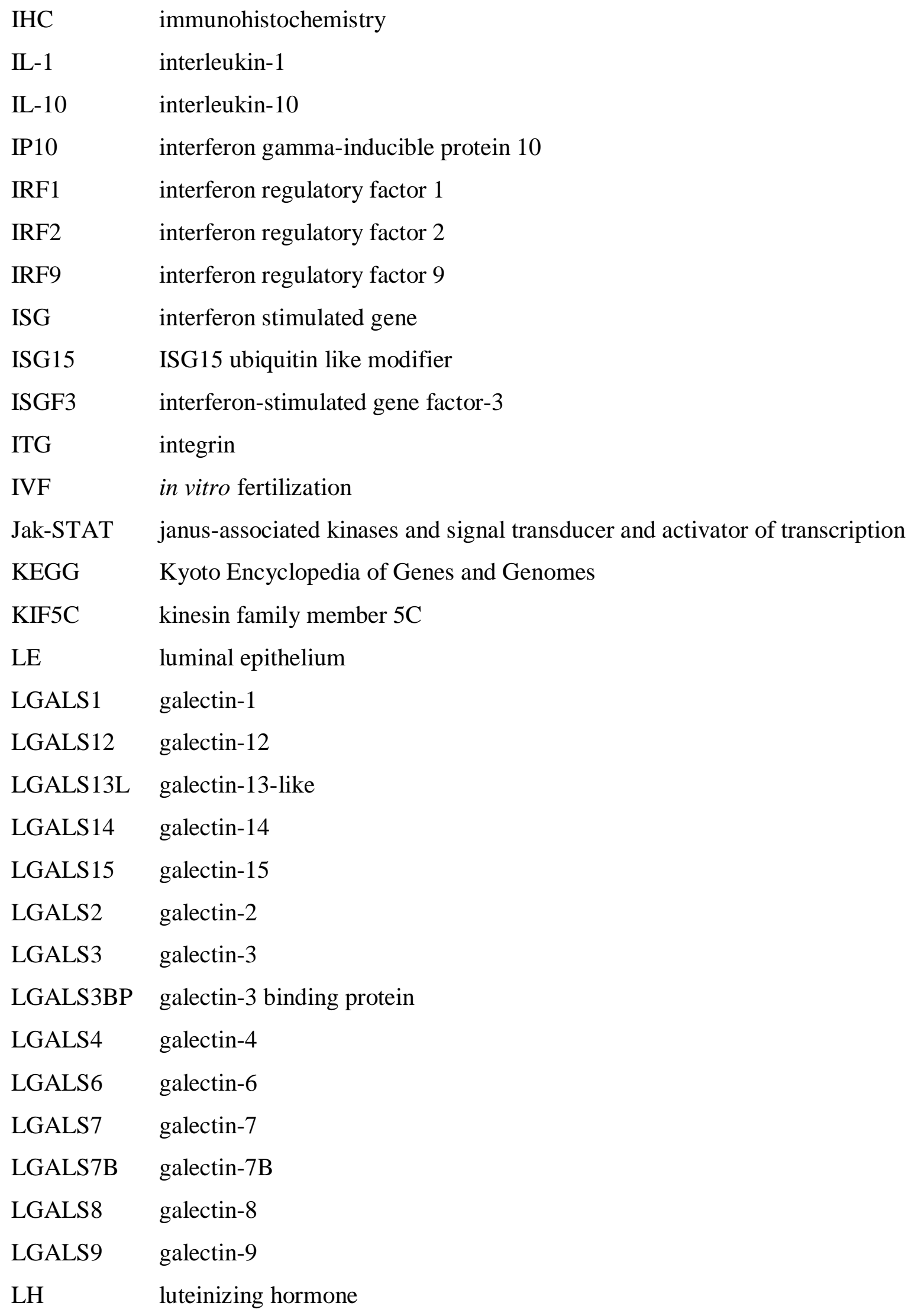




\begin{tabular}{|c|c|}
\hline LIF & leukemia inhibitory factor \\
\hline $\log 10$ & $\log$ base 10 \\
\hline $\log \mathrm{FC}$ & log fold change \\
\hline LPS & lipopolysaccharide \\
\hline LSM & least square means \\
\hline MAP6 & microtubule associated protein 6 \\
\hline MAPK & mitogen-activated protein kinases \\
\hline MCHR1 & melanin concentrating hormone receptor 1 \\
\hline MHC & major histocompatibility complex \\
\hline Min & minutes \\
\hline $\mathrm{mL}$ & milliliter \\
\hline $\mathrm{mm}$ & millimeter \\
\hline MMPs & Matrix etalloproteinases \\
\hline MMP-1 & metalloproteinase-1 \\
\hline MX1 & MX dynamin like GTPase 1 \\
\hline MX2 & MX dynamin like GTPase 2 \\
\hline NFkB & nuclear factor kappa B \\
\hline ng & nanogram \\
\hline NRQ & normalized relative quantity \\
\hline OAS & oligoadenylate synthetase \\
\hline OAS1 & 2'-5'-oligoadenylate synthetase 1 \\
\hline OAS2 & 2'-5'-oligoadenylate synthetase 2 \\
\hline oIFNT & ovine interferon-tau \\
\hline OTR & oxytocin receptor \\
\hline $\mathrm{P} 4$ & progesterone \\
\hline PAG & pregnancy associated glycoproteins \\
\hline PARM1 & prostate androgen-regulated mucin-like protein 1 \\
\hline PBS & phosphate buffered saline \\
\hline PF & persistent follicle \\
\hline PG & prostaglandin \\
\hline PGE2 & prostaglandin E2 \\
\hline
\end{tabular}




$\begin{array}{ll}\text { PGF } & \text { prostaglandin F2 alpha } \\ \text { PGI2 } & \text { prostaglandin I2 } \\ \text { PGR } & \text { progesterone receptor } \\ \text { PI3K } & \text { phosphatidylinositol 3-kinase } \\ \text { PIF } & \text { preimplantation factor } \\ \text { PL } & \text { placental lactogen } \\ \text { PLAC8 } & \text { placenta-specific } 8 \\ \text { PPIA } & \text { peptidylprolyl isomerase A } \\ \text { PROC GLM } & \text { general linear model procedure } \\ \text { PRRT3 } & \text { proline-rich transmembrane protein 3 } \\ \text { PTGS2 } & \text { prostaglandin synthase 2 } \\ \text { RIN } & \text { RNA integrity number } \\ \text { RNA-Seq } & \text { RNA Sequencing } \\ \text { RNF11 } & \text { ring finger protein 11 } \\ \text { RPL23A } & \text { 60S ribosomal protein L23A } \\ \text { RPMI } & \text { Roswell Park Memorial Institute 1640 } \\ \text { RQ } & \text { relative quantity } \\ \text { RSAD2 } & \text { radical S-adenosyl methionine domain containing 2 } \\ \text { RT-qPCR } & \text { Quantitative real-time PCR } \\ \text { S } & \text { seconds } \\ \text { SAMD9 } & \text { sterile alpha motif domain containing 9 } \\ \text { SD } & \text { standard deviation } \\ \text { SDHA } & \text { succinate dehydrogenase complex flavoprotein subunit A } \\ \text { SEM } & \text { standard error of the least squares means } \\ \text { sGE } & \text { surface glandular epithelium } \\ \text { siRNA } & \text { small interfering RNA } \\ \text { SLC15A3 } & \text { solute carrier family 14 member 3 } \\ \text { SLC25A19 } & \text { solute carrier family 25 member 19 } \\ \text { SLC25A28 } & \text { solute carrier family 25 member 28 } \\ \text { SLC25A30 } & \text { solute carrier family 25 member 30 } \\ \text { SOLD1 } & \text { Ly-6 domain 1 } \\ \text { PNA }\end{array}$


Sqrt square root

SSC4D scavenger receptor cysteine-rich family member with 4 domains

STAT1 signal transducer and activator of transcription 1

STAT2 signal transducer and activator of transcription 2

TEER transepithelial electrical resistance

TMC trophoblast mononucleate cells

$\mathrm{TNF}_{\alpha} \quad$ tumor necrosis factor alpha

TNFR1 tumor necrosis factor receptor 1

TNFR2 tumor necrosis factor receptor 2

TNFSF10 TNF superfamily member 10

TNFSF13B TNF superfamily member 13b

TYK tyrosine kinsase-2

UGKO uterine gland knockout

UV ultra-violet

Wnt Wingless-related integration site

YWHAZ tyrosine 3-monooxygenase/tryptophan 5-monooxygenase activation protein zeta

ZAP zinc-finger antiviral protein

ZBP1 Z-DNA binding protein 1

ZC3HAV1 zinc finger CCCH-type antiviral protein 1

$\Delta \Delta \mathrm{Cq} \quad$ delta-delta quantification cycle 


\section{CHAPTER ONE}

\section{LITERATURE REVIEW}

\section{Introduction}

The beef cow/calf industry experiences an annual loss exceeding $\$ 1.2$ billion, with the largest contributing factor being embryonic loss [1]. The highest incidence of pregnancy loss in cattle occurs during the embryonic period of gestation, with $40 \%$ occurring between day (d) 8 and 17 [2-4]. The critical period for maternal recognition of pregnancy in cattle is $\mathrm{d} 15-16$ meaning that, in this time period, the conceptus begins to elongate in structure and secretes a substance to communicate with the dam the presence of a pregnancy and to convert the corpus luteum (CL) of the estrous cycle to a CL of pregnancy [5]. This secretory protein of the bovine trophectoderm is called interferon tau (IFNT) and its presence stimulates the expression of interferon-stimulated genes (ISGs) in the endometrium. The endometrial ISGs are considered classical or nonclassical and alter the endometrium in preparation for embryonic attachment and a successful gestation. Integrin proteins are imperative to attachment as they serve as a ligand for extracellular matrix compounds such as fibronectin. Galectins, specifically LGALS3, have been shown to interact with integrins to promote antiapoptotic effects during the period of implantation in humans and could promote adhesion between the conceptus and endometrium [6]. The purpose of this chapter is to review the literature that has contributed to the current understanding of the establishment of pregnancy in cattle, the origins of embryonic loss, and the possible involvement of LGALS3 during early pregnancy in cattle. 


\section{The Bovine Estrous Cycle}

The female cow will reach puberty at approximately one year and will begin her reproductive cycle. The cycle is referred to as the estrous cycle with the time point of being sexually receptive termed "estrus". Approximately every $21 \mathrm{~d}$, a cyclic cow or heifer has the chance to become pregnant as the cycle is continuous. The estrous cycle is defined as the period from one standing estrus to the next and consists of four stages; proestrus, estrus, metestrus, and diestrus [7]. Each estrous cycle can be divided into two phases, the follicular and luteal phases. The follicular phase consists of $20 \%$ of the estrous cycle and includes both proestrus and estrus. Proestrus continues from $\mathrm{d} 17$ to $\mathrm{d} 20$ of the bovine estrous cycle.

The beginning of the follicular phase, proestrus, is a result of luteolysis and is driven by alternations in the endocrine profile. Luteolysis marks the beginning of the follicular phase and is characterized by the regression of a functional $\mathrm{CL}$ due to uterine produced prostaglandin $\mathrm{F}_{2}$ alpha (PGF). Progesterone (P4) synthesized by the CL develops after the expulsion of an oocyte from a follicle and prevents further ovulation. Regression of the CL and subsequent decline of circulating P4 allows for gonadotropin-releasing hormone $(\mathrm{GnRH})$ to be released from the hypothalamus at a higher amplitude and frequency. Luteinizing hormone (LH) and follicle stimulating hormone (FSH) are released from the anterior pituitary. The regulation of the two differs as FSH is controlled by negative feedback from inhibin and estrogen, both originating from developing follicles. The pulse frequency of LH is controlled by the pulses of GnRH. The FSH aids in the development of follicles during proestrus by recruiting a cohort of follicles at the start of every follicular wave. Sirois and Fortune (1988) developed a model of bovine follicular development and regression by utilizing ultrasonography. Findings suggested that follicular development in heifers occurs in wave-like patterns while during each wave, a selected follicle 
increases in size and asserts dominance on other developing follicles [8]. The selection process begins several days in advance to the dominant follicle reaching a preovulation diameter and causes regression of other developing follicles. The $\mathrm{LH}$ aids in selection which is the further development of the dominant follicle. Increased follicular development results in elevated inhibin production from granulosa cells which inhibits further FSH secretion. Following either atresia of the developing follicle or ovulation of the oocyte, FSH levels will once again rise to initiate another follicular wave [7].

The production of estradiol (E2), in large concentrations, will result in positive feedback on hypothalamic GnRH secretion leading to the preovulatory LH surge. This will trigger "standing estrus" meaning the female will become sexual receptive while exhibiting behavioral signs such as lordosis, increased movement, and the mounting of other animals. In cattle, estrus, which is a result of the LH surge, lasts approximately $15-18 \mathrm{~h}$ and ends at ovulation on $\mathrm{d} 0$ marking the end of the follicular phase. Ovulation typically takes place $30 \mathrm{~h}$ after the initiation of estrus [7].

The luteal phase, which begins after ovulation, consists of metestrus and diestrus and continues from $\mathrm{d} 0$ to $\mathrm{d} 17$ of the estrous cycle. Triggered by the preovulatory LH surge, the CL is formed from a newly ovulated follicle following luteinization in which the theca interna and granulosa cells of the follicle differentiate into small and large luteal cells, respectively. A corpus hemorrhagicum $(\mathrm{CH})$ is the structure present immediately after ovulation as a result of the rupture of blood vessels as the oocyte complex is released from the follicle. The $\mathrm{CH}$ will then transition into a functional CL between $\mathrm{d} 3$ to $\mathrm{d} 5$ of the estrous cycle. Metestrus is characterized by the development of a functional CL and the transition to elevated P4 levels and declining E2. During this time, the first polar body appears as the oocyte undergoes meiosis. Corpus luteum 
mass is directly correlated with CL P4 secretions levels as both plateau in the middle of the cycle [9].

Thecal and granulosal cells intermix post-ovulation and both contain the capability to produce P4. The P4 targets the hypothalamus to suppress GnRH and consequently, LH and FSH, by decreasing GnRH receptors located on gonadotrophs in the anterior pituitary. The uterine environment is influenced by $\mathrm{P} 4$ by aiding in endometrial secretions, termed histotroph, as well as restricting contractility of the myometrium. In addition, $\mathrm{P} 4$ has the ability to aid in mammary gland development. Granulosa cells form large luteal cells while thecal cells form small luteal cells. Large luteal cells, as a result of ovulation, possess secretory granules that contain oxytocin which will be critical for luteolysis [10].

The end of the luteal phase is marked by the occurrence of luteolysis which is induced by endometrial PGF. Luteolysis is characterized by a 1-3d regression of the CL resulting in reduced blood P4 levels. The PGF originates in the uterine epithelium and travels to the ovary to initiate luteolysis through a vascular countercurrent exchange between the uterine vein and ovarian artery [11]. This system enables PGF to be transported to the ovary avoiding dilution and metabolism that would occur in general circulation [7]. A large portion of PGF secreted by the uterine epithelium travels through the utero-ovarian vein and diffuses into the ovarian artery. The PGF can initiate apoptosis in luteal cells. As a result, blood P4 concentrations decrease and the cycle will transition into a new follicular phase characterized by elevated E2 levels.

\section{Early Bovine Pregnancy}

Once the physiological and hormonal profiles are precise, the oocyte will ovulateallowing the oocyte to migrate to the oviduct. In cattle, past research has shown that the number 
of ovulations occurring in the right compared to the left ovary is not proportionate with the right ovary having a greater ovulation rate $[12,13]$. Following ovulation, the infundibulum captures the ovulated oocyte and permits the oocyte to travel to the ampulla-isthmic junction (AIJ) for possible fertilization. During natural mating, spermatozoa travel from the site of deposition, the cranial vagina, through the reproductive tract, to the AIJ [7].

If fertilization is successful, the presence of both the male and female pronuclei within the oocyte's cytoplasm confirms the existence of an ootid. The male pronucleus is formed once the sperm nucleus enters the oocyte's cytoplasm. The male pronucleus then undergoes decondensation allowing the female and male pronuclei fuse together to form a single nucleus. The resulting zygote is composed of a single cell [7]. Within $24 \mathrm{~h}$, the single-celled embryo will undergo cytokinesis and will cleave into a two-celled embryo with two blastomeres. Blastomere cleavages will continue, where the two-cell embryo will cleave into a four-cell embryo followed sequential cleavages. It is also important to note that early embryonic development, until d5, occurs within the oviduct which has unique secretions in comparison to the uterine horns. The oviduct provides an optimal environment for the developing conceptus by providing a specific combination of amino acids, energy substrates, and ions [14-16]. Past research has also found that the presence of oviductal cells or oviduct conditioned media during culture improves embryo viability [17].

Near $\mathrm{d} 4$, the embryo becomes a morula. Visually, the morula is identified as a solid mass of cells which cannot be easily distinguished from one another and quantified. During this time, the developing conceptus, which refers to the embryo body and extra-embryonic tissues, is transferred from the oviduct into the uterus. Tight junctions between the outer cells of the morula aid in the accumulation of fluid within the intercellular spaces inside the morula. Sodium is 
pumped into the intercellular space and, consequently, water accumulates. Blastocyst formation occurs around d7 of pregnancy in cattle. The blastocyst contains a fluid-filled cavity termed a blastocoele which consists of two distinct cell populations. One population forms the inner cell mass, which will give rise to the body of the developing embryo. The other cell population forms the outer layer and is referred to as trophoblast cells which will develop into the chorion of the placenta [7]. Lastly, between d7-8 of pregnancy, the blastocyst will hatch from the zona pellucida. At this point, the blastocyst is exposed to the uterine secretions. Expulsion of the blastocyst is a result of increasing internal pressure due to a combination of early embryonic growth, the enzymatic degradation of the zona pellucida, and contraction of the conceptus [7].

Once hatched from the zona pellucida, the embryo undergoes dramatic morphological change, increasing in size from around $0.15 \mathrm{~mm}$ in diameter to over $60 \mathrm{~mm}$ in total length due to the process of elongation [18]. The bovine embryo will double in length every day between $\mathrm{d} 9$ 16 of gestation [19-21]. The sphere-shaped blastocyst will transform into an ovoid conceptus on approximately d12. Finally, the conceptus will transition into a tubular structure on approximately d13-14 of gestation [22]. The conceptus will span both uterine horns by d18 of gestation, later attaching to the uterine surface [7]. Alterations of the uterine environment, including histotroph gene expression, are mediated by an increased concentration of $\mathrm{P} 4$ which promotes rapid conceptus growth [23]. Uterine histotroph consists of enzymes, growth factors, cytokines, hormones, transport proteins, and other substances [20, 24-27]. During this time, the extraembryonic membranes of the pre-attachment embryo rapidly develop and are comprised of the yolk sac, chorion, amnion, and allantosis. Bovine pre-attachment blastocysts are characterized by having a filamentous and thread-like structure near d16-17 [22].

As the development of the embryo progresses beyond the blastocyst stage, a dependency 
on the maternal uterine environment develops. Bovine blastocysts can be produced by in vitro fertilization (IVF) technology; however, the uterine environment is essential for the elongation of the developing conceptus [28, 29]. Ex vivo, outside of the uterus, ruminant blastocysts are unable to elongate as histotroph from endometrial glands is essential for this process [30, 31]. Gray and coauthors (2002) utilized uterine gland knockout (UGKO) sheep to investigate the role of endometrial secretions on elongation. The UGKO ewes were generated by utilizing synthetic progestin which results in the lack of uterine glands after postnatal chronic exposure in ewe lambs [31]. In sheep, conceptuses normally elongate around d14 of gestation. Day 14 conceptuses from UGKO ewes were observed to be fragmented, growth-retarded, and tubular. In addition, it was concluded that development was interrupted in embryos from knock-out gland ewes due to lack of endometrial glands opposed to alterations in the expression of molecules that impact adhesiveness of the luminal epithelium [30].

\section{Maternal Recognition of Pregnancy}

Reciprocal communication takes place between the embryo and the uterine environment. Increased levels of steroid hormones, $\mathrm{P} 4$ and E2, affects uterine gland gene expression promoting elongation and growth of the conceptus. Progesterone also controls the expression of genes that aid in uterine receptivity to the conceptus. Uterine receptivity is essential for

embryonic growth, development, and attachment [20,32]. In addition, the conceptus will release proteins, steroids, and other factors that affect endometrial cell gene expression. Conceptus IFNT, a cytokine, causes modifications to endometrial PGF production that disrupts luteolysis allowing continuous $\mathrm{P} 4$ synthesis [33]. This process is termed maternal recognition of pregnancy and must occur between d15-16 of gestation for pregnancy to successfully continue. Trophoblast 
cells are characterized into two groups: trophoblast mononucleate cells (TMC) and trophoblast binucleate cells (BNC) [34]. The TMCs are responsible for the secretion of the maternal recognition of pregnancy factor in ruminants. IFNT will then inhibit the transcription of the oxytocin receptor (OTR) in the LE/sGE of the uterus by first silencing estrogen receptor alpha (ESR1) expression $[33,35]$. In the absence of oxytocin, luteolytic pulses of PGF cannot occur, thus prolonging the CL lifespan. Comparing pregnant to cyclic animals, basal levels of PGF and prostaglandin E2 (PGE2) in pregnant animals remain elevated due to continued uterine prostaglandin synthase 2 (PTGS2) expression [35]. The silencing of ESR1 by IFNT disables E2 from inducing endometrial epithelial progesterone receptor (PGR) transcription which allows stromal cells expressing PGR to regulate expression of ISGs [36].

Ulbrich et al. (2009) quantified prostaglandins (PGs) in the uteri of preimplantation pregnancy stage heifers in comparison to non-pregnant control heifers. It was found the presence of an embryo influenced the intrauterine environment of d15 pregnant heifers to consist of higher concentrations of prostaglandin I2 (PGI2) and secondly, PGF, both of which were greater than PGE2 [37]. Overall, clear evidence was found that the ratio of PGF/PGE2 was not altered between cyclic and pregnant heifers as the embryo contributes to the PG environment. Likely, PGI2 plays a role in the permeability of maternal vasculature. Both PGE2 and PGI2 have been found to be critical during the regulation of implantation and decidualization in other species including humans and mice [38, 39].

Interferon-tau is a type I interferon. Type I interferons are important in most viral defenses. Type I interferons bind the interferon alpha receptor (IFNAR) to signal a response biologically while the single Type II interferon family member, interferon gamma (IFNG) binds 
interferon gamma receptor (IFNGR) [40]. The pregnancy recognition signal, IFNT, will differentially impact gene expression of cells in the luminal epithelium (LE), deep glandular epithelium (dGE), surface glandular epithelium (sGE), and stroma [36, 41]. The ISGs and are suggested to play various roles in the differentiation of the endometrium in preparation for pregnancy. There are two distinct classifications of ISGs, classical and non-classical, which are spatially stimulated by IFNT within the stroma/dGE and LE/sGE, respectively [42, 43]. Type I and II IFNs initiate the expression of classical ISGs through stimulation of janus-associated kinases and signal transducers and activators of transcription (Jak-STAT) pathways resulting in phosphorylation of their respective receptors activating STAT.

There is a greater understanding of IFNT mediated ISG effects in the ovine endometrium compared to cattle. The working hypothesis is as follows: conceptus-derived IFNT binds its receptor, IFNAR, in the LE/sGE. There, interferon regulatory factor 2 (IRF2), which is a transcriptional repressor, is up-regulated. The IRF2 inhibits ISGs which are considered classically activated such as STAT1, STAT2, interferon regulatory factor 9 (IRF9), beta-2 microglobulin (B2M), ISG15 ubiquitin-like modifier (ISG15), major histocompatibility complex (MHC), and oligoadenylate synthetase (OAS). However, IFNT is able to activate genes in the non-classical category of ISGs such as cystatin-3 (CST3), cathepsin-L (CTSL), and galectin-15 (LGALS15) in the LE/sGE of sheep through a currently unknown biological cell-signaling pathway [42]. Inversely, dGE and stromal cells lack expression of IRF2 resulting in activation of JAK1 and tyrosine kinase-2 (Tyk2), and consequently, STAT2. Once STAT2 is phosphorylated, STAT1 is able to become phosphorylated as well. With STAT1 and 2 activation, interferonstimulated gene factor-3 (ISGF3) and interferon regulatory factor-1 (IRF1) transcription factors become activated allowing for the transactivation of classical ISGs $[42,44]$. The LE and sGE 
may lack classical ISG expression during early pregnancy as a method of defense against the immune rejection of the partially genetically dissimilar conceptus [45, 46].

The BNCs of the trophoblast appear between d18 and 20 of gestation in cattle and migrate from the chorionic tissue to the maternal endometrium where they secrete factors such as placental lactogen (PL) and pregnancy-associated glycoproteins (PAGs). The BNCs also secret PG, along with estrogens, during preimplantation development. The BNC derived PAGs are believed to play a role in the regulation of placentation, mammogenesis, steroidogenesis, and immune function [47-50]. Other vital trophoblastic secreted molecules include Bcl-2-related protein A1 (BCL2A1) which is BNC derived and is an imperative anti-apoptotic factor involved in cell maintenance [51]. Bovine TMCs and BNCs, along with maternal tissues, have been found to contain secreted protein of Ly-6 domain 1 (SOLD1) which plays various roles including reconstruction of the post-partum uterus, fetal and placental growth, and placental expulsion. Further, investigators found SOLD1 is involved in trophoblast cell migration and induced invasion $[52,53]$.

\section{Bovine Embryonic Attachment}

Implantation of the developing ruminant conceptus is rather non-invasive and consists of the process by which the fetal membranes attach to the maternal endometrial epithelium. Bovine embryonic attachment occurs near $\mathrm{d} 21$ of gestation, a time when the allantois formation becomes apparent macroscopically $[54,55]$. Post-elongation, the conceptus will begin to attach to the LE while trophoblastic projections become incorporated into the openings of the maternal uterine glands [56]. The driving force of preparation of the endometrium for attachment of the developing conceptus is $\mathrm{P} 4[35,57]$. Implantation is accompanied by increased production of 
secretions by the epithelial cells within the uterine lumen.

Past research in cattle and sheep has found certain histotroph components to be of significant importance during the attachment phase [30, 42]. Successful implantation requires a normally developed blastocyst, a receptive endometrium, and corresponding communication between the two- a process which is orchestrated by various cytokines and growth factors such as interleukin-10 (IL-10), leukemia inhibitory factor (LIF), colony-stimulating factors (CSF), interleukin-1 (IL-1), and insulin-like growth factor 1 (IGF-1) [58, 59]. Members of the family of proteins called integrins (ITGs) are imperative for successful implantation [60]. Integrins serve as a receptor for fibronectin, vitronectin, laminin, collagen type IV, and osteopontin—all of which compose the extracellular matrix [60-62]. Interferon gamma-inducible protein 10 (IP10), LGALS15, and insulin-like growth factor-binding protein 1 (IGFBP1), all of which are components of the uterine histotroph, have been described to induce ITGs during the attachment of the trophectoderm to uterine tissue [61, 63-65].

Growth factors that are endometrial and/or conceptus derived, such as tumor necrosis factor alpha (TNF $\alpha)$, initiate direct communication between the maternal and trophoblastic cells. The pro-inflammatory cytokine, $\mathrm{TNF} \alpha$, is involved in various cellular activities including cell differentiation, survival, and tissue homeostasis. The TNF $\alpha$ has the capability to bind two distinct receptors, TNF receptor 1(TNFR1) or TNF receptor 2 (TNFR2), which can have dissimilar functions. Interestingly, TNFR1 activation is involved in cell apoptosis while TNFR2 can be involved in either cell proliferation or apoptosis. Along with TNFR2, TNF $\alpha$ protein and mRNA have been found to be expressed in pregnant and cyclic endometria of cattle and expressed in endometrial and placental tissues of other species including humans during early 
and late gestation $[66,67]$. It is speculated that nuclear factor kappa $\mathrm{B}(\mathrm{NF} \kappa \mathrm{B})$, a transcription factor that is activated by $\mathrm{TNF} \alpha$, is down-regulated in the blastocyst to suppress immune function during blastocyst formation. The endometrium is believed to regulate TNF $\alpha$ concentrations via controlling the secretion of $\mathrm{TNF} \alpha$ into the histotroph as well as regulating the embryo's transcription of both TNF $\alpha$ and TNFR2 mRNA [67]. TNF $\alpha$ has been shown to stimulate PGF synthesis in endometrial stromal cells and IFNT has been shown to have an inhibitory effect on TNF $\alpha$ [68].

Preimplantation factor (PIF) is a peptide found to be secreted by murine, human, and bovine embryos, as well as placental tissue. Additionally, PIF has been found to be in human maternal general circulation $[69,70]$. Trophoblastic PIF is expressed largely in the first and second trimesters and may be an indication of viable embryos that are in vitro produced by determining culture medium levels [71]. Human decidua cells cultured with PIF exhibited a role in immune regulation, adhesion, and regulation of apoptotic processes [72].

\section{Early Pregnancy Loss in Cattle}

Embryonic mortality is defined as the loss of pregnancy from the time of conception to d45 of gestation in cattle with early embryonic loss occurring from d0-27 and late embryonic loss occurring from d28-45 of gestation [73]. Most pregnancy losses occur in the first 50 days of gestation with losses before d20 attributing to $75 \%$ of all reproductive failures $[74,75]$. Revenue from both dairy and beef farms depend on reproductive success. Therefore, it is important to address the causes of early embryonic loss to minimize financial loss. Reported fertilization rates in beef cattle are high, with values ranging from $93-96 \%$ when insemination occurs at the proper time in relation to ovulation [76-78]. Most reproductive failure following insemination occurs 
post-fertilization. Methods known to minimize loss during the first eight days of pregnancy include alleviating heat stress, inflammatory diseases, body condition loss, and by increasing preovulatory follicular development progesterone levels as this time period comprises $20-50 \%$ of all embryonic loss [18]. Researchers addressed the role of a persistent follicle (PF) on early embryonic loss and found evidence that an oocyte from a PF is capable of becoming fertilized but exhibited a disability to grow into a 16-cell stage embryo [76]. The reduction in fertility is due to biochemical and morphological alterations that take place within a follicle that remains dominant for an extended period of time [75]. Along with an altered endocrine profile, studies have shown the occurrence of PF in cattle is accompanied by altered follicular steroid and gonadotropin receptor expression [79-81].

\section{$\underline{\text { Galectin-3 }}$}

Galectin-3 (LGALS3) is located on chromosome 10 in cattle and is a member of a large family of $\beta$-galactoside-binding animal lectins that have numerous physiological functions. Lectins bind carbohydrates and result in cell agglutination while playing vital roles in pathogen defense, cell trafficking, and immune regulation [82, 83]. Currently, 15 members have been identified in mammals [84]. Galectins are ancient members of a lectin family which are characterized by having conserved amino acid sequences with at least one carbohydrate recognition domain (CRD) and the ability to recognize $\beta$-galactoside structures located on cell surface glycoconjugates $[85,86]$. Galectin family members have been categorized into three groups based on the number and organization of CRDs present: 1) the prototype, consisting of a single CRD, 2) the chimera type, whose only member is LGALS3 and consists of one CRD along with a non-lectin domain, and 3) the tandem repeat which consists of a short peptide linked 
by two CRDs $[82,87,88]$.

Galectin-3 is a 29 to $35 \mathrm{kDa}$ protein and consists of a 110-130 amino acid N-terminal domain connected to glycine and proline-rich repeats, along with a single C-terminal CRD [87]. A conformational change occurs when LGALS3 or its CRD interact with carbohydrate ligands leading to rearrangement of the backbone loops located nearby its binding site. Multiple ligands of LGALS3 have been identified and include extracellular glycoproteins and glycolipids [89, 90]. N-terminal domain and CRD have been shown to interact in the formation of LGALS3 multimers as LGALS3 possess bivalent and multivalent binding properties [87, 91]. It is also unique in that it is the only chimera-type galectin found in vertebrates and has been discovered in various cell types including tumor cells, macrophages, activated $\mathrm{T}$ cells, epithelial cells, and fibroblasts. The localization of LGALS3 protein is dependent on the cell type as LGALS3 protein has been reported to be found in the cytoplasm or secreted through non-classical pathways [87, 92]. Galectin-3 does not contain an $\mathrm{N}$-terminal signal sequence and becomes externalized through an endoplasmic reticulum-Golgi complex independent mechanism [93]. Also, LGALS3 may translocate to the nucleus or become secreted via a non-classical pathway of secretion following its cytoplasmic ribosomal synthesis. [94-96]. Intracellularly, LGALS3 has been shown to interact with nuclear and cytoplasmic proteins leading to the modulation of signaling pathways [86]. In addition, intracellular LGALS3 mediates anti-apoptotic effects by inhibiting apoptosis caused by nitrogen-free radicals [97]. Extracellular LGALS3 binds to oligosaccharides located on the surface of cells and promotes apoptosis by the release of cytochrome c and caspase-3 activation [98].

Galectin-3 has functions in the regulation of the immune response and may be involved 
in the development of cancer and heart disease. Galectin-3 is also involved in various biological processes including cell adhesion, cell activation, chemoattraction, proliferation, cellular differentiation, and apoptosis [84, 87, 99]. Regarding immunology, LGALS3 is a regulator of inflammation and is secreted by macrophages, monocytes, dendritic cells, eosinophils, mast cells, natural killer cells, and both activated B and T cells [89, 100].

Cancer researchers have determined that LGALS3 promotes tumor cells growth in certain cancer types while promoting anti-apoptotic effects on tumor cells in various other cancers [101]. Contrarily, in cancers such as breast, non-melanoma skin, prostate, endometrial, and leukemia cancers, LGALS3 exerts tumor suppression effects on cancerous cells [102]. In the case of endometrial and breast cancers, a down-regulation of LGALS3 is associated with amplified aggressiveness while in pancreatic cancer, LGALS3 up-regulation is linked to cancer cell proliferation and invasion [102-104]. A study utilizing LGALS3 small interfering RNA (siRNA) found the knockdown resulted in a reduction in migration of cancer cells, invasion, cell proliferation, anchorage-independent colony formation, and tumor growth in mice with prostate cancer [105]. Signaling pathways of LGALS3 vary between cancers as well. Research has shown in cases of melanoma and gastric cancer, LGALS3 promotes tumor growth through the upregulation of metalloproteinase-1 (MMP-1) and by the regulation of mitogen-activated protein kinases (MAPK) pathway in lung cancer [41, 106, 107]. In human breast cancer, LGALS3 has been shown to activate wingless-related integration site (Wnt) signaling, which is characterized by nuclear accumulation of $\beta$-catenin — a major component of the Wnt pathway [108-110]. In human colon cancer cells, via the phosphatidylinositol 3-kinase (PI3K) and protein kinase B

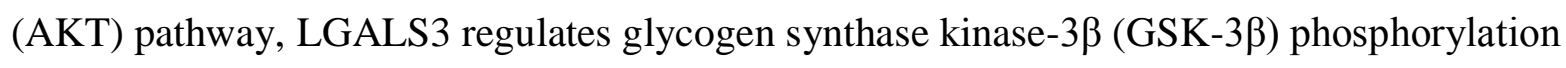
leading to the degradation of $\beta$-catenin [108]. 
Expression of LGALS3 in myocardial cells of healthy humans and rodents is low, however, LGALS3 protein up-regulation has been observed during cardiac stressors leading to cardiac fibrosis and ultimately, heart failure [111]. Expression levels are found to correlate with progression and severity of cardiac damage, therefore, levels are utilized as a biomarker for heart failure [112]. It is hypothesized that $L G A L S 3$ expression in heart failure is triggered hormonally by aldosterone or angiotensin II. Also, the combination of LGALS3 and aldosterone or angiotensin II instigates sclerosis, fibrosis, and hypertrophy of the renal system, cardiac tissue, as well as vascular tissue [113, 114]. Cardiac fibroblast proliferation is triggered by LGALS3 which induces detrimental collagen I deposition that will impact the diastolic and systolic functions of the heart [99].

\section{Galectin-3 in Reproduction}

Recently, LGALS3 was identified to play an important part in the preparation of the endometrium for implantation with a presence in the endometrium and trophoblast cells. Given the resemblances of tumor invasion and the migration of trophoblast cells, investigators have addressed the possible roles of LGALS3 at the maternal-fetal interface regarding implantation $[115,116]$. Previous work suggests $L G A L S 3$ expression is regulated by different mechanisms in placental tissues compared to uterine expression. After conducting immunohistochemistry (IHC) studies on pregnant murine uteroplacental tissue samples, it was concluded that LGALS3 is synthesized by all cell types within the murine uteroplacental samples. Levels of LGALS3 mRNA remained constant in murine uterine tissues until d12 of gestation and declined thereafter until parturition. Interestingly, in placental tissues, LGALS3 mRNA levels remained constant after $\mathrm{d} 12$ of gestation until term [115]. In bovine tissues, LGALS3 protein has been identified in 
the cervix, oviduct, uterus, atretic follicles, and CL [117]. Specifically, in the nonpregnant bovine uterus, LGALS3 has been localized via IHC in some epithelial cells as well as macrophages located in the submucosa but were absent in endometrial glands [117]. In the bovine CL, LGALS3 expression was elevated at the regressed state in comparison to all other luteal stages and was localized on steroidogenic cells in the CL [118].

Successful implantation or attachment requires tight regulation of endometrial receptivity preparations including cellular proliferation proceeded by differentiation [119]. The expression of cell surface molecules alters as uterine receptivity develops though not a lot is known about molecular interactions occurring at the maternal-fetal interface. Galectins have been found to increase cell-adhesion by associating surface glycoproteins on opposing cells in addition to strengthening other intercellular adhesion molecules [120].

\section{The Role of Galectin-3 in Apoptosis}

A study utilizing the human epithelial endometrial derived cell line, RL95-2, addressed the effects of intracellular LGALS3 on apoptosis. Apoptosis inducers were utilized to determine if expression levels of LGALS3 were altered and it was found LGALS3 expression was increased in apoptotic conditions [6]. To address whether the upregulation of $L G A L S 3$ was pro-apoptotic, a siRNA technique was used to silence LGALS3 in RL95-2 epithelial cells. It was observed that in the presence of apoptosis inducers, RL95-2 cells with LGALS3 siRNA were more sensitive to the induced apoptosis. It was then suggested that the upregulation of $L G A L S 3$ during the time of implantation in the human menstrual cycle may result in endometrial antiapoptotic effects [6]. In addition, LGALS3 was postulated to be an antiapoptotic factor under $\mathrm{P} 4$ and $\mathrm{E} 2$ regulation. When RL95-2 cells were treated with LGALS3 siRNA, the previously exhibited antiapoptotic roles of 
P4 and E2 were eliminated. Through an underdetermined relationship, P4 and E2 are proposed to indirectly or directly promote $L G A L S 3$ expression and, consequently, antiapoptotic effects [6]. Further, when studying women with endometriosis, decreased endometrial LGALS3 expression was observed while P4 and E2 regulated LGALS3 expression in endometrial epithelial cells. Ultimately, the lack of $L G A L S 3$ expression was thought to have caused resistance to a $\mathrm{P} 4$ uterine environment leading to endometriosis-related infertility [121].

Integrins are significant during the preimplantation period as they play a major role in cell adhesion. Via surface interactions with extracellular matrix ligands, integrins have been found to play a role in the embryo-endometrium cross talk in humans [122, 123]. Extracellular LGALS3 binds to $\beta-1$ integrin and induces apoptosis. Bovine luteal cells express $\beta-1$ integrin and contain glycans to which LGALS3 will bind. Hashiba et al. (2014) found that PGF stimulated secreted LGALS3 from cultured luteal steroidogenic cells and LGALS3 plays a structural luteolytic role through binding to $\beta$-1 integrin [118]. Induced by LGALS3, a form of programmed cell death, termed anoikis, occurs in the bovine luteal steroidogenic cells due to inhibition of $\beta-1$ integrin-extracellular matrix binding [118, 124, 125].

\section{$\underline{3 D \text { Cell Culture }}$}

In the past, two-dimensional (2D) monoculture techniques have been utilized to investigate cellular processes of bovine epithelial and fibroblast cells [126]. To better simulate the columnar arrangement of epithelial cells in vivo, a three-dimensional (3D) culture allows epithelial cells to maintain a physiological polarity in vitro due to tight junctions unlike the traditional 2D cell culture techniques $[127,128]$. Tight junctions are imperative to epithelial cellular functions because the passage of ions and molecules paracellularly is regulated by tight 
junctions $[129,130]$. The 3D transwell culture system enables the coculture of two cells types which physiologically interact in vivo. Transepithelial electrical resistance (TEER), a measurement which reflects epithelial integrity, can be measured via an epithelial volt-ohm meter [127]. The following studies investigated the expression of galectins in bovine conceptuses and in the endometrium. Further, the effect of IFNT and $L G A L S 3$ on the endometrial epithelium and fibroblast transcriptomes in a 3D cell culture system was investigated. 


\title{
CHAPTER TWO
}

\section{GALECTIN GENE EXPRESSION IN BOVINE AND OVINE ELONGATING CONCEPTUSES AND PREGNANT AND CYCLIC ENDOMETRIUM}

\begin{abstract}
Pregnancy loss in cattle is greatest in the first 30 days of gestation. Near d15 of gestation, bovine conceptuses elongate and express $L G A L S 1$, an immunosuppressive glycan-binding protein believed to be essential for implantation. However, other members of the bovine galectin family, including $L G A L S 3, L G A L S 4, L G A L S 7, L G A L S 8, L G A L S 9$ and a galectin-13-like gene ( $L G A L S 13 L$ ), also may be expressed by the elongating conceptus. Therefore, galectin expression in elongating, d16 bovine conceptuses and intercaruncular endometrium as well as elongating, d14 ovine conceptuses and intercaruncular endometrium was assessed by RT-qPCR. Angus heifer and Texel ewes underwent estrous cycle synchronization and either inseminated or not bred. On d16 (heifers) or d14 (ewes) after synchronized estrus (d0), reproductive tracts of pregnant (heifers, $n=4$; ewes, $n=3$ ) and cyclic (heifers, $n=4$; ewes, $n=3$ ) animals were removed. Conceptuses and intercaruncular endometrial samples were then collected. Conceptuses and intercaruncular endometrium samples were individually snap frozen and stored at $-80^{\circ} \mathrm{C}$ until RT-qPCR. Bovine and ovine conceptus gene expression was normalized to control genes GAPDH and $Y W H A Z$, and endometrial gene expression was normalized to control genes $H 3 F 3 A$ and RNF11. A general linear model procedure (PROC GLM) in SAS was used to test for differences. For the conceptus data, alpha was set at 0.05 , and a Tukey's test was included in the analysis. Conceptus data are presented as non-transformed means \pm standard deviation (SD) of
\end{abstract}


the mean. Endometrial data are presented as non-transformed least square means (LSM) \pm standard error of the mean (SEM) and $P \leq 0.05$ was considered significant. In bovine conceptuses, expression of LGALS3 (24.47 \pm 6.41$)$ and LGALS1 (21.80 \pm 2.07$)$ was similar, yet, greater than all other galectins measured $(\alpha=0.05)$. Expression of LGALS8 $(1.73 \pm 0.27)$ was 12-fold less than $L G A L S 1$, however, LGALS8 expression was greater than $L G A L S 9$ (0.77 \pm 0.77$)$, $\operatorname{LGALS13L}(0.30 \pm 0.10), \operatorname{LGALS} 4(0.08 \pm 0.01)$ and $L G A L S 7(0.02 \pm 0.01)(\alpha=0.05)$. In bovine intercaruncular endometrium, expression of $L G A L S 1, L G A L S 8$, and $L G A L S 9$ were greatest. Compared to cyclic heifers, endometrial expression of $L G A L S 7$ was less $(5.80 \pm 2.35$ and $2.62 \pm$ 2.35; cyclic and pregnant, respectively; $P \leq 0.05)$, while expression of $L G A L S 9(9.26 \pm 2.25$ and $24.56 \pm 2.25$; cyclic and pregnant, respectively; $P \leq 0.001)$ and $L G A L S 3$ were greater $(2.62 \pm$ 0.52 and $4.40 \pm 0.52$; cyclic and pregnant, respectively; $P \leq 0.05)$ during pregnancy. In sheep

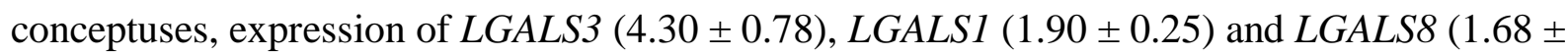
0.25) were similar. Compared to all other galectins measured, LGALS4 $(0.20 \pm 0.10)$ had the lowest level of expression $(\alpha=0.05)$. In ovine intercaruncular endometrium, expression of LGALS3, LGALS8, and LGALS15 were greatest. Compared to cyclic ewes, expression of LGALS7 was greater in pregnant ewes $(0.81 \pm 0.24$ and $2.25 \pm 0.24$; cyclic and pregnant, respectively; $P \leq 0.05)$ while $L G A L S 4(3.10 \pm 0.38$ and $1.78 \pm 0.38$; cyclic and pregnant, respectively; $P=0.06$ ) tended to be less during pregnancy and LGALS15 tended to be greater during pregnancy $(104.30 \pm 234.20$ and $591.35 \pm 234.20, P=0.07$; cyclic and pregnant, respectively). In conclusion, elongating bovine and ovine conceptuses express various members of the galectin gene family, and select galectin genes are differentially expressed in the endometrium during pregnancy. The galectins may have important functions during early pregnancy in ruminants. 


\section{INTRODUCTION}

Galectins are a large family of $\beta$-galactoside-binding animal lectins that have numerous physiological functions. Lectins bind carbohydrates and result in cell agglutination while playing vital roles in pathogen defense, cell trafficking, and immune regulation [82, 83]. Currently, 15 members of the galectin family have been identified in mammals [84]. Galectins are ancient members of a lectin family, which are characterized by having conserved amino acid sequences with at least one $\mathrm{CRD}$ and the ability to recognize $\beta$-galactoside structures on cell surface glycoconjugates $[85,86]$. Galectins also interact with proteins independently of carbohydratesacting in an autocrine manner to inhibit cell growth and division [133]. The galectin family of proteins has been shown to play a crucial role in regulating tumor and placental angiogenesis $[134,135]$. In addition, galectins play a large role immunologically in inflammation, adaptive and innate immune responses, and immune tolerance [136, 137]. Elongating bovine conceptuses express galectin-1 (LGALS1) which has also been associated with the viability of $\mathrm{d} 7$ bovine blastocysts. Expression of LGALSI was found to be elevated in in-vivo produced blastocysts compared to less viable in-vitro produced d7 bovine blastocysts [138]. Further, the endometrium of sheep produces $L G A L S 15$ after d10 of gestation to aid in trophectoderm migration and attachment. However, LGALS15 is not found in cattle [64].

Galectin family members have been categorized into three groups based on the number and organization of CRDs present. The prototype group, consisting of a single CRD, includes LGALS1, 2, 5, 7, 10,11,13,14, and 15 . The chimera type group, whose only member is $L G A L S 3$, consists of one CRD along with a non-lectin domain. The tandem repeat group, which include a short peptide linked by two CRDs, members include LGALS4, 6, 8, 9, and 12 [82, 87, 
88]. According to published transcriptomic and proteomic data and published bovine genome sequences in NCBI, cattle have genes encoding LGALS1, galectin-2 (LGALS2), LGALS3, galectin-4 (LGALS4), galectin-7 (LGALS7), galectin 7B (LGALS7B), galectin-8 (LGALS8), LGALS9, galectin-12 (LGALS12), and galectin-13Like (LGALS13L) while the ovine genome contains galectin genes for LGALS1, LGALS2, LGALS3, LGALS4, LGALS7, LGALS8, LGALS9, LGALS12, galectin-14 (LGALS14), and LGALS15 (https://www.ncbi.nlm.nih.gov/genbank/ version 19.12.2017, 23.30.00).

Alterations of the uterine environment, including histotroph gene expression, are mediated by an increased concentration of P4 which promotes rapid conceptus growth [23]. Uterine histotroph consists of enzymes, growth factors, cytokines, hormones, transport proteins, and other substances [20, 24-27]. The bovine conceptus will double in length every day between d9-16 of gestation [19-21]. Bovine pre-attachment blastocysts are characterized by having a filamentous and thread-like structure, which arises around d16-17 [22]. The conceptus will span both uterine horns by d18 of gestation, later attaching to the uterine surface [7]. Early conceptuses secrete factors, including proteins and steroids, that aid in alteration of the maternal endometrium [131, 132].

The aim of this study was to characterize galectin gene expression in the early bovine and ovine conceptus during the elongation phase of development as well as to characterize their expression in the endometrium in response to the conceptus. 


\section{MATERIALS AND METHODS}

$\underline{\text { Animals and Tissue Collection }}$

All procedures were in compliance with the Guide for the Care and Use of Agricultural Animals in Research and Teaching and approved by the West Virginia University Institutional Animal Care and Use Committee (WVU IACUC). All animals were housed at the West Virginia University Animal Science Farm (Morgantown, WV). Angus and Hereford heifers were subjected to a Co-Sync $+7 \mathrm{~d}$ controlled intravaginal drug releasing device (CIDR; Zoetis, Parsippany-Troy Hills, NJ) protocol to synchronize estrus [139]. Approximately 52-56 h post CIDR removal, heifers received GnRH and were either inseminated ( $\mathrm{n}=4)$ with semen from an Angus bull or not bred $(n=4)$. Estrus was synchronized in Texel ewes using a 5d CIDR program [140]. Ewes were then either placed with a Texel ram to be naturally bred $(n=3)$ or not placed with the ram $(n=3) 24$ hours after CIDR removal. To obtain pregnant and cyclic reproductive tissues, heifers and ewes were slaughtered at a local abattoir 16 and 14 days later, respectively. Within 45 min, all reproductive tracts were flushed using $20 \mathrm{~mL}$ of 1X PBS (Thermo Fisher, Waltham, MA). Conceptuses were then collected and intercaruncular endometrial samples were collected from the uterine horn ipsilateral to the CL. All tissue samples were immediately snapfrozen and stored at $-80^{\circ} \mathrm{C}$ until RNA extraction.

\section{$\underline{\text { RNA Extraction }}$}

RNA was extracted from bovine $(n=4)$ and ovine $(n=3)$ conceptuses and endometrium. A 5-mm steel bead (Qiagen, Hilden, Germany), washed in RNaseZap (Thermo Fisher), was placed in each screw-cap tube containing the conceptus along with $350 \mu \mathrm{L}$ of lysis buffer. Screw-cap tubes were placed in a Mini-Beadbeater-24 (Biospec Products, Bartlesville, Oklahoma) and 
homogenized for $30 \mathrm{~s}$ at maximum speed. The lysate was transferred to a homogenizer spin column (Omega Bio-Tek, Inc., Norcross, GA) along with an additional $350 \mu \mathrm{L}$ of lysis buffer. Columns were centrifuged for 2 min at maximum speed. The RNA was extracted from the lysate according to recommendations from the manufacturer of the E.Z.N.A. DNA/RNA kit (Omega Bio-Tek, Inc.).

Intercaruncular endometrium samples $(<50 \mathrm{mg})$ were placed in a screw-cap tube containing a single steel bead (Qiagen) and $1.0 \mathrm{~mL}$ of Trizol (Thermo Fisher). Screw-cap tubes were then placed in a Mini-Beadbeater-24 (Biospec Products) and homogenized for $2 \mathrm{~min}$ at maximum speed. After centrifuging, $0.1 \mathrm{~mL}$ of chloroform was added to the lysate, vigorously shaken, and allowed to rest for $3 \mathrm{~min}$. Samples were then transferred to a precooled centrifuge $\left(4^{\circ} \mathrm{C}\right)$ and spun at $12,000 \mathrm{x}$ for $15 \mathrm{~min}$. The aqueous supernatant from the tubes was removed, combined with $1.5 \mathrm{x}$ volumes of $100 \%$ ethanol, and gently mixed. The E.Z.N.A Total RNA Kit 1 (Omega Bio-Tek, Inc.) was then used to extract RNA following the manufacturer's recommendations. The concentration of RNA and integrity was determined using NanoDrop (NanoDrop ND-1000, NanoDrop Technologies, Wilmington, DE) and Bioanalyzer (2100 Bioanalyzer, Agilent Technologies, Santa Clara, CA). The RNA was stored at $-80^{\circ} \mathrm{C}$ until cDNA was synthesized.

\section{$\underline{\text { Reverse Transcription and RT-qPCR }}$}

Following the manufacturer's recommendations, cDNA was synthesized using a High Capacity cDNA Reverse Transcription Kit (Applied Biosystems, Foster City, CA). Briefly, 500 ng of RNA and nuclease-free water was added to $10 \mu \mathrm{L}$ of master mix to reach a total volume of $20 \mu \mathrm{L}$. No-reverse transcriptase control samples were prepared. Following a $2 \mathrm{~h}$ cDNA synthesis 
at $37^{\circ} \mathrm{C}, 5 \mu \mathrm{L}$ of each sample was pooled and the remaining cDNA was diluted 1:20 using nuclease-free water. Pooled cDNA was used to generate 7 standards (1:4 serial dilutions). Standards were used to calculate primer efficiencies $\left(E=\left[10^{(-1 / \text { slope })}-1\right)\right.$. The slope is a plot of observed $\mathrm{Ct}$ values versus the 7 standard serial dilutions. Percent efficiency was then obtained by dividing E by 2 and multiplying by 100 .

Quantitative real-time PCR was utilized to measure the expression of galectin genes. The CFX96 Real-Time PCR machine (Bio-Rad Laboratories, Hercules, CA) was used to perform RT-qPCR reactions. All primers were designed using Primer3Plus (Version 2.4.2) unless otherwise noted. Primer sets for bovine and ovine cDNA were identical unless otherwise noted. Sample RT-qPCR reactions were carried out in $20 \mu \mathrm{L}$ reactions in duplicate $[10 \mu \mathrm{L}$ of SYBR Green Master Mix (Catalog Number: A25743; Applied Biosystems), $1.2 \mu \mathrm{L}$ of forward and reverse primer mix (1 $\mu \mathrm{M}$ final concentration), $2.6 \mu \mathrm{L}$ nuclease-free water, and $5 \mu \mathrm{L}$ of cDNA template (6.6 ng RNA equivalent)]. RT-qPCR reaction of no-reverse transcriptase controls and no-template controls were included. Thermo-cycling conditions were as follows: $50^{\circ} \mathrm{C}$ for $2 \mathrm{~min}$, $95^{\circ} \mathrm{C}$ for $2 \mathrm{~min}$, which was followed by 40 cycles of $95^{\circ} \mathrm{C}$ for $15 \mathrm{~s}$ and $60^{\circ} \mathrm{C}$ for $1 \mathrm{~min}$. A disassociation analysis was included for each primer set and the presence of a single, sharp peak was confirmed.

The qbase+ package (Biogazelle; Zwijnaarde, Belgium) was used to select reference genes. Average RT-qPCR Ct values were imported into qbase+ software, which was used to analyze real-time data and generate the normalized relative quantity (NRQ) of genes of interest using a generalized delta-delta quantification cycle method $(\Delta \Delta \mathrm{Cq}$; also known as $\Delta \Delta$ cycle threshold $(\mathrm{Ct})$ )[141]. A panel of eight prospective reference genes was analyzed (GAPDH, ACTB, RPL18, PPIA, YWHAZ, RNF11, H3F3A, SDHA) across all conceptus cDNA samples and 
a subset of 12 endometrium cDNA samples. Appropriate reference genes were selected using the qbase+ geNorm function [141]. Bovine and ovine conceptus target gene expression was normalized to two housekeeping genes, glyceraldehyde 3-phosphate dehydrogenase (GAPDH) and tyrosine 3-monooxygenase/tryptophan 5-monooxygenase activation protein zeta ( $Y W H A Z$ ) (geNorm $M \leq 0.5$ ). The endometrial expression for both heifers and ewes was normalized to ring finger protein $11(R N F 11)$ and $\mathrm{H} 3$ histone family member $3 \mathrm{~A}(H 3 F 3 A)($ geNorm $M \leq 0.5)[142]$. Conceptus and endometrium gene expression was calculated using the following equation: Relative quantity $(\mathrm{RQ})=2^{(35-\mathrm{Ct})}$. The RQ values were divided by the normalization factor (geometric mean of control gene RQ) to obtain the normalized relative quantity (NRQ). The NRQ values were then multiplied by a factor of 100. RT-qPCR amplicon size was validated using gel electrophoresis $(0.8 \%$ agarose gel, $1 \mathrm{X}$ Tris/Borate/EDTA Buffer, and $0.5 \mu \mathrm{g} / \mathrm{mL}$ ethidium bromide) and a 50 bp DNA ladder (New England BioLabs, Ipswich, MA). Gels were visualized under ultra-violet (UV) light using the DigiDoc-It Imaging System (Analytik Jena, Jena, Germany). Amplicons from RT-qPCR on cDNA from conceptuses were visualized using gel electrophoresis to ensure primer specificity (Figure 2.3).

\section{$\underline{\text { Immunohistochemistry }}$}

An elongating d15 bovine conceptus was obtained during a previous study [143]. After flushing the conceptus from the reproductive tract, the conceptus was placed in $4 \%$ buffered formalin phosphate (Thermo-Fisher) overnight and embedded in $2 \%$ agarose before processing. Conceptuses were then embedded in paraffin and sections $(4 \mu \mathrm{m})$ were mounted on microscope slides which were deparaffinized using xylene, and were rehydrated through a series of EtOH washes, and boiled for $6 \mathrm{~min}$ in $0.01 \mathrm{M}$ sodium citrate buffer as an epitope retrieval technique. 
Slides were allowed to cool for $45 \mathrm{~min}$ on ice and then were washed twice for $5 \mathrm{~min}$ in $1 \mathrm{X}$ PBS. The tissue on slides was then enclosed using a wax pen and sections were incubated in $0.3 \%$ hydrogen peroxide in methanol for $30 \mathrm{~min}$ to block endogenous peroxidase activity. Slides were washed in $1 \mathrm{X}$ PBS for 5 min and then blocking serum provided with the Rabbit IgG Vectastain Elite ABC-Peroxidase Kit (Cat. Number: PK-6101, Vector Laboratories, Inc., Burlington, CA) was added to each slide for 20 min to block non-specific binding. Slides were rinsed with $1 \mathrm{X}$ PBS and then the Streptavidin/Biotin Blocking Kit (Vector Laboratories, Inc.) was used to block endogenous streptavidin and biotin. Following a rinse with 1 X PBS, slides were incubated with StartingBlock (PBS) Blocking buffer (Thermo Fisher) for 30 min. A primary rabbit anti-bovine polyclonal antibody (SAB2101338, Sigma Aldrich, St. Louis, MO) directed towards the N terminal region of $L G A L S 3$, was diluted in 1 X PBS (1:500) and $500 \mu \mathrm{L}$ of the solution was added to a serial section of the conceptus. Rabbit $\operatorname{IgG}$, at the same concentration as the primary antibody, was used as an antibody control and $500 \mu \mathrm{L}$ added to $\mathrm{IgG}$ control slides at the same concentration as the primary antibody. The primary antibody and antibody control were left on slides overnight at $4^{\circ} \mathrm{C}$. The following morning, a biotinylated secondary antibody, included in the Vectastain Elite ABC-Peroxidase Kit, was added to slides according to the manufacturer's recommendations. Following a $30 \mathrm{~min}$ incubation with the secondary antibody solution, slides were rinsed with $1 \mathrm{X}$ PBS for 15 min. Slides were then covered with Vectastain Elite ABC reagent for $30 \mathrm{~min}$ and once again, rinsed with $1 \mathrm{X}$ PBS for $15 \mathrm{~min}$. ImmPACT DAB peroxidase substrate (SK-4105, Vector Laboratories) was added to tissue sections and allowed to incubate for 2-5 min. Sections were rinsed in running tap water for 5 min followed by 9 seconds in hematoxylin (GH5216, Sigma Aldrich). Sections were immediately rinsed with double distilled water for 2 min. Slides were then dipped in Scott's tap water and placed in double distilled 
water. Slides were dehydrated in graded alcohol followed by xylene. Coverslips were mounted over tissues using Permount (Thermo Fisher) and images were taken using a Zeiss Axio Lab.A1 microscope (Zeiss, Oberkochen, Germany).

\section{$\underline{\text { Statistical Analysis }}$}

Relative expression data were analyzed using the general linear model procedure (PROC GLM) in the statistical analysis software (SAS Institute Inc.; Cary, NC). For the conceptuses, the analyses tested for differences in relative galectin family members. For the endometrium, the analysis tested for an effect of pregnancy status on gene expression of select galectin family members. All data were log base 10 transformed. Conceptus data are presented as the nontransformed means \pm standard deviation of the mean (SD). Alpha was set at 0.05 and a Tukey’s test was included in the analysis of conceptus gene expression. Endometrial data are presented as non-transformed least squares means $(\mathrm{LSM}) \pm$ standard error of the mean (SEM). $P$-values represent the transformed data and $P \leq 0.05$ was considered significant.

\section{RESULTS}

According to GenBank, LGALS1, 2, 3, 4, 7, 8, 9, 12, and 13like are present in the bovine genome while genes for $L G A L S 1,2,3,4,7,8,9,12,14$, and 15 are listed as being present in the ovine genome in GenBank. Therefore, we investigated the expression of galectins in elongating bovine and ovine conceptuses and pregnant and cyclic intercaruncular endometrium. Representative images of elongating bovine and ovine conceptuses obtained are shown in Figure 2.2 . 
Bovine Day 16 Conceptus and Endometrium Galectin Gene Expression

The expression of IFNT was investigated via RT-qPCR in d16 elongating bovine conceptuses (1293.24 \pm 420.87 ; mean \pm SD) as well as the third-most stable reference gene, H3F3A (78.91 \pm 17.19 ; mean $\pm \mathrm{SD})$. Expression of galectins in d16 bovine conceptuses, depicted in Figure 2.3, were found to include LGALS1 (21.80 \pm 2.07 ; mean $\pm \mathrm{SD}), L G A L S 3(24.47 \pm 6.41$; mean $\pm \mathrm{SD})$, LGALS4 $(0.08 \pm 0.01 ;$ mean $\pm \mathrm{SD})$, LGALS7 (0.02 $\pm 0.01 ;$ mean $\pm \mathrm{SD}), L G A L S 7 B$ $(0.01 \pm 0.005 ;$ mean $\pm \mathrm{SD}), \operatorname{LGALS} 8(1.73 \pm 0.27 ;$ mean $\pm \mathrm{SD}), \operatorname{LGALS} 9(0.77 \pm 0.77 ;$ mean \pm $\mathrm{SD})$, and $L G A L S 13 L(0.29 \pm 0.10$; mean $\pm \mathrm{SD})$.

Intercaruncular endometrium of pregnant and cyclic heifers expressed LGALS1 (25.66 \pm 2.15 and $30.10 \pm 2.15$; cyclic and pregnant, respectively; $\mathrm{LSM} \pm \mathrm{SEM}), \operatorname{LGALS} 3(2.62 \pm 0.52$ and $4.40 \pm 0.52$; cyclic and pregnant, respectively; LSM $\pm \mathrm{SEM} ; P \leq 0.05), L G A L S 4(5.47 \pm 0.66$ and $4.64 \pm 0.66$; cyclic and pregnant, respectively; $\mathrm{LSM} \pm \mathrm{SEM}), \operatorname{LGALS7}(5.80 \pm 2.35$ and 2.62 \pm 2.35 ; cyclic and pregnant, respectively; LSM \pm SEM; $P \leq 0.05), L G A L S 7 B(5.04 \pm 2.59$ and $10.04 \pm 2.59 ;$ cyclic and pregnant, respectively; $\mathrm{LSM} \pm \mathrm{SEM}), \operatorname{LGALS} 8(21.01 \pm 3.95$ and 25.24 \pm 3.95; cyclic and pregnant, respectively; LSM \pm SEM), LGALS9 $(9.26 \pm 2.25$ and $24.56 \pm 2.25$; cyclic and pregnant, respectively; LSM \pm SEM; $P \leq 0.001)$, and $L G A L S 13 L(0.24 \pm 0.07$ and $0.14 \pm 0.07$; cyclic and pregnant, respectively; LSM \pm SEM) (Figure 2.4). Expression of LGALS1, LGALS8, and LGALS9 were greatest. Compared to cyclic heifers, endometrial expression of LGALS7 was less $(5.80 \pm 2.35$ and 2.62 \pm 2.35 ; cyclic and pregnant, respectively; $\mathrm{LSM} \pm \mathrm{SEM} ; P \leq 0.05)$, while expression of $\operatorname{LGALS} 9(9.26 \pm 2.25$ and $24.56 \pm 2.25$; cyclic and pregnant, respectively; $\mathrm{LSM} \pm \mathrm{SEM} ; P \leq 0.001)$ and $L G A L S 3$ were greater $(2.62 \pm 0.52$ and 4.40 \pm 0.52 ; cyclic and pregnant, respectively; LSM \pm SEM; $P \leq 0.05)$ during pregnancy. 


\section{Ovine Day 14 Conceptus and Endometrium Galectin Gene Expression}

We were unable to detect gene expression of LGALS2 and LGALS12 in the ovine elongating conceptuses nor the endometrium of pregnant and cyclic ewes which could be due to primer sets that were not efficient or the tissue did not express these genes. The expression of IFNT was investigated via RT-qPCR in d14 elongating ovine conceptuses (Figure 2.5; $3296.74 \pm$ 1090.66; mean \pm SD) as well as the third-most stable reference gene, $H 3 F 3 A(35.71 \pm 1.43$; mean \pm SD). Expression of galectins in d14 ovine conceptuses, depicted in Figure 2.5, was found to include $L G A L S 1(1.90 \pm 0.25 ;$ mean $\pm \mathrm{SD}), L G A L S 3(4.30 \pm 0.78$; mean $\pm \mathrm{SD}), L G A L S 4(0.19$ \pm 0.10 ; mean $\pm \mathrm{SD}), \operatorname{LGALS7}(0.04 \pm 0.02$; mean $\pm \mathrm{SD}), \operatorname{LGALS} 8(1.68 \pm 0.25 ;$ mean $\pm \mathrm{SD})$, and LGALS13L (1.33 \pm 1.09 ; mean $\pm \mathrm{SD})$.

Intercaruncular endometrium of pregnant and cyclic ewes expressed LGALS1 (0.83 \pm 0.21 and $0.50 \pm 0.21$; cyclic and pregnant, respectively; $L S M \pm S E M), L G A L S 3(7.60 \pm 1.94$ and $12.36 \pm 1.94$; cyclic and pregnant, respectively; LSM \pm SEM), LGALS4 (3.10 \pm 0.38 and $1.78 \pm$ 0.38; cyclic and pregnant, respectively; $\mathrm{LSM} \pm \mathrm{SEM} ; P=0.06), \operatorname{LGALS7}(0.81 \pm 0.24$ and 2.25 \pm 0.24 ; cyclic and pregnant, respectively; LSM \pm SEM; $P \leq 0.05), L G A L S 8(72.84 \pm 17.45$ and $96.60 \pm 17.45$; cyclic and pregnant, respectively; LSM \pm SEM), and LGALS15 (104.30 \pm 234.20 and $591.35 \pm 234.20$; cyclic and pregnant, respectively; LSM \pm SEM; $P=0.07$ ) (Figure 2.6). Expression of $L G A L S 3, L G A L S 8$, and $L G A L S 15$ were greatest. Compared to cyclic ewes, expression of $L G A L S 7$ was greater in pregnant ewes $(0.81 \pm 0.24$ and $2.25 \pm 0.24$; cyclic and pregnant, respectively; $\mathrm{LSM} \pm \mathrm{SEM} ; P \leq 0.05)$ while $L G A L S 4(3.10 \pm 0.38$ and $1.78 \pm 0.38$; cyclic and pregnant, respectively; $\mathrm{LSM} \pm \mathrm{SEM} ; P=0.06)$ tended to be less during pregnancy and LGALS15 tended to be greater during pregnancy $(104.30 \pm 234.20$ and $591.35 \pm 234.20 ; \mathrm{LSM} \pm$ SEM; $P=0.07$; cyclic and pregnant, respectively). 
Localization of $L G A L S 3$ Protein in an Elongating Bovine Conceptus

The presence and localization of $L G A L S 3$ protein was investigated in a d15 elongating bovine conceptus. Figure 2.8 exhibits staining of $L G A L S 3$ protein in the bovine conceptus but not in the isotype control slide, rabbit IgG. Staining appeared to be within both the trophectoderm and endoderm cytoplasm.

\section{DISCUSSION}

Galectins have been suggested to play roles in the regulation of tumors and placental angiogenesis, and an immunological role through the regulation of inflammation, adaptive and innate immune responses, and immune tolerance [134-137]. Successful implantation or attachment requires tight regulation of endometrial receptivity preparations including cellular proliferation preceded by differentiation [119]. The expression profile of cell surface molecules alters as uterine receptivity develops. Galectins have been found to increase cell-adhesion by associating surface glycoproteins on opposing cells in addition to strengthening other intercellular adhesion molecules [120]. Galectins have been highly researched in human and mice reproductive biology. The role of many galectins during bovine and ovine pregnancy is currently undetermined. In this study, we aimed to better characterize galectin genes expressed by the early bovine and ovine conceptus during the elongation phase of development as well as to characterize their expression in the endometrium during pregnancy.

We were unable to detect gene expression of LGALS2 and LGALS12 in the bovine elongating conceptuses nor the endometrium of pregnant and cyclic animals which could be due to primer sets that were not efficient or the tissue did not express these genes. Early bovine 
conceptuses have been previously reported to express $L G A L S 1$ [144]. Data from the current study suggest that both the bovine and ovine elongating conceptuses express $L G A L S 1$. Bovine endometrial expression of LGALS1 was greater than any other galectin investigated; however, expression was not affected by pregnancy status which supports previously published data by Okumu et al. (2013) [138]. Tirado-González et al. (2013) reported systemic levels of LGALS1 were elevated during the first trimester of normal human pregnancy compared to women who subsequently suffered a miscarriage, and they suggested that circulating LGALS1 could serve as an indicator of early successful pregnancy in humans. Their results supported that LGALS1 is playing an immunoregulatory role during pregnancy through the modulation of human leukocyte antigen $\mathrm{G}$ expressed on trophoblast cells [145]. Expression of LGALS1 also has been associated with migration of trophoblast stem cells as the knockout of $L G A L S 1$ in trophoblast stem cells resulted in the down-regulation of matrix metalloproteinases (MMPs), which are associated with successful cytotrophoblast invasion. Overexpression of LGALS1 resulted in the up-regulation of MMPs. Pre-eclampsia patients have a higher placental expression of LGALS1 than normal patients suggesting that expression of $L G A L S 1$ is a fetal response to elevated maternal systemic inflammation. Therefore, LGALSI was suggested to play a role in human maternal-fetal immune tolerance [147].

Investigators have addressed the possible roles of $L G A L S 3$ at the maternal-fetal interface $[115,116]$. Bovine and ovine embryos both expressed $L G A L S 3$ at d16 and d14, respectively. Okumu et al. (2011) published that endometrial LGALS3 expression was not different in pregnant and cyclic heifers [138]. Data from the current study suggest expression of LGALS3 is higher in the endometrium of pregnant heifers. Previous work suggests $L G A L S 3$ expression is regulated by different mechanisms in placental tissues compared to in the uterus. After 
conducting immunohistochemistry (IHC) studies on pregnant murine uteroplacental tissue samples, it was concluded that $L G A L S 3$ is synthesized by all cell types within the murine uteroplacental samples. Levels of $L G A L S 3$ mRNA remained constant in murine uterine tissues until d12 of gestation and declined thereafter until parturition. Interestingly, in placental tissues, LGALS3 mRNA levels remained constant after d12 of gestation until term [115]. In bovine tissues, LGALS3 protein has been identified in the cervix, oviduct, uterus, atretic follicles, and CL [117]. Specifically, in the nonpregnant bovine uterus, LGALS3 has been localized via IHC in epithelial cells as well as macrophages located in the submucosa but absent in endometrial glands [117]. In the bovine CL, LGALS3 expression was elevated at the regressed state in comparison to all other luteal stages and was localized on steroidogenic cells in the CL [118].

In addition to $L G A L S 1$ and $L G A L S 3, \mathrm{~d} 16$ bovine conceptuses expressed $L G A L S 8$, $L G A L S 9$, and $L G A L S 13$ while expression of $L G A L S 4, L G A L S 7$, and $L G A L S 7 B$ was minimal. Expression of LGALS4 and $L G A L S 7 B$ was detected in the bovine endometrium; however, neither was affected by pregnancy status. Pregnancy increased endometrial expression of LGALS9. The endometrium of cyclic heifers expressed greater $L G A L S 7$ in comparison to pregnant animals. First-trimester human placentas express $L G A L S 7$ and $L G A L S 7$ might play a role in adhesion during early pregnancy [148]. In addition, LGALS7 was elevated from weeks 10-12 and 17-20 in the serum of women who developed pre-eclampsia later on in pregnancy [149].

Interestingly, LGALS8 expression in the bovine endometrium was similar to that of LGALS1 and LGALS9. In addition, expression of LGALS8 was detected in ovine conceptuses and endometrial samples. Though the functions of $L G A L S 8$ during early pregnancy have not been fully elucidated, LGALS8 was expressed in similar patterns to LGALS1 and LGALS3 in the 
human trophoblast during the first trimester [150]. In humans, uterodomes form on the plasma membrane during the window of implantation (mid-secretory phase) to allow for the blastocyst to implant, and LGALS9 was highly expressed by uterodomes during this timeframe, suggesting LGALS9 could serve as an endometrial marker of receptivity [151].

Specifically expressed in sheep, endometrial LGALS15 has been hypothesized to be a regulator of blastocyst and trophoblast development. In addition to endometrial LGALS15 in sheep, the d14 ovine conceptus expressed LGALS15. Past research reports that the treatment of ovine trophectoderm cells with $L G A L S 15$ resulted in increased proliferation and migration. Through integrin binding, LGALS15 aids in the attachment and migration of the trophectoderm [64].

\section{CONCLUSIONS}

Collectively, findings from this study confirm that various galectins are present in the elongating ruminant embryo and are differentially expressed by the endometrium during early pregnancy. Previous research on human and mice tissue has noted that the dysregulation of galectins leads to abnormal pregnancies and infertility [152]. As little research has focused on

galectins in ruminant reproduction, future research should focus on characterizing the functions of specific galectins during early pregnancy in ruminants. 
Table 2.1. GenBank accession number, gene name, primer direction, primer sequence, product size and percent amplification efficiency of cDNAs amplified during real time quantitative-polymerase chain reaction (RT-qPCR).

\begin{tabular}{|c|c|c|c|c|c|c|c|c|}
\hline $\begin{array}{c}\text { Bovine } \\
\text { GenBank } \\
\text { Acc. Number }\end{array}$ & $\begin{array}{c}\text { Ovine } \\
\text { GenBank } \\
\text { Acc. Number }\end{array}$ & Gene & Primer & Primer Sequence $\left(5^{\prime}-3^{\prime}\right)$ & $\begin{array}{l}\text { Product } \\
\text { Size } \\
\text { (bp) }\end{array}$ & $\begin{array}{c}\text { Bovine } \\
\text { Amp. } \\
\text { Efficiency }\end{array}$ & $\begin{array}{c}\text { Ovine } \\
\text { Amp. } \\
\text { Efficiency }\end{array}$ & Source \\
\hline NM_175782.1 & NM_001009287.1 & LGALS1 & $\begin{array}{l}\text { Forward } \\
\text { Reverse }\end{array}$ & $\begin{array}{l}\text { GTGGCCGCAGACGCCAAGAG } \\
\text { ACGTCCCCATGCGCGTTGAAA }\end{array}$ & 99 & $90 \%$ & $90 \%$ & [143] \\
\hline NM_001102341.2 & XM_004010664.4 & $L G A L S 3$ & $\begin{array}{l}\text { Forward } \\
\text { Reverse }\end{array}$ & $\begin{array}{c}\text { CAGTGCAGAGGCGTCGGGAAA } \\
\text { CTGCCCCAGCAGGCTGGTTT }\end{array}$ & 121 & $97 \%$ & $99 \%$ & This Study \\
\hline NM_001034768.2 & XM_027978255.1 & $L G A L S 4$ & $\begin{array}{l}\text { Forward } \\
\text { Reverse }\end{array}$ & $\begin{array}{l}\text { TCATGGTCATGACGGAGCACTTCA } \\
\text { ATTGAAGCATCAGGTCGCCATCCA }\end{array}$ & 127 & $106 \%$ & $107 \%$ & This Study \\
\hline XM_002694975.5 & XM_004015233.4 & $L G A L S 7$ & $\begin{array}{l}\text { Forward } \\
\text { Reverse }\end{array}$ & $\begin{array}{l}\text { CTTTAACGTCCCCCACAAGA } \\
\text { ATCACTGCCTGGTTCCTCAC }\end{array}$ & 136 & $102 \%$ & $104 \%$ & This Study \\
\hline XM_002694977.4 & --- & $L G A L S 7 B$ & $\begin{array}{l}\text { Forward } \\
\text { Reverse }\end{array}$ & $\begin{array}{l}\text { GAGCTTTAATGTCCCCCACA } \\
\text { ATCACTGCCTGGTTCCTCAC }\end{array}$ & 139 & $101 \%$ & --- & This Study \\
\hline NM_001045954.2 & XM_027962309.1 & $L G A L S 8^{*}$ & $\begin{array}{l}\text { Forward } \\
\text { Reverse }\end{array}$ & $\begin{array}{l}\text { TCGTGATCATGGTCCTGAAA } \\
\text { TGAAGCCCACAGAGTGAATG }\end{array}$ & 141 & $96 \%$ & $98 \%$ & This Study \\
\hline NM_001015570.3 & XM_004012486.3 & LGALS9 & $\begin{array}{l}\text { Forward } \\
\text { Reverse }\end{array}$ & $\begin{array}{l}\text { TCAGCTTCCAGCCTCCAGGG } \\
\text { TCCAGGGGCGCTGTGTATGGT }\end{array}$ & 86 & $96 \%$ & $93 \%$ & {$[153]$} \\
\hline--- & NM_001009238.1 & LGALS15 & $\begin{array}{l}\text { Forward } \\
\text { Reverse }\end{array}$ & $\begin{array}{l}\text { GGTGGATTTCGGCACTGGTA } \\
\text { TCCCGTCCGTGAAAGTGTTC }\end{array}$ & 98 & --- & $93 \%$ & This Study \\
\hline XM_024979086.1 & --- & $L G A L S 13 L$ & $\begin{array}{l}\text { Forward } \\
\text { Reverse }\end{array}$ & $\begin{array}{l}\text { GGTGGATTTCTGCACGGGTA } \\
\text { ATCACCACCATGCTGTTCGT }\end{array}$ & 81 & $97 \%$ & --- & This Study \\
\hline NM_001168279.1 & NM_001123400.1 & $I F N T$ & $\begin{array}{l}\text { Forward } \\
\text { Reverse }\end{array}$ & $\begin{array}{c}\text { TGCAGGACAGAAAAGACTTTGGT } \\
\text { CCTGATCCTTCTGGAGCTGG }\end{array}$ & 69 & $91 \%$ & $91 \%$ & [154] \\
\hline
\end{tabular}

*To amplify ovine LGALS8, a separate forward primer was used with the following sequence (3'-5'): TCGTGATCATGGTGCTG 
Figure 2.1. Images of a d16 bovine (A) and d14 ovine (B) conceptus.
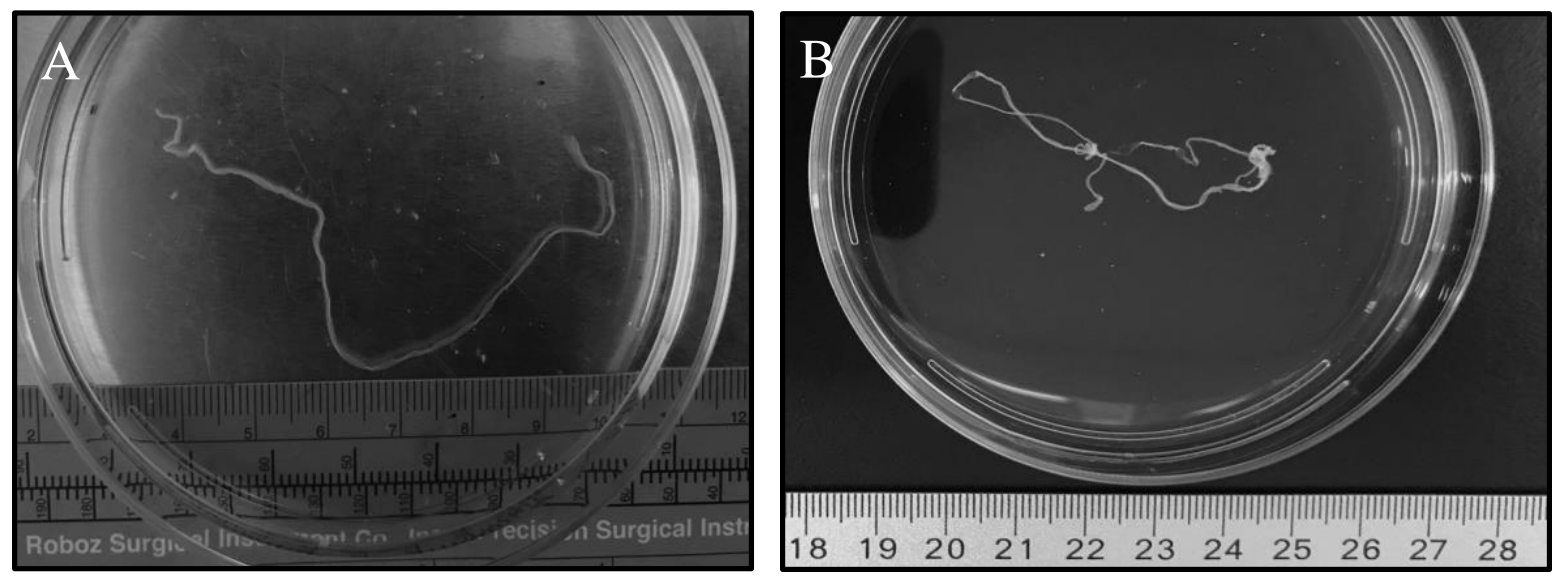
Figure 2.2. Galectin RT-qPCR products visualized on a $0.8 \%$ agarose gel and a 50 bp DNA ladder. Amplicons for cattle (C) and sheep (S) galectins side by side.

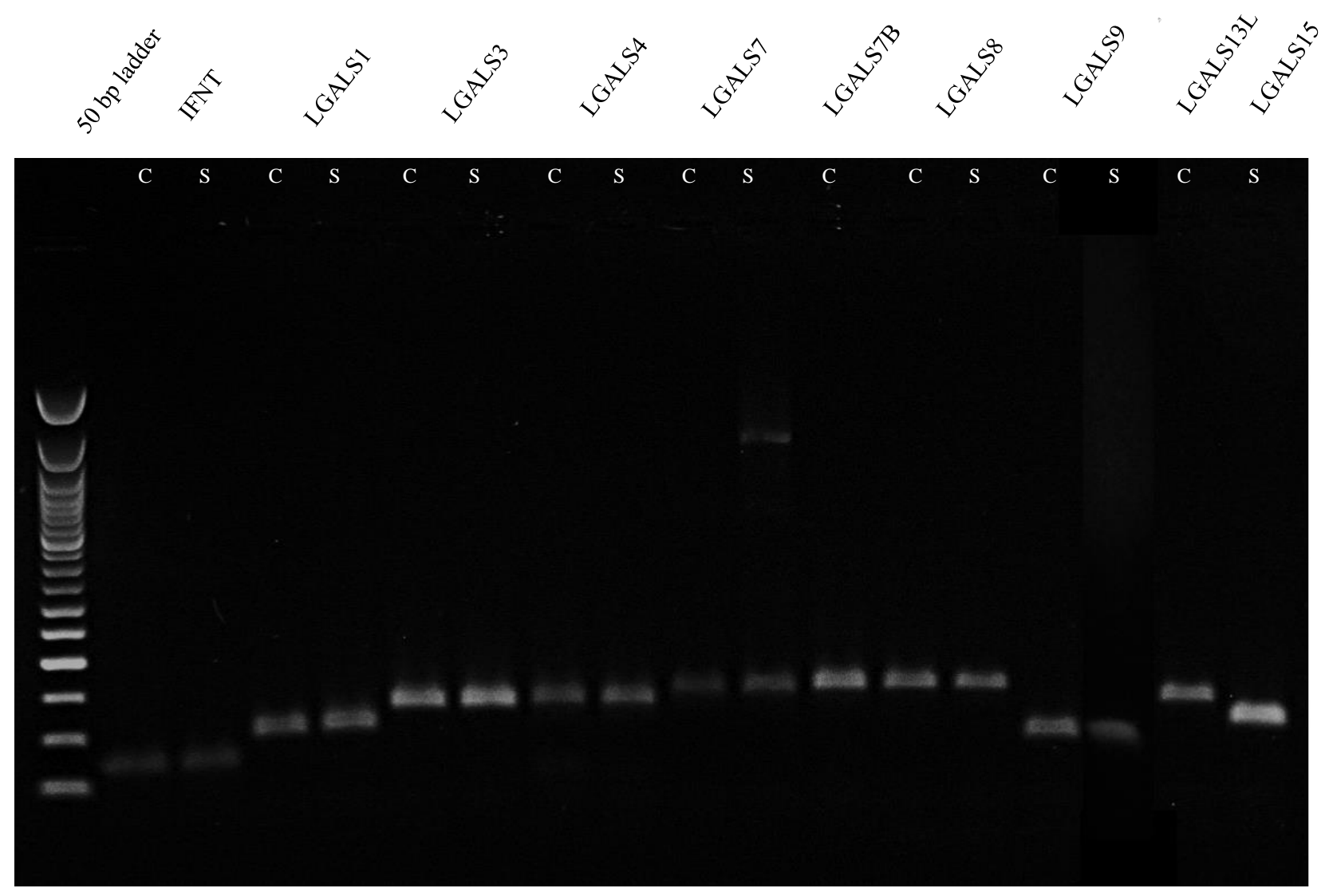


Figure 2.3. Quantitative real-time PCR analysis of galectins in d16 bovine conceptuses. Data presented are the means \pm SD.

Expression of the genes was normalized to the two control genes, GAPDH and YWHAZ. Relative expression of IFNT and the control gene, $H 3 F 3 A$, are also presented. (a-h) Means with the same letter are not statistically different $(\alpha=0.05)$.

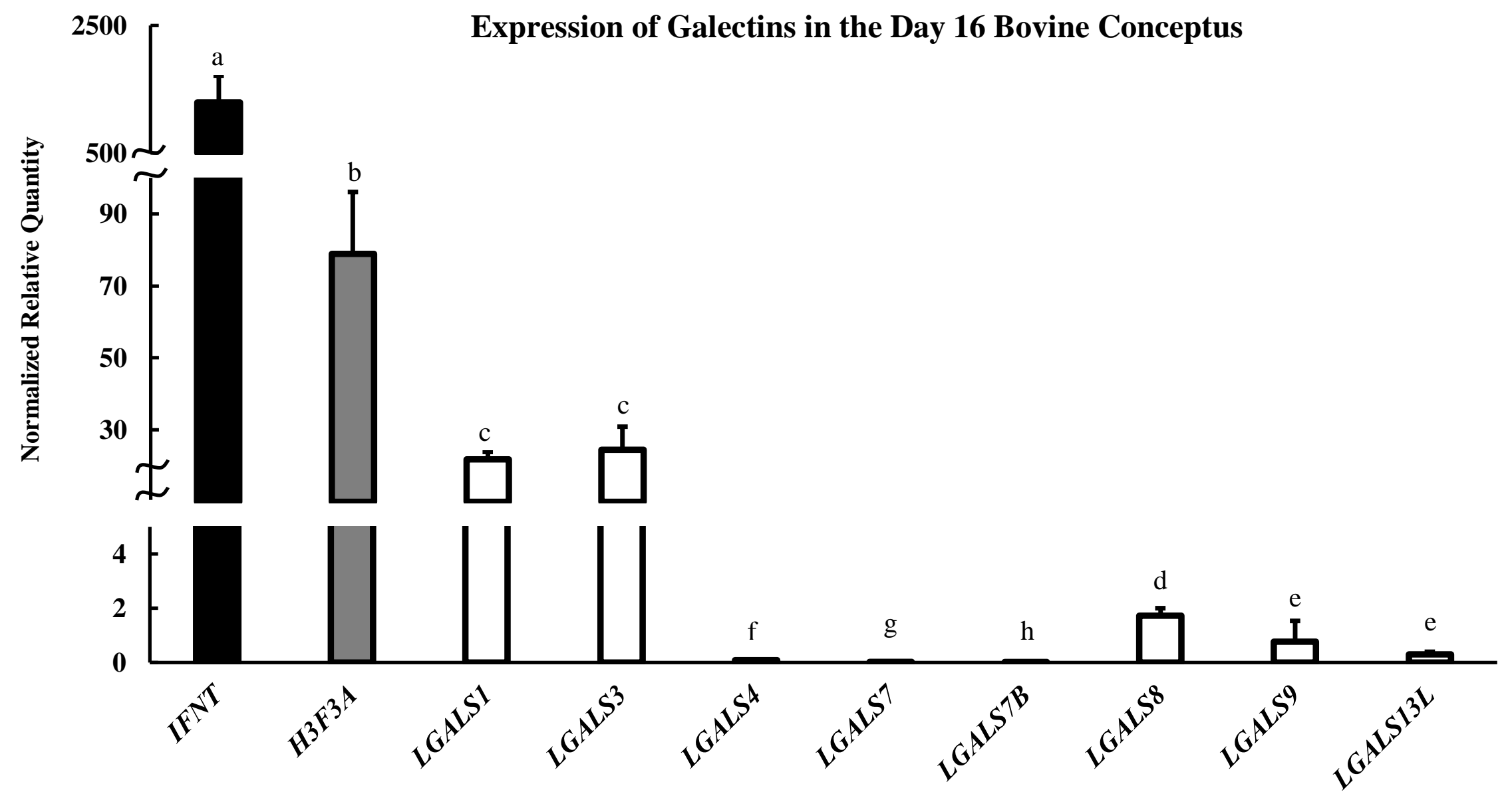


Figure 2.4. Quantitative real-time PCR analysis of galectins in pregnant $(n=4)$ and cyclic $(n=4)$ d16 bovine intercaruncular endometrium. Galectin expression was normalized to two control genes, H3F3A and RNF11. Data are presented as LSM \pm SEM.

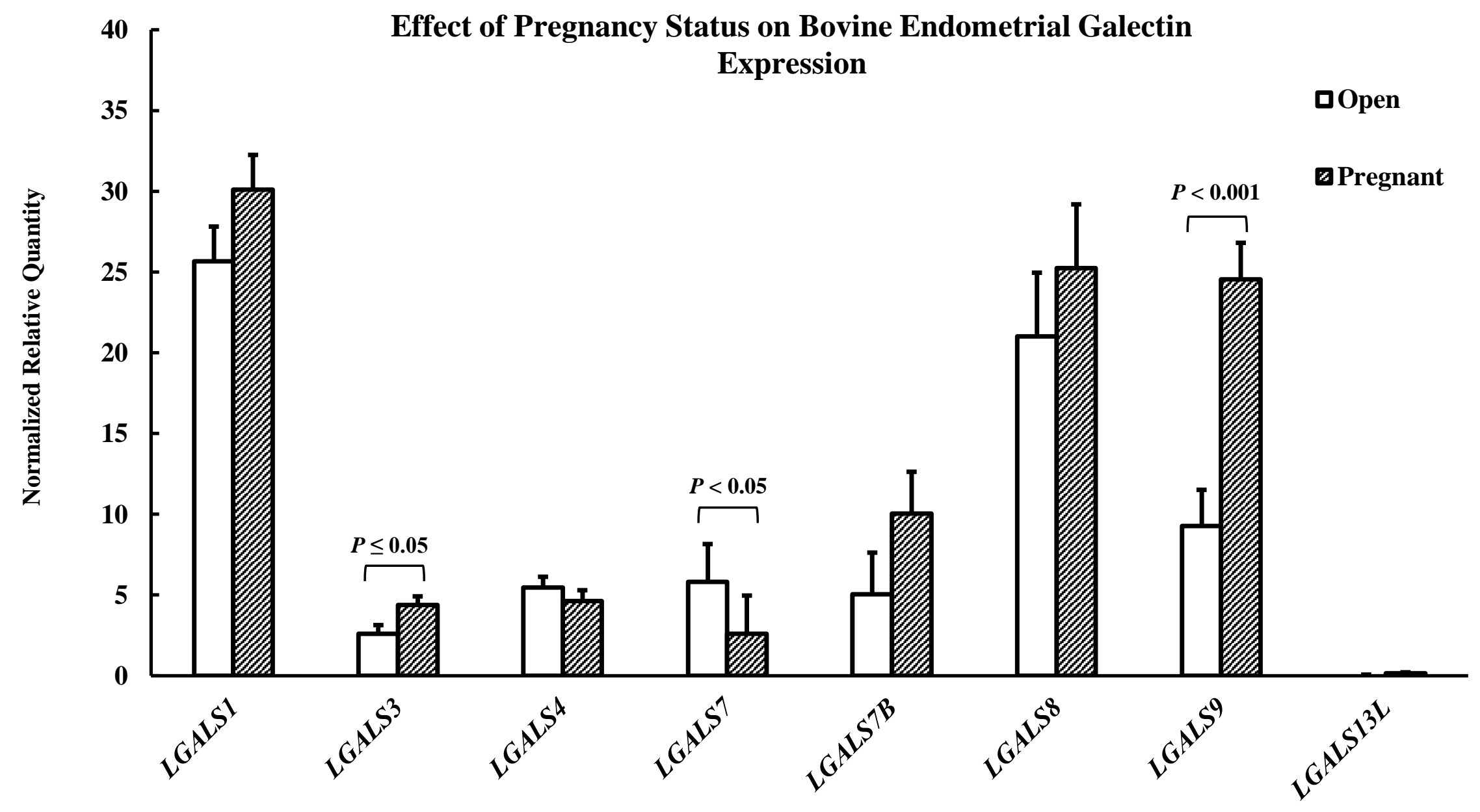


Figure 2.5. Quantitative real-time PCR analysis of galectins in d14 ovine conceptuses. Data presented are the means \pm standard deviation. Expression of the genes was normalized to the two control genes, GAPDH and $Y W H A Z$. Relative expression of IFNT and the control gene, $H 3 F 3 A$, are also presented. (a-g) Means with the same letter are not significantly different $(\alpha=$ $0.05)$.

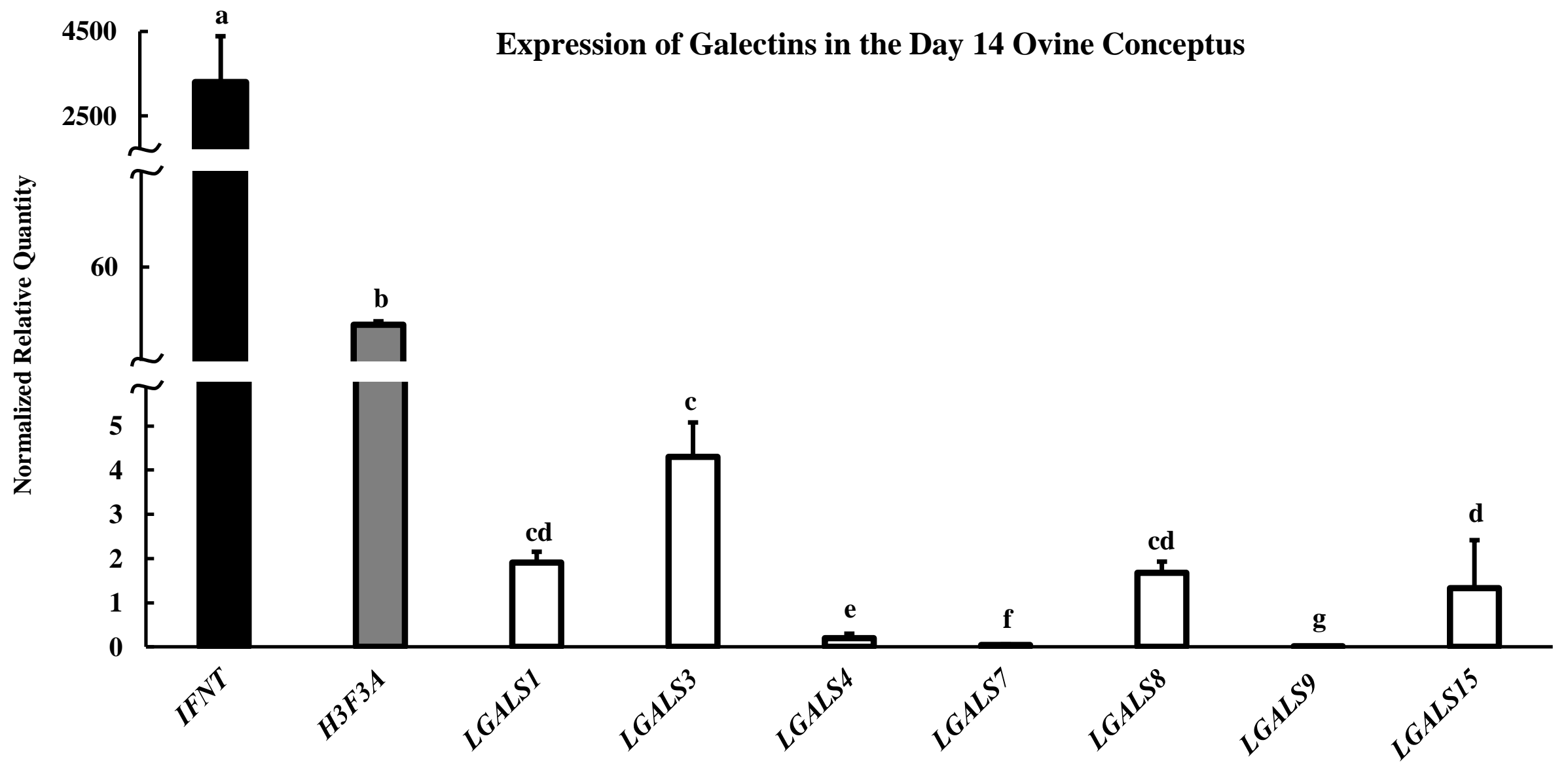


Figure 2.6. Quantitative real-time PCR analysis of galectins in pregnant $(n=3)$ and cyclic $(n=3)$ d14 ovine intercaruncular endometrium. Galectin expression is relative to two control genes, H3F3A and RNF11. Data are presented as LSM \pm SEM.

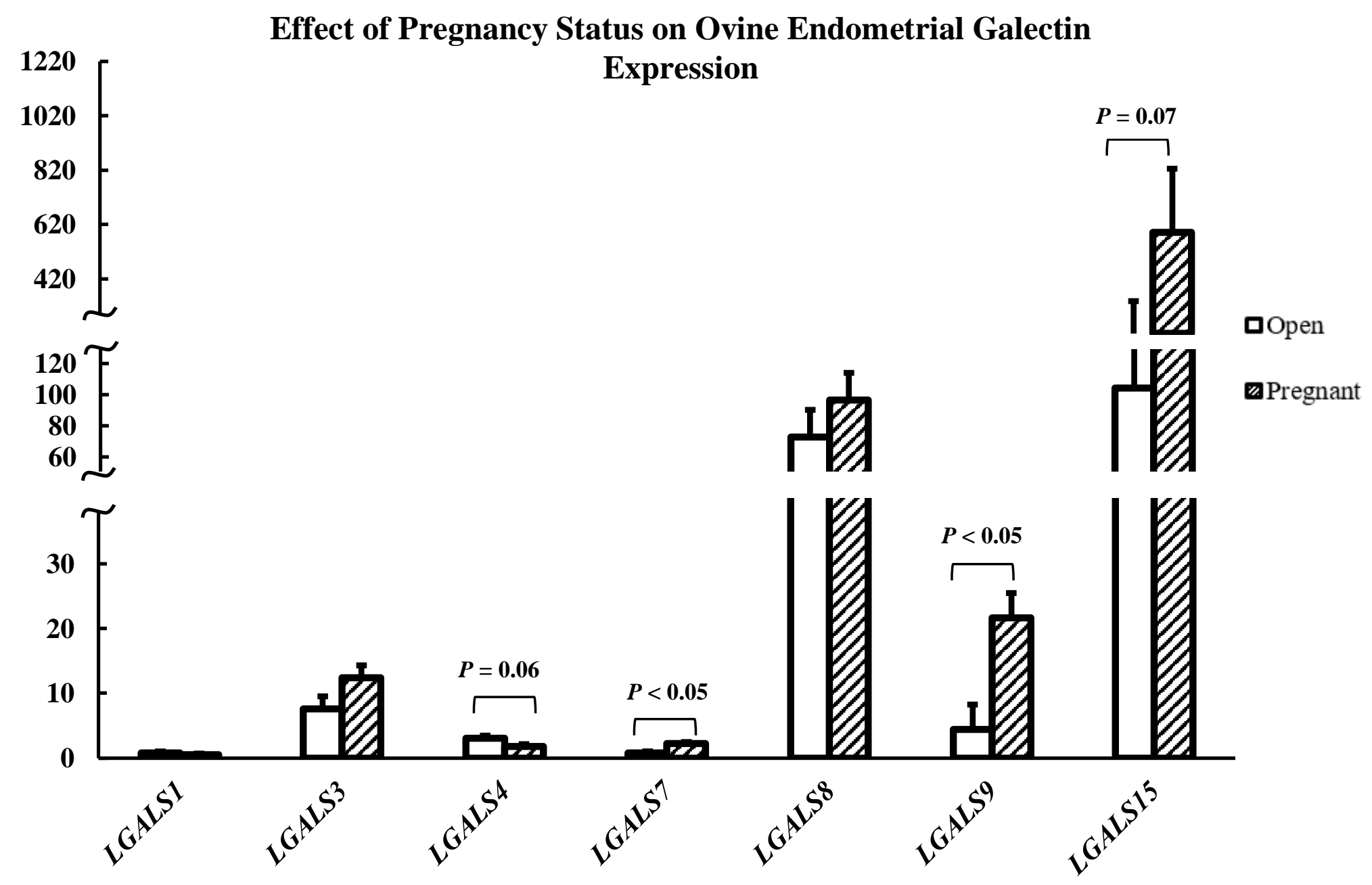




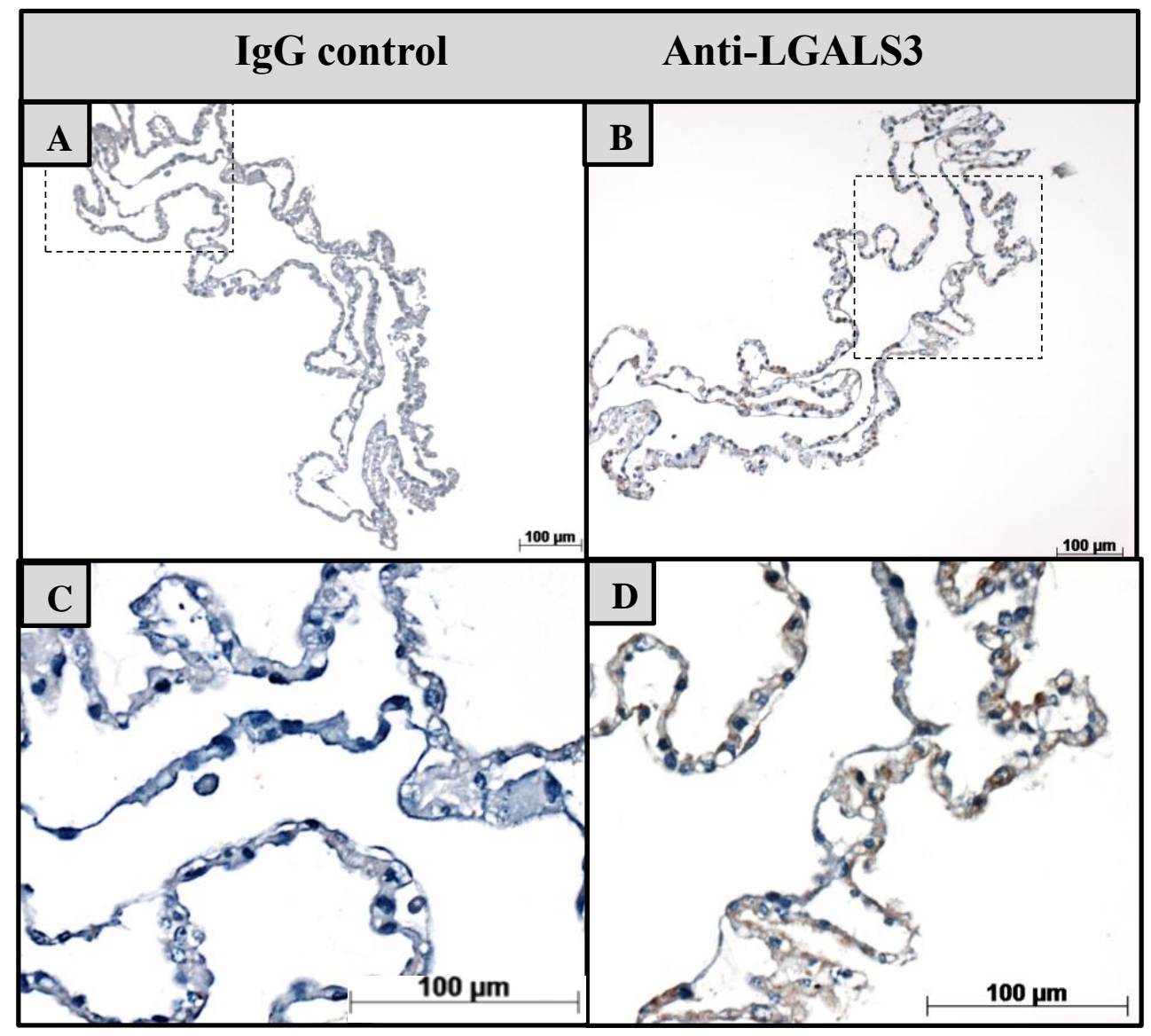

Figure 2.7. (B and D) Galectin-3 (LGALS3) protein in an elongating d15 bovine conceptus. (A and $\mathrm{C}$ ) Absence of DAB staining in IgG isotype control serial section of the conceptus. Images were taken on a Zeiss Axio Lab.A1 microscope at $10 \mathrm{X}$ (A-B) and $20 \mathrm{X}$ (C-D) magnification. 


\title{
CHAPTER THREE
}

\section{EFFECT OF INTERFERON TAU AND GALECTIN-3 ON BOVINE ENDOMETRIAL EPITHELIAL AND FIBROBLAST CELL TRANSCRIPTOMES IN 3D CELL CULTURE}

\begin{abstract}
Interferon-tau (IFNT), secreted by the elongating bovine conceptus, is the maternal recognition of pregnancy signal that suppresses the endometrial luteolytic mechanism by modifying expression of genes in specific cell types within the endometrium. The conceptus also secretes galectin proteins, specifically galectin-3. This study assessed the effect of IFNT (Experiment 1) and LGALS3 (Experiment 2) on bovine endometrial epithelial and fibroblast cell transcriptomes when the mid-luteal phase endometrial cells were cultured in a 3D environment. In Experiment one, epithelial cells, cultured in Transwell inserts above the fibroblast cells, were treated with RPMI media alone (control; $\mathrm{n}=4$ ) or treatment media (RPMI with 5\% FBS and $1 \%$ ABAM) containing $100 \mathrm{ng}$ of recombinant ovine IFNT $(n=3)$ for 6 h. In Experiment two, cells were treated with either RPMI media alone (Control; $n=5)$, pregnant ovine uterine flush fluid, theoretically containing INFT, diluted with treatment media $1: 1(n=4)$, or treatment media (RPMI with 5\% FBS and 1\% ABAM) containing either 100 or 1000 ng of recombinant mouse LGALS3 $(n=5)$ for $6 \mathrm{~h}$. Total RNA was extracted from both cell types and the transcriptomes were assayed by RNA Sequencing and RT-qPCR. Interferon-tau regulated 673 and 83 genes
\end{abstract}


(differentially expressed genes or DEGs) in epithelial and fibroblast cells, respectively ( $P \leq$ 0.001; FDR $P \leq 0.05$ ). Many of the DEGs identified in the epithelial (205) and fibroblast cells (64) were previously reported as IFNT and bovine conceptus-induced DEGs in intact bovine endometrium, including well-known ISGs such as ISG15, MXI, MX2, OAS1, and OAS2. Surprisingly, the ZCBHAVI gene, which was recently found to be up-regulated in intact bovine endometrium in response to the conceptus, was only up-regulated in fibroblast cells despite applying IFNT to the apical surface of the epithelial cells in 3D culture. The RNA-Seq analysis of the bovine endometrial cells treated with mouse LGALS3 protein resulted in the identification of a single gene, RPL23A, that was upregulated in epithelial cells treated with $100 \mathrm{ng}$ of LGALS3 ( $P \leq 0.001$; FDR $P \leq 0.05)$. This study supports the idea that the 3D culture of bovine endometrial cells may be utilized to study early conceptus-maternal crosstalk and identify endometrial cell type-specific responses to the conceptus.

\section{INTRODUCTION}

The beef cow/calf industry experiences an annual loss exceeding $\$ 1.2$ billion, with the largest contributing factor being embryonic loss [1]. The highest incidence of pregnancy loss in cattle occurs during the embryonic period of gestation, with $40 \%$ occurring between $\mathrm{d} 8$ and $\mathrm{d} 17$ [2-4]. Bovine embryos will elongate from approximately $2 \mathrm{~mm}$ on d13 into an approximately 6 cm filamentous structure, spanning the length of the uterine horn by d19 [19, 20, 30]. During this time, the conceptus secretes a substance to communicate to the maternal endometrium its presence and prolong progesterone (P4) production by the CL [5]. This secretory protein, IFNT, is derived from the bovine mononuclear trophectoderm. The presence of IFNT stimulates the 
expression of ISGs in addition to blocking the pulsatile secretion of endometrial PGF from the uterine horn and ultimately, luteolysis [42]. Luteolysis, the functional and structural regression of the CL, is prevented due to the paracrine release of IFNT from the conceptus which acts to modify endometrial PGF through the silencing of uterine epithelial cell estrogen receptor alpha (ESRI) and thus, epithelia oxytocin receptor $(O T R)$ [155]. Overall, luteal P4 is maintained and supports gestation until the establishment of placental P4.

Interferon-tau is a type I interferon. The type I interferons bind IFNAR to signal a biological response. There is a single Type II interferon family member, IFNG, which binds the IFNGR [40]. The IFNT acts on the endometrium and modifies endometrial cell gene expression. The pregnancy recognition signal, IFNT, affects the differential expression of genes in the LE, dGE, sGE, and stroma [36, 41]. The genes affected, ISGs, are categorized in two distinct classifications, classical and non-classical ISGs, which are spatially stimulated by IFNT within the stroma/dGE and LE/sGE, respectively [42, 43]. Type I and II IFNs initiate the expression of classical ISGs through stimulation Jak-STAT pathways resulting in phosphorylation of their respective receptors activating STAT. Classical ISGs expressed in the stroma/dGE in response to IFNT include $S T A T 1$ and STAT2, IRF1, ISG15, and 2'-5'-oligoadenylate synthetase 1 (OASI) $[45,156,157]$. Transcriptomic analysis of ruminant endometrium has led to the identification of non-classical ISGs which are stimulated by IFNT and are primarily induced by P4 spatially in the LE/sGE [20, 41]. Genes include CST3, CTSL, and LGALS15 in sheep [42]. In the LE/sGE, interferon regulatory factor-2 (IRF2) prevents the IFNT from regulating gene expression of classical ISGs.

Mathew et al. (2019) published data identifying conceptus and IFNT induced DEGs 
[143]. Endometrial explants were cocultured with d15 conceptuses from artificial insemination or IVF origin, or $100 \mathrm{ng}$ of IFNT, or media alone. Transcriptome differences were analyzed via RNA-Seq and RT-qPCR. Conceptus induced, IFNT-dependant DEGs were identified through the grouping of explant DEGs that were differentially expressed in response to all three treatment groups as well as DEGs similar between the IFNT and AI conceptus treated explants [143].

Galectins are a large family of $\beta$-galactoside-binding animal lectins that have numerous physiological functions. Lectins bind carbohydrates and result in cell agglutination while playing vital roles in pathogen defense, cell trafficking, and immune regulation [82, 83]. Galectins are ancient members of a lectin family which are characterized by having conserved amino acid sequences with at least one $\mathrm{CRD}$ and the ability to recognize $\beta$-galactoside structures located on cell surface glycoconjugates [85, 86]. Elongating bovine embryos have been found to express galectin-1 (LGALS1) and LGALS3. Recently, LGALS3 was identified to play an important part in the preparation of the endometrium for implantation with a presence in the endometrium and trophoblast cells. Given the resemblances of tumor invasion and the migration of trophoblast cells, investigators have addressed the possible roles of $L G A L S 3$ at the maternal-fetal interface regarding implantation $[115,116]$. After conducting IHC studies on pregnant murine uteroplacental tissue samples, it was concluded that LGALS3 is synthesized by all cell types within the murine uteroplacental samples. Levels of LGALS3 mRNA remained constant in murine uterine tissues until d12 of gestation and declined thereafter until parturition. Interestingly, in placental tissues, LGALS3 mRNA levels remained constant after d12 of gestation until term [115]. In bovine tissues, LGALS3 protein has been identified in the cervix, oviduct, uterus, atretic follicles, and CL [117]. Specifically, in the nonpregnant bovine uterus, LGALS3 has been localized via IHC in epithelial cells as well as macrophages located in the 
submucosa but were absent in endometrial glands [117].

In the past, 2D monoculture techniques have been utilized to investigate cellular processes of bovine epithelial and fibroblast cells [129, 130]. The 3D transwell culture system published by MacKintosh et al. (2013) enables the coculture of two cells types, which would normally interact in vivo [127]. MacKintosh et al. utilized bovine endometrial epithelial and fibroblast cells in this system to investigate the effects of lipopolysaccharide (LPS) in a postpartum uterine disease [127]. To better simulate the columnar arrangement of epithelial cells in vivo, a 3D culture allows epithelial cells to maintain a physiological polarity in vitro due to tight junctions unlike traditional 2D cell culture techniques $[127,128]$. Tight junctions are imperative to epithelial cellular functions because the passage of ions and molecules paracellularly is regulated by tight junctions. A measurement that reflects epithelial integrity, TEER, can be measured via an epithelial volt-ohm meter [127].

This aim of this study was to examine the effect of IFNT and LGALS3 on bovine endometrial epithelial and fibroblast cell transcriptomes when cells are cultured in a 3D environment.

\section{MATERIALS AND METHODS}

\section{$\underline{\text { Primary Cell Isolation, Culture, and Treatment }}$}

Bovine reproductive tracts utilized to isolate endometrial cells were collected from a local abattoir. The tracts were chosen based on the appearance of a mid-luteal phase CL and the absence of either pregnancy and/or infection [158]. Cells were isolated from different animals for the IFNT Experiment (Experiment 1; n=3-4) and LGALS3 Experiment (Experiment 2; n=4-5). The reproductive tracts were immediately placed on ice and transported to the laboratory. Upon 
arrival at the laboratory, reproductive tracts were rinsed with water, and the broad ligament and the cervix were removed. The remaining reproductive tract was sprayed with $70 \%$ ethyl alcohol (EtOH), and the uterine horn ipsilateral to the $\mathrm{CL}$ was removed with a scalpel. The tract was then placed in a cold dissecting tray lined with $70 \% \mathrm{EtOH}$ soaked paper towels and sprayed once again with $70 \% \mathrm{EtOH}$. A cut was made along the anti-mesometrial side of the uterine horn ipsilateral to the CL.

Bovine endometrial epithelial and fibroblast cells were isolated from uterine horn ipsilateral to the CL [127]. Briefly, the exposed endometrium was rinsed with $1 \mathrm{X}$ phosphate buffered saline (PBS) (Gibco, Gaithersburg, MD) containing 1\% antibiotic-antimycotic (ABAM) (Gibco). Thin intercaruncular endometrial strips were dissected and placed in $25 \mathrm{~mL}$ of hank's balanced salt solution (HBSS) (Gibco). Endometrial strips were washed twice in $25 \mathrm{~mL}$ of HBSS and trimmed into $3-5 \mathrm{~mm}$ pieces and washed in a final HBSS wash $(25 \mathrm{~mL})$ containing $1 \%$ $\mathrm{ABAM}$. Endometrial strips were then incubated for $10 \mathrm{~min}$ at $38.8^{\circ} \mathrm{C}$ in atmospheric oxygen and $5 \% \mathrm{CO}_{2}$. The wash was then drained from the conical tube and $40 \mathrm{~mL}$ of filter-sterilized enzyme solution [49.5 mL HBSS, $25 \mathrm{mg}$ Collagenase II (Sigma-Aldrich), $50 \mathrm{mg}$ bovine serum albumin (BSA) (Sima-Aldrich), $700 \mu \mathrm{L}$ Trypsin-EDTA-HBSS solution (Sigma-Aldrich; Gibco), and 125 $\mu \mathrm{L}$ DNase I (Sigma-Aldrich)] was added. The endometrium in enzyme solution was placed in a water bath at $38.8^{\circ} \mathrm{C}$ for $1 \mathrm{~h}$ with manual agitation every $10 \mathrm{~min}$.

Following incubation, the endometrium in enzyme solution was filtered through a 100 $\mu \mathrm{M}$ filter placed over a $40 \mu \mathrm{M}$ filter (Corning Inc.; Tewksbury, MA). The filtered solution was placed with $5 \mathrm{~mL}$ of prewarmed $\left(38.8^{\circ} \mathrm{C}\right) \mathrm{HBSS}$ with $10 \%$ fetal bovine serum (FBS) (VWR International, Radnor, PA). The $40 \mu \mathrm{M}$ filter, containing sheets of epithelial cells, was then overturned and washed with $30 \mathrm{~mL}$ of pre-warmed $\left(38.8^{\circ} \mathrm{C}\right)$ Roswell Park Memorial Institute 
1640 (RMPI) (Gibco), 5\% FBS (VWR International), and 1\% ABAM (Gibco) (complete media). Fifteen $\mathrm{mL}$ aliquots of the cell suspension were transferred into T75 flasks (Greiner Bio-One, Monroe, NC) and cells were allowed to attach for $48 \mathrm{~h}$ at $38.8^{\circ} \mathrm{C}$ in atmospheric oxygen and $5 \%$ $\mathrm{CO}_{2}$. Fibroblasts, in filtered solution, were centrifuged at $700 \mathrm{xg}$ for $7 \mathrm{~min}$ at $25^{\circ} \mathrm{C}$. The supernatant was aspirated and $5 \mathrm{~mL}$ of prewarmed $\left(38.8^{\circ} \mathrm{C}\right)$ sterile water was added to the pellet and lightly vortexed for $30 \mathrm{~s}$. After, $45 \mathrm{~mL}$ of HBSS (Gibco) containing 10\% FBS (VWR International) was added to the cells which were then filtered once again through a $40 \mu \mathrm{M}$ filter. Flow through was centrifuged at $700 \mathrm{x}$ g for $7 \mathrm{~min}$ at $25^{\circ} \mathrm{C}$. The supernatant was aspirated and $45 \mathrm{~mL}$ of complete media was added to re-suspend pellet. Fifteen $\mathrm{mL}$ aliquots were added to T75 flasks which were placed in the incubator at $38.8^{\circ} \mathrm{C}$ in atmospheric oxygen and $5 \% \mathrm{CO}_{2}$. After $18 \mathrm{~h}$, fibroblasts in flasks were washed with $10 \mathrm{~mL}$ of prewarmed 1X PBS (Gibco) and $15 \mathrm{~mL}$ of complete media was added. Every 2d, both fibroblast, and epithelial flasks were rinsed with $1 \mathrm{X}$ PBS (Gibco) and $15 \mathrm{~mL}$ of fresh complete media was added until the cells reached confluency. Once approximately $80 \%$ confluent, cells were dislodged from the flask with $1.5-2 \mathrm{~mL}$ of Accutase (Sigma-Aldrich) and passed into new T75 flasks in complete media.

Cells were counted using a hemocytometer and once the epithelial cell concentration of $3 \times 10^{5}$ cells $/ \mathrm{mL}$ was reached, cells were removed using 2-3 mL of Accutase (Sigma-Aldrich) and placed in polyethylene terephthalate transwell cell culture inserts with a pore size of $0.4 \mu \mathrm{m}$ (Millipore Sigma, Burlington, MA). Before the addition of epithelial cells, transwell inserts were coated with 25-30 $\mu \mathrm{L}$ of Matrigel (Corning Inc.) with ice-cold RPMI (Gibco) at a 1:8 dilution. Transwell inserts were placed in a 24 -well plate containing $800 \mu \mathrm{L}$ of complete media. Cells were cultured in transwell inserts for 9d. On d9 (day of treatment), TEER was calculated using 
the following formula: TEER $\left(\Omega \mathrm{cm}^{2}\right)=($ sample resistance - blank resistance $) \mathrm{X}$ membrane area. Resistance values were obtained by using a Millicell ERS-Voltohmmeter (Millipore Sigma). The 3D cultures were conducted as previously described [127]. The day prior to treatment, $1 \mathrm{~mL}$ of fibroblast cells at the concentration of 1 X $10^{5}$ cells $/ \mathrm{mL}$ were plated per well in new 24 plates. Fibroblasts were allowed to adhere and $18 \mathrm{~h}$ later, the cells were washed with $1 \mathrm{X}$ PBS (Gibco) and new media was added [treatment media; RPMI (Gibco), 5\% FBS (VWR International), and 1\% ABAM (Gibco)]. The transwell inserts containing epithelial cells were then added to the fibroblast cells and new treatment media was added to the transwell inserts.

\section{Experiment One}

After $2 \mathrm{~h}$, new treatment media alone (Control) or treatment media containing $100 \mathrm{ng}$ of recombinant ovine IFNT (oIFNT), kindly donated by Dr. Gilles Charpigny of INRA, Biologie du Développement et Reproduction (Jouy en Josas, France), was added to well inserts containing epithelial cells for $6 \mathrm{~h}$ [143]. Fibroblast cell media was not changed. The experiment was repeated at least 4 times (cells from 4 different uteri). However, the oIFNT treatment for one uterus was lost, therefore, $n=3-4$. Both treatments were applied to three $3 \mathrm{D}$ cell cultures from each uterus.

\section{Experiment Two}

After $2 \mathrm{~h}, 300 \mu \mathrm{L}$ of new treatment media alone (Control), d14 pregnant ovine flush fluid (FF) (diluted 1:1 with treatment media), or treatment media containing either 100 or $1000 \mathrm{ng}$ of recombinant mouse LGALS3 protein (Catalog Number: 9039-GA; R\&D Systems, Minneapolis, MN) was added to well inserts containing epithelial cells for $6 \mathrm{~h}$. The ovine pregnant uterine 
flush fluid, theoretically containing IFNT, was obtained during a previous study by flushing the uterine horn ipsilateral to the CL of a d14 pregnant ewe with $20 \mathrm{~mL}$ of 1 X PBS (Thermo Fisher). The presence of a conceptus confirmed pregnancy. Fibroblast media was not changed. The experiment was replicated with cells from five different uteri. The FF treatment from one replication was lost, therefore, $n=4-5$ uteri. All treatments were applied to three 3D cell cultures from each uterus.

\section{RNA Isolation and RNA Sequencing (RNA-Seq)}

Total RNA was extracted from both cell types, separately, using the Qiagen RNeasy Kit (Qiagen) for Experiment one while the E.Z.N.A. Total RNA Kit I (Omega Bio Tek, Inc.) was used to collect RNA for Experiment two. Both kits were used according to the manufacturer's recommendations. Briefly, the media was collected and the membrane from transwell inserts was removed using a scalpel, placed in lysis buffer, and agitated using a pipette tip. Lysis buffer was added to fibroblast cells in wells and gently scraped using a pipette tip to obtain fibroblast RNA. The three RNA samples per treatment for both cells types were pooled. The concentration of RNA and integrity was determined using NanoDrop (NanoDrop ND-1000, NanoDrop Technologies) and Bioanalyzer (2100 Bioanalyzer, Agilent Technologies), respectively. The RNA integrity number (RIN) values obtained from the Bioanalyzer ranged from 8.6-10.0. The RNA was stored at $-80^{\circ} \mathrm{C}$ until cDNA was synthesized.

RNA library preparation and sequencing was performed by the University of Missouri DNA Core facility as previously described by Moraes et al. [159]. The raw sequences (fastq) underwent adapter removal and quality trimming utilizing Trimmomatic [160]. The quality reads were then mapped to the bovine reference genome ARS-UCD1.2 using Hisat2 mapper, a 
sensitive and fast alignment program of next-generation sequencing data [161]. The sorted binary alignment maps and the NCBI gene annotation of the ARS-UCD1.2 assembly were subjected to FeatureCounts [162] to quantify read counts of genes for each sample. Differential gene expression analysis between sample groups was performed by robustly fitting the expression data to a weighted generalized linear model (GLM) using edgeR robust [163].

To perform a Gene Ontology (GO) analysis of statistically significant transcripts generated by RNA-Seq data, DAVID Bioinformatics Resource 6.8 was utilized [164]. Pathway analyses included were an enriched biological process (BP) in addition to the Kyoto Encyclopedia of Genes and Genomes (KEGG). During the annotation, the GO Direct category was used which provides mappings directly annotated by the source database and the Homo sapien background was used during the analysis. The GO Direct and KEGG categories were considered enriched when $P \leq 0.05$.

\section{Reverse Transcription and Quantitative real-time PCR (RT-qPCR)}

Following the manufactures recommendations, cDNA was synthesized using the High Capacity cDNA Reverse Transcription Kit (Applied Biosystems). Briefly, 500 ng of RNA and nuclease-free water was added to $10 \mu \mathrm{L}$ of master mix to reach a total volume of $20 \mu \mathrm{L}$. Noreverse transcriptase control samples were also prepared. Following a $2 \mathrm{~h}$ cDNA synthesis at $37^{\circ} \mathrm{C}, 5 \mu \mathrm{L}$ of each sample was pooled and the remaining cDNA was diluted 1:20 using nuclease-free water. Pooled cDNA was used to generate 7 standards (1:4 serial dilutions). Standards were used to calculate primer efficiencies (E) using the following equation: $\mathrm{E}=\left[10^{(-}\right.$ 1/slope)-1]. The slope is a plot of observed Ct values versus the 7 standard serial dilutions. Percent efficiency was then obtained by dividing E by 2 and multiplying by 100 . 
Quantitative real-time PCR was utilized to examine gene expression differences in response to treatment and to verify the data obtained from RNA-Seq. The CFX96 Real-Time PCR machine (Bio-Rad Laboratories) was used to perform RT-qPCR reactions. All primers were designed using Primer3Plus (Version 2.4.2) unless otherwise noted. Sample RT-qPCR reactions were carried out in $20 \mu \mathrm{L}$ reactions in duplicate [10 $\mu \mathrm{L}$ of SYBR Green Master Mix (Catalog Number: A25743; Applied Biosystems), $1.2 \mu \mathrm{L}$ of forward and reverse primer mix (1 $\mu \mathrm{M}$ final concentration), $2.6 \mu \mathrm{L}$ nuclease-free water, and $5 \mu \mathrm{L}$ of cDNA template (6.6 ng RNA equivalent)]. The RT-qPCR reaction of no-reverse transcriptase controls and no-template controls were included. All samples from an experiment were assayed in a single 96-well plate. Thermo-cycling conditions were as follows: $50^{\circ} \mathrm{C}$ for $2 \mathrm{~min}, 95^{\circ} \mathrm{C}$ for $2 \mathrm{~min}$, which was followed by 40 cycles of $95^{\circ} \mathrm{C}$ for $15 \mathrm{~s}$ and $60^{\circ} \mathrm{C}$ for $1 \mathrm{~min}$. A disassociation analysis was included for each primer set and the presence of a single, sharp peak was confirmed.

The qbase+ package (Biogazelle) was used to analyze and calculate relative gene expression values. Average RT-qPCR Ct values were imported into qbase+ software, which was used to analyze real-time data and generate the normalized relative quantity (NRQ) of genes of interest using a generalized delta-delta quantification cycle method ( $\Delta \Delta \mathrm{Cq}$; also known as $\triangle \triangle \mathrm{CT})[141]$. A panel of eight prospective reference genes was analyzed (GAPDH, ACTB, RPL18, PPIA, YWHAZ, RNF11, H3F3A, SDHA) across a subset of 12 random cDNA samples and two reference genes were selected using the qbase+ geNorm function [141]. Expression was normalized to two housekeeping genes, succinate dehydrogenase complex flavoprotein subunit A (SDHA) and ring finger protein $11(R N F 11)$ in the oIFNT Experiment and the two genes, peptidylprolyl isomerase A (PPIA) and SDHA, in the LGALS3 Experiment. These reference genes were found to be the most stably expressed across the subset of samples for each 
experiment (geNorm $M \leq 0.5$ ) [142]. Sizes of RT-qPCR amplicons were validated using gel electrophoresis $(0.8 \%$ agarose gel, $1 \mathrm{X}$ Tris/Borate/EDTA Buffer, and $0.5 \mu \mathrm{g} / \mathrm{mL}$ ethidium bromide) and a 50 bp DNA ladder (New England BioLabs). Gels were visualized under ultraviolet (UV) light using the DigiDoc-It Imaging System (Analytik Jena).

\section{$\underline{\text { Statistical Analysis }}$}

Log-transformed sample NRQ data were analyzed using the proc GLM in the statistical analysis software (SAS Institute Inc.). The analysis tested the effect of recombinant oIFNT (Experiment one) or recombinant mouse LGALS3 (Experiment two) on endometrial cell gene expression. The epithelial and fibroblast NRQ data were analyzed separately. Residual data were scrutinized for normality using the PLOTS= (diagnostics residuals) statement. If residuals were not normally distributed, they were square root (sqrt) transformed. Data are presented as nontransformed least square means \pm standard error of the least squares means (LSM \pm SEM). Statistical significance was declared at $\mathrm{P} \leq 0.05$.

\section{RESULTS}

\section{Experiment One}

\section{Differentially Expressed Genes in Response to oIFNT}

The RNA-Seq analysis identified 673 and 83 DEGs (up- or down-regulated) in the epithelial and fibroblast cells, respectively, in response to treatment with $100 \mathrm{ng}$ of oIFNT in the 3D culture system $(P \leq 0.001$; FDR $P \leq 0.05$; Figure 3.2$)$. Epithelial cell data consisted of 632 and 41 DEGs that were up- and down-regulated, respectively. Fibroblast cell data identified 83 DEGs that were up-regulated and 0 DEGs that were down-regulated. To potentially identify 
conceptus IFNT responsive genes specifically in epithelial and fibroblast cells, data were compared to recently published RNA-Seq data of bovine endometrial explants incubated with an elongating, d15 bovine conceptus and explants treated with $100 \mathrm{ng} / \mathrm{mL}$ of recombinant oIFNT. The DEGs, published by Mathew et al. (2019) were considered to be conceptus induced, IFNT dependent DEGs (Figure 3.2) [143]. Comparison of DEGs between epithelial cells and fibroblast cells treated with $100 \mathrm{ng} / \mathrm{mL}$ of oIFNT in a 3D environment with the conceptus induced, IFNT dependent DEGs resulted in the identification of 224 DEGs in common with explants and epithelial cells or fibroblast cells in 3D culture (Figure 3.2). Sixty-nine DEGs were in common between all three groups (Figure 3.2). Explants shared 154 DEGs with epithelial cells only and a single gene was differentially expressed in explants and fibroblast cells only (Figure 3.2). All DEGs in common between explants (Mathew et al. 2019) and endometrial cells in 3D culture from the current study were up-regulated [143].

\section{Epithelial-Derived DEGs in Response to oIFNT}

Analysis of RNA-Seq data resulted in the identification of 632 genes that were upregulated and 41 genes that were down-regulated in bovine endometrial epithelial cells in response to treatment with $100 \mathrm{ng} / \mathrm{mL}$ of oIFNT ( $P \leq 0.001$; FDR $P \leq 0.05$; Figure 3.2). Epithelial cells shared 223 up-regulated genes with explant data and 154 of these DEGs were upregulated only in the epithelial cells during 3D culture. The top 10 genes with the greatest log fold change (logFC) of the 223 DEGs shared between explants and epithelial cells were kinesin family member 5C (KIF5C; $\log \mathrm{FC} 8.66)$, hematopoietic $\mathrm{SH} 2$ domain containing (HSH2D; $\log \mathrm{FC}$ 7.86), ATPase phospholipid transporting 8B4 (ATP8B4; $\log F C$ 7.52), indoleamine 2,3dioxygenase (IDO1; $\log F C$ 7.18), forkhead box S1 (FOXS1; $\log F C$ 7.17), growth hormone 
secretagogue receptor (GHSR; $\log F C$ 5.67), prostate androgen-regulated mucin-like protein 1 (PARM1; $\log \mathrm{FC}$ ), apolipoprotein L3 (APOL3; $\log \mathrm{FC} 5.34)$, melanin concentrating hormone receptor 1 (MCHR1; $\operatorname{logFC} 4.88)$, and guanylate-binding protein 2 (GBP2; $\log F C$ 4.52) (Figure 3.2; Table 3.2). The top 20 DEGs in common out of the 223 DEGs are listed in Table 3.2 with their respective epithelial log fold change differences and fibroblast log fold change differences, if applicable. Of the 223 DEGs, 69 were also up-regulated in both epithelial and fibroblast cells in response to oIFNT (Figure 3.2).

Further analysis of DEGs shared between explants and epitheial cells through RT-qPCR validated that genes including MX dynamin like GTPase 1 (MX1) (Figure 3.3; $1.92 \pm 15.45$ and $59.62 \pm 17.83$; Control and oIFNT, respectively; LSM \pm SEM; $P<0.05$ ), MX2 (Figure 3.4; 0.59 \pm 37.32 and $680.18 \pm 43.1$; Control and oIFNT, respectively; $\mathrm{LSM} \pm \mathrm{SEM} ; P<0.001), O A S 1$ (Figure 3.5; $0.80 \pm 10.34$ and $39.03 \pm 11.94$; Control and oIFNT, respectively; $\mathrm{LSM} \pm \mathrm{SEM} ; P$ $<0.05$;), galectin-3 binding protein (LGALS3BP; Figure 3.6; $0.72 \pm 0.40$ and $2.79 \pm 0.50$; Control and oIFNT, respectively; LSM \pm SEM; $P<0.001$ ), galectin-9 (LGALS9; Figure 3.7; $3.07 \pm 2.99$ and $36.78 \pm 3.45$; Control and oIFNT, respectively; LSM \pm SEM; $P<0.001)$, OAS2 (Figure 3.8; $0.59 \pm 1.06$ and $9.97 \pm 1.22$; Control and oIFNT, respectively; $\mathrm{LSM} \pm \mathrm{SEM} ; P<$ 0.01;), BATF2 (Figure 3.9; $0.59 \pm 1.03$ and $8.51 \pm 1.19$; Control and oIFNT, respectively; LSM \pm SEM; $P<0.001$ ), and TNF superfamily member $13 \mathrm{~b}$ (TNFSF13B; Figure 3.12; $0.48 \pm 0.80$ and $12.7 \pm 0.93$; Control and oIFNT, respectively; $\mathrm{LSM} \pm \mathrm{SEM} ; P<0.001$ ) were significantly upregulated in the oIFNT treated epithelial cells. Microtubule associated protein 6 (MAPG) was found to be significantly down-regulated after oIFNT treatment by RNA-Seq $(\log F C-6.50 ; P \leq$ 0.001 ; FDR $P \leq 0.05)$ and RT-qPCR validation of this gene exhibited MAP6 expression in 
response to IFNT was less than in control cells, although not significantly (Figure $3.11 ; 1.86 \pm$ 0.30 and $0.35 \pm 0.35$; Control and oIFNT, respectively; LSM \pm SEM; $P=0.17$ ).

\section{Fibroblast-Derived DEGs in Response to oIFNT}

The RNA-Seq data identified 83 up-regulated and 0 down-regulated transcripts in fibroblast cells treated with oIFNT in the 3D cell culture $(P \leq 0.001$; FDR $P \leq 0.05)$. Fibroblast cells shared 69 DEGs with both explants and epithelial cells, all of which were up-regulated. Of the 69 genes, the following were the top 10 greatest up-regulated in fibroblast cells: OAS2 ( $\log \mathrm{FC} 9.63)$, interferon induced protein 44 like (IFI44L; $\log \mathrm{FC} 8.66)$, RSAD2 (logFC 8.35),

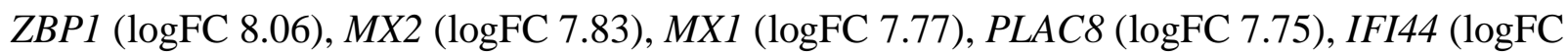
7.63), TNF superfamily member 10 (TNFSF10; $\log F C 7.50)$, and sterile alpha motif domain containing 9 (SAMD9; $\log F C$ 7.46). A single transcript (also recently reported as a conceptus and oIFNT induced DEG in endometrial explants), zinc finger CCCH-type antiviral protein 1 (ZC3HAVI; $\log \mathrm{FC} 0.87$ ) was differentially expressed in fibroblast cells (up-regulated) but not epithelial cells $(P \leq 0.05)[143]$.

Validation of RNA-Seq data through RT-qPCR confirmed genes including MXI (Figure 3.3; $0.01 \pm 0.14$ and $5.28 \pm 0.17$ Control and oIFNT, respectively; LSM $\pm \mathrm{SEM} ; P<0.001$ ), MX2 (Figure 3.4; $0.01 \pm 1.61$ and $4.37 \pm 1.85$; Control and oIFNT, respectively; $\mathrm{LSM} \pm \mathrm{SEM}$; $P<0.01$ ), OAS1 (Figure 3.5; $0.04 \pm 0.95$ and 10.86 \pm 1.09 ; Control and oIFNT, respectively; $\mathrm{LSM} \pm \mathrm{SEM} ; P<0.001$ ), LGALS3BP (Figure 3.6; $0.58 \pm 0.07$ and $1.18 \pm 0.08$; Control and oIFNT, respectively; LSM \pm SEM; $P<0.01$ ), LGALS9 (Figure 3.7; $0.04 \pm 0.15$ and $0.79 \pm 0.18$; Control and oIFNT, respectively; LSM \pm SEM; $P<0.05$ ), OAS2 (Figure 3.8; $0.25 \pm 0.13$ and $1.62 \pm 0.15$; Control and oIFNT, respectively; LSM \pm SEM; $P<0.001$ ), BATF2 (Figure 3.9; 
$0.30 \pm 0.25$ and $1.55 \pm 0.29 ;$ Control and oIFNT, respectively; $\mathrm{LSM} \pm \mathrm{SEM} ; P<0.01)$, and TNFSF13B (Figure 3.12; $0.33 \pm 0.35$ and $1.48 \pm 0.41$; Control and oIFNT, respectively; LSM \pm SEM; $P<0.05)$ were increased in response to oIFNT treatment. Expression of $Z C 3 H A V 1$ in epithelial cells was unaltered by the presence of oIFNT protein in culture, while in fibroblast cells, expression of this gene increased due to oIFNT (Figure 3.13; Control and oIFNT, respectively; $\mathrm{LSM} \pm \mathrm{SEM} ; P<0.05)$.

\section{Gene Ontology Analysis}

The gene ontology analysis of the 223 up-regulated epithelial DEGs in response to oIFNT identified 97 enriched biological processes $(P \leq 0.001$; Table 3.4). The top 5 enriched pathways include the following: 1) type I interferon signaling pathway, 2) defense response to virus, 3) interferon-gamma mediated signaling pathway, 4) response to virus, and 5) negative regulation of viral genome replication $(P \leq 0.001$; Table 3.4$)$. The KEGG pathway analysis found 12 enriched pathways ( $P \leq 0.05$; Table 3.4$)$. The top 5 pathways include 1$)$ influenza $A, 2)$ herpes simplex infection, 3) hepatitis C, 4) measles, 5) RIG-1-like receptor signaling pathway ( $P$ $\leq 0.001$; Table 3.4).

The 70 oIFNT-stimulated DEGs in fibroblast cells, which includes the 69 shared with the epithelial cells and ZC3HAV1, were identified to be associated with 43 biological processes. The top 5 enriched pathways include 1) defense response to virus, 2) type I interferon signaling, 3) response to virus, 4) negative regulation of viral genome replication, and 5) interferon-gammamediated signaling pathway $(P<0.001$; Table 3.5$)$. The KEGG pathway analysis found 7 enriched pathways ( $P \leq 0.05$; Table 3.5$)$. The top 5 pathways include 1$)$ influenza $A, 2)$ herpes 
simplex infection, 3) measles, 4) RIG-I-like receptor signaling, and 5) hepatitis $\mathrm{C}(P \leq 0.001$; Table 3.5).

Experiment Two

The Effect of Mouse-LGALS3 on Bovine Endometrial Epithelial and Fibroblast Cells in 3D Culture

The effect of a recombinant mouse LGALS3 protein on bovine endometrial epithelial and fibroblast cells in 3D culture was analyzed by RNA-Seq. Results indicated a single gene, 60S ribosomal protein L23A ( $R P L 23 A)$, was up-regulated in epithelial cells (log FC 4.05). The transcriptome of fibroblast cells was not affected by LGALS3 treatment. The gene, RPL23A, was analyzed through RT-qPCR, however, an increase in expression of this gene was unable to be validated using this method (Table 3.6). The cells that received the lower concentration of LGALS3 protein (100 ng) and the control-treated cells were analyzed through RNA-Seq. The relative expression of other genes including $\mathrm{C}-\mathrm{X}-\mathrm{C}$ motif chemokine receptor 4 (CXCR4), doublesex- and mab-3-related transcription factor A1 (DMRTA1), ISG15, LGALS3BP, leukemia inhibitory factor $(L I F)$, proline-rich transmembrane protein 3 (PRRT3), and scavenger receptor cysteine-rich family member with 4 domains (SSC4D) was assessed through RT-qPCR to see whether a higher concentration of LGALS3 (1000 ng) affected their expression. Of the genes analyzed, neither concentration of LGALS3 affected their relative expression (Table 3.6). 
The Effect of Day 14 Pregnant Ovine Flush Fluid on Endometrial Epithelial and Fibroblast Cell Transcriptomes Cultured in $3 D$

The ovine flush fluid treatment up-regulated expression of CXCR4 (5.12 \pm 0.98 and 9.50 \pm 1.10 ; Control and FF, respectively; $\mathrm{LSM} \pm \mathrm{SEM} ; P<0.01), I S G 15(0.50 \pm 5.31$ and $130.27 \pm$ 5.94; Control and FF, respectively; $\mathrm{LSM} \pm \mathrm{SEM} ; P<0.001), \operatorname{LGALS3BP}(0.98 \pm 0.16$ and 4.12 \pm 0.18 ; Control and FF, respectively; $\mathrm{LSM} \pm \mathrm{SEM} ; P<0.001)$, and $\operatorname{LIF}(4.27 \pm 0.77$ and $7.11 \pm$ 0.86; Control and FF, respectively; $\mathrm{LSM} \pm \mathrm{SEM} ; P<0.05$ ) as indicated by RT-qPCR (Table 3.6).

\section{DISCUSSION}

The aim of this study was to identify IFNT and LGALS3 induced DEGs in the bovine endometrial epithelium and fibroblast cells in a 3D cell culture system. To date, several studies have addressed endometrial genes stimulated by the elongating ruminant conceptus particularly in sheep, however, literature is lacking information examining differential expression within endometrial epithelial and/or stromal cells, specifically, during early bovine pregnancy [143, $165,166]$.

Endometrial cells of the uterus regulate maternal-conceptus communication through the differential expression of genes. The endometrium also contains other cells including glands, endothelial cells, and immune cells. Past research has noted that endometrial epithelial and fibroblast cells, which largely comprise the endometrium, have different expression profiles [38, 167-169]. During this preimplantation and conceptus elongation in ruminants, genes differentially expressed in fibroblasts have been documented to be associated with maternal 
immunosuppression to protect the semi-allogenic conceptus [42, 165]. The JAK-STAT

signaling pathway is activated via IFNT to stimulate classical ISGs during the elongation phase in the ruminant endometrium [170]. Epithelial and fibroblast cells treated with IFNT in the 3D cell culture had 69 differentially expressed transcripts in common with bovine endometrial explants treated with IFNT or an elongating Day 15 conceptus. There were 154 DEGs shared specifically between the epithelial cells and explants that were not shared with the fibroblasts. On the other hand, there was one DEG shared between the fibroblast cells and explants but not with the epithelial cells [143].

\section{D Cell Culture}

Epithelial and fibroblast cell-specific responses to IFNT have not been elucidated, particularly in a 3D cell culture system. Recently, 3D cell culture models have been utilized to investigate cellular communication mechanisms and responses. Mackintosh et al. (2013) found the coculture of bovine endometrial epithelial and stromal cells enabled the polarization of epithelial cells. The 3D cultures were treated with oxytocin and arachidonic acid to assay the physiological function of the model. The cells were also treated with lipopolysaccharide (LPS) to mimic a bacterial infection. In the present study, we assessed the use of a 3D culture system to study maternal-conceptus crosstalk.

The IFNT was administered apically to the 3D culture. The RNA-Seq data identified 673 DEGs in epithelial cells and 83 DEGs in fibroblast cells ( $P \leq 0.001$; FDR $P \leq 0.05)$, therefore, apical treatment to the 3D system elicited a response in both cell types. We do not know if the IFNT traveled through the epithelium layer to modify the fibroblast cell transcriptome or it the epithelial cells secreted factors basolaterally in response to IFNT to modify fibroblast cell gene 
expression. Considering conceptus IFNT can leave the endometrium and travel systemically, it is possible that IFNT traveled either paracellularly or transcellular to reach the fibroblast cells [171, 172].

Classical and Non-Classical ISGs stimulated by IFNT

Endometrial transcriptomic reported by Forde et al. (2011) of d16 cyclic and pregnant heifers consisted largely of classical ISGs including $B 2 M$, interferon alpha-inducible protein 6 (IFI6), ISG15, MX2, MX1, OAS1, and STAT1 [168]. The bovine endometrium has also been found to respond earlier than $\mathrm{d} 16$ as $\mathrm{d} 8$ blastocysts and $\mathrm{d} 15$ conceptuses have been documented to alter endometrial gene expression in bovine endometrial explants cultured with explants [143, 153]. The 3D cultured bovine endometrial epithelial and fibroblast cells exhibited a significant upregulation of classical ISGs including IFIT1, ISG15, MX2, OAS2, and RSAD2 in response to IFNT treatment (Table 3.3). These genes were also recently reported to be up-regulated genes in explants treated with IFNT or a conceptus [143]. The gene, $R S A D 2$, is believed to be involved in the development of an antiviral endometrial environment via the inhibition of an innate immune response $[173,174]$.

The role of various classical ISGs is still undetermined. The endometrial up-regulation of the classical ISG, ISG15, is associated with infection prevention and is hypothesized to protect the developing conceptus from a negative inflammatory response [175]. In sheep, ISG15, IFIT1, and $R S A D 2$ have been identified to be up-regulated by IFNT in the endometrial glandular epithelium and fibroblast cells after d14 of gestation [41, 42]. This agrees with data from the current study as these genes were found to be up-regulated by IFNT in both epithelial and 
fibroblast cells as well as by the coculture of endometrial explants with an elongating conceptus and IFNT.

Factors, including IFNT and P4, stimulate ovine endometrial genes in a cell-specific manner. Expression of IFNT and P4 responsive genes, including the non-classical ISGs, LGALS15, and CTSL, were shown to be upregulated in the epithelium by d14/15 of both pregnant and cyclic sheep, however, expression then resided by d16 in cyclic sheep. This led to the conclusion that LGALS15 and CTSL are stimulated by P4, IFNT extends their expression $[167,176]$. Bovine and ovine IFNT responsive endometrial genes vary as LGALS15, a gene highly upregulated during early pregnancy in sheep is not present in cattle [177]. Non-classical ISGs are hypothesized to influence proliferation, migration, attachment, and adhesion of the trophectoderm to support elongation of the conceptus [169]. The gene, LGALS3BP, has been previously reported to be abundant in both pregnant and cyclic d16 uterine luminal fluid and endometrium of heifers in comparison to $\mathrm{d} 13[138,168,178]$. Galectin- 9 was upregulated in epithelial and fibroblast cells in response to IFNT treatment, while $L G A L S 3 B P$ was found to only be up-regulated in epithelial cells (Table 3.2). Both $L G A L S 3 B P$ and $L G A L S 9$ are also reported as being stimulated by a conceptus and IFNT in bovine endometrial explants [143]. During implantation, LGALS9 has been suggested to play an immunomodulatory role through the regulation of endometrial leukocytes in humans [151]. The recently classified non-classical ISG, LGALS9 has been suggested to play an immunomodulatory role through the regulation of endometrial leukocytes during human implantation [151]. Through interaction with LGALS3, LGALS3BP forms cell aggregates and is involved in cell adhesion [179].

In the ovine model, IRF2 acts to suppress the transcriptional effects of IFNT on luminal epithelial cells, thereby inhibiting the up-regulation of many endometrial classical ISGs [45]. 
Classical ISGs contain at least a single IFN-stimulated response element (ISRE) in their promoter of which IRF2 acts to inhibit transcriptional activity [169]. Induced by IFNT, IRF1 is hypothesized to increased classical ISG expression in the stroma. Both IRF1 and IRF2 were upregulated in the epithelial cells in response to IFNT ( $\operatorname{logFC} 0.76$ and 0.66 , respectively; Table $3.2)$.

Members of the family of proteins known as SLC transporters are important during conceptus elongation in ruminants as they transport endometrial amino acids into the uterine lumen for nourishment $[25,26]$. It is believed that the effects of IFNT and P4 trigger an increase in amino acids to be transported to the uterine lumen [180]. Solute carrier family 14 member 3 $(S L C 15 A 3)$ is an amino acid transporter that transports lysosome histidine and peptides and was found to be elevated in bovine gestational d18 endometrial tissue [165]. Groebner et al. (2011) found mRNA expression of SLC15A3 increased in response to recombinant bovine IFNT treatment to cocultured bovine glandular epithelial and stromal cell. The stromal cells exhibited a significant 177-fold increase of SLC15A3 while glandular epithelial cells had a 36-fold increase [181]. Data from the current study show the up-regulation of SLC15A3 in the epithelial and fibroblast cells due to IFNT ( $\log$ FC 6.29 and 7.06, respectively; Table 3.2). Previously, SLC15A3 was identified to be IFNT-dependent along with other SLC transporters including the mitochondrial transporter of an unknown solute, solute carrier family 25 member 30 (SLC25A30), and the mitochondrial thiamine pyrophosphate transporters, solute carrier family 25 member 28 (SLC25A28) and solute carrier family 25 member 19 (SLC25A19) [143]. The transporters SLC25A30,SLC25A28, and SLC25A19 were all up-regulated by IFNT in 3D cultured epithelial cells in the current study $(\log \mathrm{FC} 1.34,2.54$, and 1.27, respectively; Table 3.2). 
Despite the apical IFNT treatment to the 3D culture of bovine endometrial epithelial and fibroblast cells, IFNT affected fibroblast gene expression as exhibited by the up-regulation of the gene $Z C 3 H A V 1$ in the fibroblast cells alone. The gene, ZC3HAV1, is an ortholog of zinc-finger antiviral protein $(Z A P)$ which degrades viral RNA through direct binding [182]. Zinc finger $\mathrm{CCCH}$-type antiviral protein 1 has antiviral properties as the $\mathrm{CCCH}$ zinc-finger motif binds viral RNA directly [183, 184]. Ozawa et al. (2012) identified ZC3HAVI as a gene that is up-regulated in the inner cell mass of $\mathrm{d} 8$ in vitro produced blastocysts in comparison to the trophectoderm [185]. The role of IFNT induced ZC3HAVI within bovine endometrial stromal cell is unknown.

Forde et al. (2015) found LGALS3 mRNA was expressed by both the d16 endometrium and conceptus but was more abundant in the d16 conceptus [178]. Therefore, we attempted to test the function of LGALS3 in the bovine endometrium using a $3 \mathrm{D}$ cell culture system. Bovine endometrial epithelial and fibroblast cells in the 3D culture were treated with 100 and $1000 \mathrm{ng}$ of recombinant mouse LGALS3 protein. Compared to Control epithelial cells, epithelial cells treated with LGALS3 had greater expression of a single gene, RPL23A (logFC 4.05). However, RPL23A gene expression differences were unable to be detected when assayed by using RTqPCR (Table 3.6). Six pseudogenes for RPL23A are present in the bovine genome, therefore, it is possible we did not amplify the correct transcript by RT-qPCR. The cells that received the lower concentration of LGALS3 (100 ng) were analyzed by RNA Seq, we investigated the gene expression all samples to examine if the higher dose of LGALS3 (1000 ng) resulted in significant gene expression differences. Of the genes examined, we were unable to detect differences between either LGALS3 treatment (100 and $1000 \mathrm{ng}$ ) and the Control-treated epithelial and fibroblast cells. A previous study successfully utilized recombinant LGALS3 protein from humans and an unidentified mammal in vitro to elicit a response on cultured bovine 
luteal cells [118]. However, we conclude that recombinant mouse LGALS3 protein did not elicit a cellular response in the bovine cells. Further studies utilizing recombinant bovine LGALS3 may conclude a role for LGLAS3 during early pregnancy during cattle. Recombinant bovine LGALS3 was not available to test the responsiveness of the endometrium cells in experiment two, therefore, we treated the cells with uterine FF collected from d14 pregnant sheep. Theoretically, the ovine FF contained IFNT produced by the conceptus. The endometrial cells treated with the ovine FF did increase the expression of IFNT stimulated genes (ISG15 and LGALS3BP; Table 3.6) indicating the cells were responsive. Interestingly, CXCR4 and LIF, genes are known to be important for implantation in mammals were also increased in the endometrial cells in response to pregnant ovine uterine FF (Table 3.6). The role LGALS3 plays in the endometrium and early ruminant embryo requires further investigation.

\section{CONCLUSIONS}

Findings from this study support the utilization of 3D culture of bovine endometrial cells to study early conceptus-maternal crosstalk and identify endometrial cell type-specific responses to the conceptus. We identified 154 IFNT-responsive genes specifically in the endometrial epithelial cells that were previously found to be upregulated in total endometrium treated with IFNT and d15 elongating bovine conceptuses [143]. A single gene, ZC3HAV1, also found to be upregulated in total bovine endometrium treated with IFNT and d15 bovine conceptuses, was upregulated in the fibroblast but not the epithelial cells. Sixty-nine genes were differentially expressed in both epithelial and fibroblast cells. Expression of specific IFNT responsive genes within specific tissue compartments of the endometrium may have important functions during 
maternal recognition of pregnancy and placentation in ruminants. The role of IFNT responsive genes and uncharacterized conceptus secretory proteins, such as galectins, needs further investigation. 
Table 3.1. GenBank accession number, gene name, primer direction, primer sequence, product size, percent amplification efficiency, and source of primer of cDNAs amplified during real-time quantitative polymerase chain reaction (RT-qPCR).

\begin{tabular}{|c|c|c|c|c|c|c|}
\hline $\begin{array}{c}\text { GenBank } \\
\text { Acc. Number }\end{array}$ & Gene & Primer & Primer Sequence $\left(5^{\prime}-3^{\prime}\right)$ & $\begin{array}{c}\text { Product } \\
\text { Size } \\
\text { (bp) }\end{array}$ & $\begin{array}{c}\text { Amp. } \\
\text { E. } \\
(\%)\end{array}$ & Source \\
\hline NM_178320 & PPIA & $\begin{array}{l}\text { Forward } \\
\text { Reverse }\end{array}$ & $\begin{array}{c}\text { CATACAGGTCCTGGCATCTTGTCC } \\
\text { CACGTGCTTGCCATCCAACC }\end{array}$ & 108 & -- & [153] \\
\hline NM_174178 & SDHA & $\begin{array}{l}\text { Forward } \\
\text { Reverse }\end{array}$ & $\begin{array}{l}\text { ACTTCACCGTTGATGGCAA } \\
\text { GCAGAAATCGCATCTGAAA }\end{array}$ & 59 & -- & {$[153]$} \\
\hline NM_001040516.1 & RPL19 & $\begin{array}{l}\text { Forward } \\
\text { Reverse }\end{array}$ & $\begin{array}{l}\text { GAAAGGCAGGCATATGGGTA } \\
\text { TCATCCTCCTCATCCAGGTT }\end{array}$ & 86 & -- & {$[153]$} \\
\hline NM_174814.2 & $Y W H A Z$ & $\begin{array}{l}\text { Forward } \\
\text { Reverse }\end{array}$ & $\begin{array}{c}\text { ACCTACTCCGGACACAGAACATC } \\
\text { CCAGTTTGGCCTTCTGTACCA }\end{array}$ & 65 & -- & {$[143]$} \\
\hline NM_001077953.1 & $R N F 11$ & $\begin{array}{l}\text { Forward } \\
\text { Reverse }\end{array}$ & $\begin{array}{l}\text { TCCGGGAGTGTGTGATCTGTATGAT } \\
\text { GCAGGAGGGGCACGTGAAGG }\end{array}$ & 131 & -- & {$[143]$} \\
\hline NM_001034034.2 & GAPDH & $\begin{array}{l}\text { Forward } \\
\text { Reverse }\end{array}$ & $\begin{array}{c}\text { TTCTACTGGCGCTGCCAAGG } \\
\text { GATCCACAACAGACACGTTGGG }\end{array}$ & 107 & -- & {$[143]$} \\
\hline NM_173979.3 & $A C T B$ & $\begin{array}{l}\text { Forward } \\
\text { Reverse }\end{array}$ & $\begin{array}{l}\text { CAGCAGATGTGGATCAGCAAGC } \\
\text { AACGCAGCTAACAGTCCGCC }\end{array}$ & 91 & -- & [143] \\
\hline NM_001014389.2 & $H 3 F 3 A$ & $\begin{array}{l}\text { Forward } \\
\text { Reverse }\end{array}$ & $\begin{array}{l}\text { CATGGCTCGTACAAAGCAGA } \\
\text { ACCAGGCCTGTAACGATGAG }\end{array}$ & 136 & -- & {$[143]$} \\
\hline NM_001029846.1 & OAS1 & $\begin{array}{l}\text { Forward } \\
\text { Reverse }\end{array}$ & $\begin{array}{l}\text { CCCGGCGGACCCTACAGGAA } \\
\text { TCCAGCCAGACCAAAGCCGC }\end{array}$ & 84 & 95 & {$[168]$} \\
\hline XM_010801645.3 & $M X 1$ & $\begin{array}{l}\text { Forward } \\
\text { Reverse }\end{array}$ & $\begin{array}{l}\text { CGAGCCGAGTTCTCCAAATG } \\
\text { CAACTCTCTGCCACGATACC }\end{array}$ & 114 & 96 & {$[153]$} \\
\hline NM_001077900.1 & STAT1 & $\begin{array}{l}\text { Forward } \\
\text { Reverse }\end{array}$ & $\begin{array}{l}\text { GCATTAGTCAGGGCCCAAATTGTTACAG } \\
\text { GCCAGATACAGGAAGCTTTGCAC }\end{array}$ & 139 & 96 & {$[153]$} \\
\hline NM_173941.2 & $M X 2$ & $\begin{array}{l}\text { Forward } \\
\text { Reverse }\end{array}$ & $\begin{array}{c}\text { GGGCAGCGGAATCATCACCCG } \\
\text { AGCTGCTGCGTAATGTTGCGGTA }\end{array}$ & 102 & 93 & [143] \\
\hline NM_001015570.3 & LGALS9 & $\begin{array}{l}\text { Forward } \\
\text { Reverse }\end{array}$ & $\begin{array}{l}\text { TCAGCTTCCAGCCTCCAGGG } \\
\text { TCCAGGGGCGCTGTGTATGGT }\end{array}$ & 86 & 97 & {$[153]$} \\
\hline NM_001046316.2 & $L G A L S 3 B P$ & $\begin{array}{l}\text { Forward } \\
\text { Reverse }\end{array}$ & $\begin{array}{l}\text { CAACTGCAGACACGACAAGG } \\
\text { AGGGATTTCGCCAGATAGGT }\end{array}$ & 88 & 95 & {$[153]$} \\
\hline NM_174301.3 & CXCR4 & $\begin{array}{l}\text { Forward } \\
\text { Reverse }\end{array}$ & $\begin{array}{l}\text { AAGGCTCAGAAGCGCAAG } \\
\text { GAGTCGATGCTGATCCCAAT }\end{array}$ & 102 & 102 & [186] \\
\hline NM_174366.1 & ISG15 & $\begin{array}{l}\text { Forward } \\
\text { Reverse }\end{array}$ & $\begin{array}{l}\text { CCAACCAGTGTCTGCAGAGA } \\
\text { CCCTAGCATCTTCACCGTCA }\end{array}$ & 76 & 97 & [143] \\
\hline NM_001024557.1 & OAS2 & $\begin{array}{l}\text { Forward } \\
\text { Reverse }\end{array}$ & $\begin{array}{l}\text { TGGATAACACCTGCTGGCTG } \\
\text { GGTCCAGGTGACTCGTTCTG }\end{array}$ & 82 & 93 & This Study \\
\hline NM_001101866.2 & IDOI & $\begin{array}{l}\text { Forward } \\
\text { Reverse }\end{array}$ & $\begin{array}{l}\text { CACCCCAAAGAAGTTTGCCG } \\
\text { GCTGAATGCCCAGGAGAACA }\end{array}$ & 80 & 99 & This Study \\
\hline NM_001114506.1 & TNFSF13B & $\begin{array}{l}\text { Forward } \\
\text { Reverse }\end{array}$ & $\begin{array}{l}\text { GGGACGAACTGAGTCTGGTG } \\
\text { TCTTAGCATCTTCCCGGGGT }\end{array}$ & 147 & 96 & This Study \\
\hline XM_005216258.4 & MAP6 & $\begin{array}{l}\text { Forward } \\
\text { Reverse }\end{array}$ & $\begin{array}{l}\text { ATAAGCCAACCCCAGCTGAC } \\
\text { GGAGGTTCCTTGAAGGGCTC }\end{array}$ & 82 & 110 & This Study \\
\hline NM_001192561.2 & $B A T F 2$ & $\begin{array}{l}\text { Forward } \\
\text { Reverse }\end{array}$ & $\begin{array}{c}\text { ATCTCCTGCACAGCTGTCAC } \\
\text { AGGAACTCTAGAGGGGCAGG }\end{array}$ & 132 & 106 & This Study \\
\hline XM_003586006.5 & ZCЗHAVI & $\begin{array}{l}\text { Forward } \\
\text { Reverse }\end{array}$ & $\begin{array}{l}\text { AGGCCTTTTGTGACCCCAAA } \\
\text { TGTGACGGATGAAGGTGTGG }\end{array}$ & 119 & 97 & This Study \\
\hline XM_003587616.5 & PRRT3 & $\begin{array}{l}\text { Forward } \\
\text { Reverse }\end{array}$ & $\begin{array}{l}\text { GAGGCCTGGGAAGTCAGTTC } \\
\text { GATGGGAGATCTGACGGCTG }\end{array}$ & 98 & 97 & This Study \\
\hline NM_001192640.1 & DMRTAl & $\begin{array}{l}\text { Forward } \\
\text { Reverse }\end{array}$ & $\begin{array}{l}\text { CACGGCATTAACTTAGCGCC } \\
\text { TGACACAATTCCCGCGATGA }\end{array}$ & 115 & 92 & This Study \\
\hline NM_001045958.2 & RPL23A & $\begin{array}{l}\text { Forward } \\
\text { Reverse }\end{array}$ & $\begin{array}{l}\text { ATGAAGATGGCGCCGAAG } \\
\text { TGGCTGTGGACACCTTTCAA }\end{array}$ & 110 & 88 & This Study \\
\hline XM_015475541.2 & $L I F$ & $\begin{array}{l}\text { Forward } \\
\text { Reverse }\end{array}$ & $\begin{array}{c}\text { GGGACAACTCAACAGCAGTG } \\
\text { GCACAGCTTGTCCAGGTTG }\end{array}$ & 91 & 96 & This Study \\
\hline
\end{tabular}


Figure 3.1. The 3D cell culture system used to coculture bovine endometrial epithelial and fibroblast cells. Epithelial cells were seeded on a transwell insert coated with Matrigel (Corning Inc.) and fibroblast cells were located below inserts. The oIFNT or LGALS3 was administered apically.

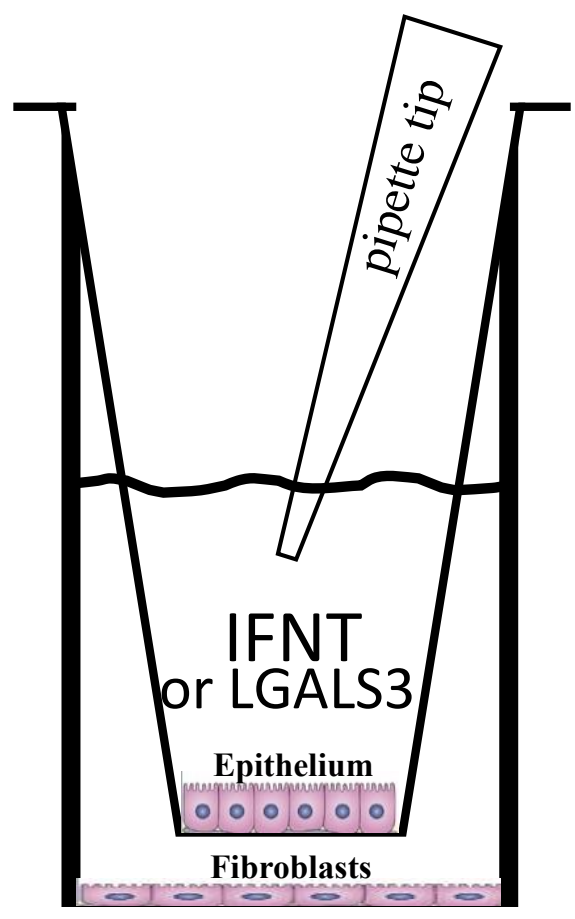




\section{Conceptus/oIFNT}

\section{Epithelial oIFNT}

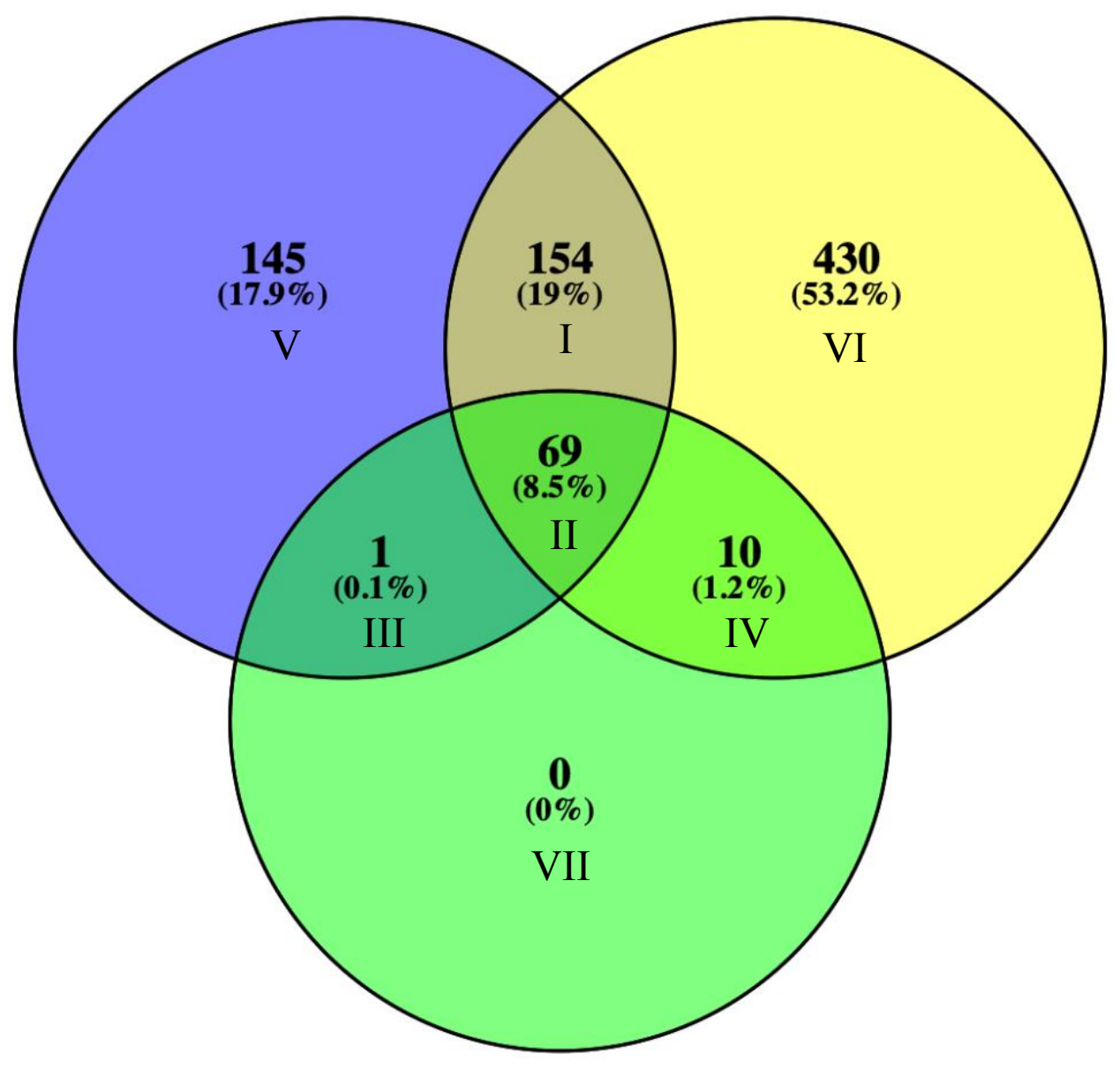

Fibroblast oIFNT

Figure 3.2. A Venn diagram (Venny 2.1 BioinfoGP) categorizing differentially expressed genes (DEGs) in response to oIFNT among bovine endometrial intercaruncular explants and bovine endometrial epithelial fibroblast cells cultured in a 3D system. Explants, treated with oIFNT and d15 bovine conceptus [143], shared 224 transcripts with endometrial epithelial and fibroblast cells. Of those DEGs, 154 were specific to the epithelium while a single transcript, ZC3HAVI, was exclusive to the fibroblast cells cultured in the 3D system. Explants treated with a conceptus or oIFNT shared 69 transcripts that were differentially expressed with both epithelial and fibroblast cells treated with oIFNT. 
Table 3.2. Genes up- or down-regulated in the Venn diagram (Figure 2.1).

\begin{tabular}{|c|c|c|c|c|c|c|c|c|c|}
\hline \multicolumn{5}{|c|}{ I } & \multicolumn{3}{|c|}{ II } & \multirow{3}{*}{$\frac{\text { III }}{\underline{\mathbf{U p}}}$} & \multirow{2}{*}{$\frac{\text { IV }}{\text { Up }}$} \\
\hline Up & GTF2B & BCL2L14 & RNF31 & MITD1 & Up & EIF2AK2 & DHX58 & & \\
\hline$\frac{\sim}{\mathrm{GBP} 2}$ & STAT2 & PSMB8 & PAPD7 & TLR3 & $\frac{\overline{M X} 2}{\mathrm{MX}}$ & SP100 & CASP7 & & $\mathrm{OAS} 1 \mathrm{Z}$ \\
\hline GBP6 & IRF8 & PSMF1 & SLC25A19 & CASP8 & IFIT3 & IRF4 & IFI27 & & LOC112441507 \\
\hline SLFN11 & HSH2D & LEKR1 & CCDC82 & FBXO33 & RSAD2 & DTX3L & & & OAS1Y \\
\hline IDO1 & OPTN & NAMPT & IL15RA & RICTOR & IFIT1 & PML & & & CCDC194 \\
\hline IFITM3 & DAXX & IRF3 & TRIM26 & ABHD1 & IFI44 & TRIM5 & & & SP140L \\
\hline ACKR4 & ATXN3 & TAP2 & CCDC6 & RNF114 & IFIT2 & IRF9 & & & LOC 107132617 \\
\hline TNFSF13B & GNB4 & CMTR1 & TRIM16 & SHISA5 & ISG15 & IRF7 & & & CGAS \\
\hline MLKL & RBCK1 & PAPD4 & PPP2R3C & PLEKHA7 & GBP4 & TIFA & & & C7H19orf66 \\
\hline MASTL & NMI & SCLY & HEATR5B & CDK18 & IFI44L & XAF1 & & & LOC112446427 \\
\hline SP110 & PLSCR2 & NT5C3A & IRF2 & PDCD4 & SAMD9 & PARP12 & & & TMPRSS2 \\
\hline KIF5C & GDAP2 & CDKN2AIP & FAM111B & POLH & $\mathrm{OAS} 2$ & IFIT5 & & & \\
\hline IFITM1 & MOV10 & RAB8B & JADE2 & TRIM38 & BST2 & PARP10 & & & \\
\hline WARS & STAT1 & ZNF607 & DUSP11 & $\mathrm{C} 2$ & UBA7 & PNPT1 & & & \\
\hline FOXS1 & ATAD1 & OGFR & YTHDC2 & ARSH & USP18 & SLC15A3 & & & \\
\hline ISG20 & LGALS3BP & PSME2 & TMEM268 & XRN2 & ZBP1 & FAM3B & & & \\
\hline GNGT2 & AKAP7 & ANKFY1 & CHMP5 & ELMO2 & OAS1X & IFI16 & & & \\
\hline SLFN12 & USP25 & PXK & PLSCR4 & IRF1 & MX1 & SP140 & & & \\
\hline APOL3 & ANXA1 & PSMA2 & CTC1 & RAB37 & GBP1 & TRANK1 & & & \\
\hline TMEM140 & SLC25A28 & LAP3 & XPO1 & TMEM106A & CMPK2 & ADAR & & & \\
\hline CDADC1 & PARM1 & DNAJC1 & RBMS2 & TREX1 & RTP4 & PLEKHA4 & & & \\
\hline CD274 & NCOA7 & SLC25A30 & NFE2L3 & DDX19B & RNF213 & TRIM34 & & & \\
\hline GHSR & VCPIP1 & SERTAD1 & MAT2B & & BATF2 & CMTR2 & & & \\
\hline HES4 & TRIM56 & ERAP1 & TAPBPL & & EPSTI1 & TDRD7 & & & \\
\hline CASP4 & GRINA & RIPK3 & PRICKLE3 & & DDX58 & LGALS9 & & & \\
\hline BCL2L15 & SPATS2L & STK38L & NUB1 & & PARP14 & PARP9 & & & \\
\hline DRAM1 & ATP10A & TAPBP & DNPEP & & TNFSF10 & IFI6 & & & \\
\hline IFI35 & NLRC5 & CUL4B & KIFC3 & & HERC6 & RBM43 & & & \\
\hline FAM212A & $\mathrm{CNP}$ & NR3C1 & CD47 & & IFIH1 & UBE2L6 & & & \\
\hline BOLA-DMB & CBLN3 & RNF19B & RNF139 & & GBP5 & RNASEL & & & \\
\hline SASS6 & ATP8B4 & AIDA & B2M & & HERC5 & TRIM21 & & & \\
\hline BPNT1 & MAD2L2 & RBBP6 & KAT2A & & PLAC8 & N4BP1 & & & \\
\hline MORC3 & PSMB9 & & AZI2 & & ZNFX1 & TAP1 & & & \\
\hline & BCL2L12 & & MCHR1 & & & TRIM25 & & & \\
\hline
\end{tabular}




\begin{tabular}{|c|c|c|c|c|c|c|c|c|}
\hline \multicolumn{5}{|c|}{$\mathbf{V}$} & \multicolumn{4}{|c|}{ VI } \\
\hline$\underline{\text { Up }}$ & REGAKINE-1 & FAM172B & TOR1AIP2 & Down & Up & PCK1 & LOC512672 & SLC13A5 \\
\hline CLEC4F & TMEM74B & $\mathrm{C} 4 \mathrm{~A}$ & FYTTD1 & KIT & CNGB1 & SYT16 & LOC101903126 & ANKRD53 \\
\hline CCL8 & SLC2A6 & IP6K1 & IFRG15 & CHST15 & SAA4 & LOC107132327 & LOC101905257 & CCDC190 \\
\hline CXCL11 & BL37L & STOML1 & CFLAR & FAM101B & LYZ3 & KIF26A & STAT4 & LOC530929 \\
\hline CXCL10 & C3AR1 & FAS & PAPD5 & PECAM1 & PRM1 & $\mathrm{ABCC} 11$ & B3GNT3 & LOC101902154 \\
\hline TIMD4 & PTPRO & GSDMD & VPS13C & CD93 & SOX10 & $\mathrm{ZC} 3 \mathrm{H} 12 \mathrm{D}$ & LY6L & CPLX1 \\
\hline APOBEC $3 Z 1$ & C21ORF91 & TLE4 & JAK2 & AFAP1L1 & LOC781494 & MYAML2 & TSPAN32 & LOC112444847 \\
\hline OAS1 & PDCD1 & DYSF & TCEAL1 & FAM124B & JAKMIP3 & LOC100141258 & ATP8A2 & ISG12(B) \\
\hline GBP7 & CD53 & DYNC1H1 & USF1 & APLNR & NUGGC & IL3RA & CLEC2D11 & BST1 \\
\hline GVINP1 & CLEC2D & RAPGEF3 & MIA3 & SOX18 & MUC12 & ANKRD35 & GOLCA6L22 & TACR1 \\
\hline CXCL9 & POLD3 & PARP8 & USP34 & PALD1 & LOC511617 & LUZP2 & ERBB4 & PLA2R1 \\
\hline IFI47 & TFEC & SYNE2 & SOCS2 & VASH1 & OASL & UPB1 & PSCA & OVCH1 \\
\hline MYADML & C19ORF66 & PLPP3 & $\mathrm{ABCB} 7$ & JAG1 & BIRC7 & HS3ST1 & C5H22orf23 & LOC512323 \\
\hline MB21D1 & $\mathrm{ABCG} 2$ & LIFR & DNAJC13 & & LOC787234 & SLC9C1 & THEM6 & CSPG5 \\
\hline SECTM1 & STARD8 & RIPK2 & GAB1 & & ADGRG7 & C1R & CHST4 & TAF4B \\
\hline TNFSF13BL & MICB & KYAT3 & BID & & IFNL3 & LRIT3 & TRIM14 & IL34 \\
\hline ISG12B & C3ORF38 & ARHGEF3 & MXD1 & & LOC512869 & PLA2G7 & LOC101905194 & LOC782527 \\
\hline LOR & HEG1 & SCARF1 & TTC9C & & BVES & CAPN8 & LOC 104970178 & WDR17 \\
\hline CYP2J2 & IL23A & ZC3H12C & PHF11 & & TMPRSS5 & LOC112445995 & TNFRSF9 & SOCS1 \\
\hline TCF15 & HORMAD1 & ZCCHC6 & UNC93B1 & & TNFSF4 & BREH1 & LOC 112448863 & SCN9A \\
\hline KYNU & IL15 & AIFM2 & LDB2 & & SBK3 & SLC23A2 & DSC1 & ADAM19 \\
\hline BL37 & NEURL3 & PSME1 & PSMA8 & & ASB5 & TAGAP & LOC515697 & CYP2S1 \\
\hline P2RY6 & PTPN11 & ZNF628 & PLA2G16 & & CNDP1 & ARHGAP9 & LPL & JPH2 \\
\hline CLEC10A & SIGLEC1 & TGM2 & CXORF21 & & FRAS1 & CDHR4 & LOC509972 & RAB19 \\
\hline CDHR5 & CD40 & PDE5A & UNC45B & & ACVR1C & ABCB5 & LOC112446668 & KRT42 \\
\hline RUBCN & PHACTR1 & MTO1 & ART3 & & SLCO2B1 & IFITM2 & SCNN1B & MY01A \\
\hline REC8 & ACOT9 & MRPL32 & C1ORF115 & & SLC22A10 & CLDN16 & GMNC & VWA5A \\
\hline C1ORF109 & TAL1 & ECM1 & NCF1 & & OXT & SULT6B1 & LOC616948 & FAM71A \\
\hline ZNF366 & FRMD4B & KIAA1033 & IFI27L & & ODF3L1 & TGM7 & & ARID3C \\
\hline BL36 & ACSL5 & PPFIBP1 & ALS2 & & DPY19L2 & C5 & & IQCD \\
\hline TLR4 & TSKU & SSAT-1 & MAN1C1 & & LOC512440 & MESP2 & & GANC \\
\hline EHD3 & ADGRF5 & FUNDC1 & C2ORF68 & & ELMOD1 & CD34 & & COX7A1 \\
\hline LPCAT2 & DECR2 & PPA1 & & & TRIM15 & PDCD1LG2 & & RIPOR3 \\
\hline AGRN & CTSS & SLK & & & TRPC3 & RPE65 & & \\
\hline & & & & & GPR63 & LOC521656 & & \\
\hline
\end{tabular}




\begin{tabular}{|c|c|c|c|c|c|c|c|c|}
\hline \multicolumn{9}{|c|}{ VI Cont. } \\
\hline Up & DRAM2 & DENND2D & LOC518495 & ACOX3 & HFE & FPGT & SPPL2A & NBEAL2 \\
\hline MASP1 & FLT3LG & GRAMD1C & A2ML1 & FBXO7 & RNF39 & WDR18 & PDK3 & SRD5A1 \\
\hline SIX1 & IL18 & ALDH9A1 & TRAPPC2 & ARL6IP5 & DBNL & F2R & ZCCHC8 & VPS33A \\
\hline CCDC39 & FAM172BP & CROT & LYPD6B & SARS & MTPAP & TMED8 & SLC35C1 & MLEC \\
\hline SCNN1G & NKX3-1 & CSRNP1 & PRKAR1B & RFX5 & DNMT1 & SCP2 & NARS & MEGF9 \\
\hline $\mathrm{ZCCHC} 2$ & LY6E & TACSTD2 & ZDHHC14 & TAF5 & TPRKB & TCOF1 & KAT2B & NAV2 \\
\hline PMAIP1 & BOLA-NC1 & CLDN1 & TICRR & APRT & EIF2AK1 & MIER3 & DESI1 & UNC5B \\
\hline TM6SF2 & SFN & CLSTN2 & TRMT13 & STXBP3 & SPTY2D1 & MRPL44 & HAUS3 & TUBB3 \\
\hline EPHX2 & TMEM171 & FAM192A & CPOX & ZNF197 & GALM & RNF135 & PRKAB1 & SAMD1 \\
\hline FBXO16 & FUT10 & YARS & ITPR2 & SERINC2 & SLC1A5 & DENND4C & FGD4 & BCAT1 \\
\hline PGR & PLA2G3 & FAM129A & WIPF3 & PSMB10 & COA7 & OSBPL8 & ARHGEF16 & ARVCF \\
\hline INPP5F & MISP & AKAP6 & GIPC2 & PRKD2 & TMEM255B & SNX6 & ZMYM1 & PPARA \\
\hline IQUB & CALCOCO2 & ZNF852 & DCK & S1PR2 & MTFP1 & CENPO & CNOT9 & PIAS2 \\
\hline NFIX & ERAP2 & LIPA & SLC6A12 & DDX24 & PRMT9 & SEC24B & UHRF2 & MTFR1 \\
\hline ORC5 & CCDC102A & MTR & ATP7A & GCHFR & TTC4 & PRPSAP1 & DNAJC8 & TUBA1A \\
\hline TCTN3 & CSDC2 & SAT1 & TMEM41A & $\mathrm{C} 16 \mathrm{H} 1$ orf112 & FYB2 & NISCH & KCTD9 & PTCH1 \\
\hline EHD4 & ZUP1 & TATDN3 & GABARAPL1 & ELF1 & TSPYL1 & SSBP3 & PELI1 & EML1 \\
\hline OVOL1 & ARL6IP1 & BSPRY & SLC25A12 & RRM2B & PALM & ANAPC11 & MCL1 & AKAP12 \\
\hline CATSPERE & NEB & ALPK1 & CAMK2D & HNF4G & SARNP & STRIP1 & FAM168B & LMCD1 \\
\hline CIITA & LOC508153 & NOSTRIN & APOBEC $3 \mathrm{H}$ & TWISTNB & STARD3 & FAM110C & HNRNPLL & ETV4 \\
\hline RAD21L1 & CTSL & XRCC5 & OSMR & ID4 & DNAJC7 & JDP2 & KRT7 & ALDH1A3 \\
\hline BTC & WDR86 & C1H3orf38 & LNPEP & LOC101905041 & TXNRD1 & PJA2 & TRIM4 & FITM2 \\
\hline LOC515736 & VAMP5 & SIDT2 & TMEM144 & B4GALT1 & RCBTB1 & MARCKSL1 & & SLC25A15 \\
\hline GDA & SAMHD1 & CSRNP2 & FAM76A & EMP1 & SEPT7 & CBLL1 & Down & KLF13 \\
\hline DUSP15 & C16H1orf115 & LENG1 & MOCS1 & ACSS2 & GYG1 & STAMBP & DESI2 & SCRN1 \\
\hline PLIN2 & AP5B1 & TCAF2 & UBIAD1 & PCGF5 & TMEM230 & KAT5 & MBTPS1 & FAM92A \\
\hline ZFP36 & ICAM1 & RBMX2 & ACP2 & $\mathrm{ADM} 2$ & NECTIN2 & ZNF710 & GNPAT & GVQW3 \\
\hline IL22RA1 & ICAM2 & MST1R & AP1AR & SNX4 & AVEN & HGH1 & GTF2A1 & PCDHA5 \\
\hline FBXO45 & INA & MUC1 & EVA1A & VPS33B & BIRC3 & CEPT1 & ZDHHC23 & ZMYND10 \\
\hline LOC618733 & CHST1 & SLC27A1 & C11H2orf68 & POLR2K & MOCOS & GTPBP2 & PSD4 & HIST1H3A \\
\hline ICA1L & TACR3 & UTP23 & PPAT & CGN & GPHN & TIPARP & PKD1 & MAP6 \\
\hline HSPB 11 & FOXQ1 & HK2 & BTBD11 & HKDC1 & PLEKHO1 & CSTF1 & SESN3 & \\
\hline APOBEC1 & GABRP & SEMA4A & BOLA & ADPGK & SCO1 & ACADM & ENTR1 & \\
\hline DDIT3 & THEM4 & FCHSD2 & HACD2 & DNAJA1 & APOPT1 & MTMR4 & NETO2 & \\
\hline
\end{tabular}


Table 3.3. The $\log F C$ of the top 20 genes up-regulated in bovine endometrial epithelial cells and shared with explants treated with oIFNT and a d15 conceptus [143] (I and II of Figure 2.2). The fibroblast cell $\log \mathrm{FC}$ is listed if the gene was also up-regulated in fibroblast cells.

\begin{tabular}{lccc}
\hline \hline $\begin{array}{c}\text { GenBank Acc. } \\
\text { Number }\end{array}$ & Gene & $\begin{array}{c}\text { Epithelial } \\
\text { Cell LogFC }\end{array}$ & $\begin{array}{c}\text { Fibroblast } \\
\text { Cell LogFC }\end{array}$ \\
\hline XM_005227105.4 & BATF2 & 11.88 & 2.80 \\
XM_015473641.2 & MX2 & 10.26 & 7.83 \\
XM_002686295.6 & IFI44 & 9.95 & 7.63 \\
XM_015460598.2 & IFIT1 & 9.65 & 3.56 \\
NM_001024557.1 & OAS2 & 9.51 & 9.63 \\
XM_024993137.1 & PLAC8 & 8.96 & 7.75 \\
NM_001076127.2 & KIF5C & 8.66 & -- \\
XM_015474249.2 & ZBP1 & 8.47 & 8.06 \\
NM_001045941.1 & RSAD2 & 8.46 & 8.35 \\
NM_001075414.1 & IFIT3 & 8.15 & 3.36 \\
NM_174366.1 & ISG15 & 7.94 & 6.90 \\
XM_003586247.5 & HSH2D & 7.86 & - \\
XM_024981673.1 & IFI27 & 7.85 & 5.03 \\
XM_024998051.1 & ATP8B4 & 7.52 & -- \\
XM_015471926.2 & BST2 & 7.25 & 6.47 \\
NM_001101866.2 & IDO1 & 7.18 & - \\
NM_001099716.1 & FOXS1 & 7.17 & -- \\
XM_003585891.5 & IFI44L & 7.09 & 8.66 \\
NM_001206162.1 & IRF4 & 6.97 & 5.73 \\
NM_178108.2 & OAS1X & 6.78 & 7.35 \\
\hline \hline
\end{tabular}


Table 3.4. Gene ontology (GO) Biological Process Direct for 223 genes up-regulated in bovine endometrial epithelial cells treated with $100 \mathrm{ng}$ of oIFNT in 3D culture (I and II of Figure 2.2).

\begin{tabular}{|c|c|c|}
\hline Term & P-Value & Genes \\
\hline \multicolumn{3}{|l|}{ GO Biological Process Direct } \\
\hline $\begin{array}{l}\text { Type I interferon signaling } \\
\text { pathway }\end{array}$ & $<0.001$ & $\begin{array}{l}\text { RNASEL, IFITM1, IFITM3, RSAD2, OAS2, IFI35, ISG20, ISG15, XAF1, } \\
\text { MX1, MX2, SP100, BST2, STAT1, PSMB8, STAT2, IFIT3, IRF9, IFIT2, } \\
\text { IFIT1, IFI27, IRF7, IRF8, IRF1, IRF2, IRF3, IRF4, GBP2, IFI6, ADAR }\end{array}$ \\
\hline Defense response to virus & $<0.001$ & $\begin{array}{l}\text { RNASEL, IFITM1, IFITM3, PML, TLR3, RSAD2, IFI44L, OAS2, ISG20, } \\
\text { TRIM5, NLRC5, ISG15, MX1, MX2, DHX58, BST2, HERC5, TRIM25, } \\
\text { IFI6, STAT1, STAT2, IRF9, IFIT3, TRIM56, IFIT2, IFIT1, TRIM34, IFIT5, } \\
\text { IRF1, IRF3, SLFN11, EIF2AK2, GBP1, ADAR }\end{array}$ \\
\hline $\begin{array}{l}\text { Interferon-gamma-mediated } \\
\text { signaling pathway }\end{array}$ & $<0.001$ & $\begin{array}{l}\text { SP100, NMI, PML, TRIM26, TRIM25, OAS2, STAT1, TRIM21, B2M, IRF9, } \\
\text { TRIM38, TRIM5, TRIM34, IRF7, IRF8, IRF1, IRF2, IRF3, IRF4, GBP2, } \\
\text { GBP1 }\end{array}$ \\
\hline $\begin{array}{l}\text { Negative regulation of viral } \\
\text { genome replication }\end{array}$ & $<0.001$ & $\begin{array}{l}\text { RNASEL, IFITM1, BST2, IFITM3, RSAD2, PARP10, IFI16, ISG20, IFIT1, } \\
\text { ISG15, EIF2AK2, MX1, ADAR }\end{array}$ \\
\hline $\begin{array}{l}\text { Negative regulation of type I } \\
\text { interferon production }\end{array}$ & $<0.001$ & $\begin{array}{l}\text { DDX58, NLRC5, IFIH1, ISG15, HERC5, UBA7, UBE2L6, TRIM25, IRF3, } \\
\text { DHX58 }\end{array}$ \\
\hline Innate immune response & $<0.001$ & $\begin{array}{l}\text { IFIH1, BST2, ANXA1, PML, HERC5, TLR3, TRIM26, TRIM25, IFI16, } \\
\text { TRIM21, B2M, DDX58, NLRC5, TRIM5, CASP4, IFIT5, IRF7, C2, } \\
\text { EIF2AK2, MX1, MX2, DHX58, ADAR, ZBP1 }\end{array}$ \\
\hline Protein polyubiquitination & $<0.001$ & $\begin{array}{l}\text { DTX3L, HERC6, HERC5, RBBP6, RNF213, TRIM21, PSMB8, PSMB9, } \\
\text { PSMA2, PSMF1, RNF114, PSME2, RNF139, RBCK1, RNF19B, RNF31 }\end{array}$ \\
\hline \multicolumn{3}{|l|}{$\begin{array}{l}\text { Antigen processing and } \\
\text { presentation of endogenous } \\
\text { peptide antigen via MHC class }\end{array}$} \\
\hline I & $<0.001$ & TAP2, TAP1, ERAP1, TAPBP, B2M \\
\hline Response to interferon-beta & $<0.001$ & BST2, IFITM1, IFITM3, XAF1, STAT1 \\
\hline $\begin{array}{l}\text { Positive regulation of I-kappa } \\
\text { b kinase/NF-kappa b signaling }\end{array}$ & $<0.001$ & $\begin{array}{l}\text { TRIM5, APOL3, TRIM38, TNFSF10, BST2, CASP8, SHISA5, RBCK1, } \\
\text { TRIM25, IRF3, LGALS9, RNF31 }\end{array}$ \\
\hline $\begin{array}{l}\text { Response to interferon-gamma } \\
\text { Positive regulation of } \\
\text { interferon-beta production }\end{array}$ & $<0.001$ & SP100, BST2, IFITM1, NUB1, IFITM3, TRIM21 \\
\hline $\begin{array}{l}\text { Negative regulation of viral } \\
\text { release from host cell }\end{array}$ & $<0.001$ & TRIM5, PML, TRIM26, TRIM25, TRIM21 \\
\hline ISG15-protein conjugation & $\begin{array}{l}<0.001 \\
<0.001\end{array}$ & $\begin{array}{l}\text { ISG15, HERC5, UBA7, UBE2L6 } \\
\text { TRIM5, IFITM1, IFITM3, TRIM26, TRIM25 }\end{array}$ \\
\hline
\end{tabular}




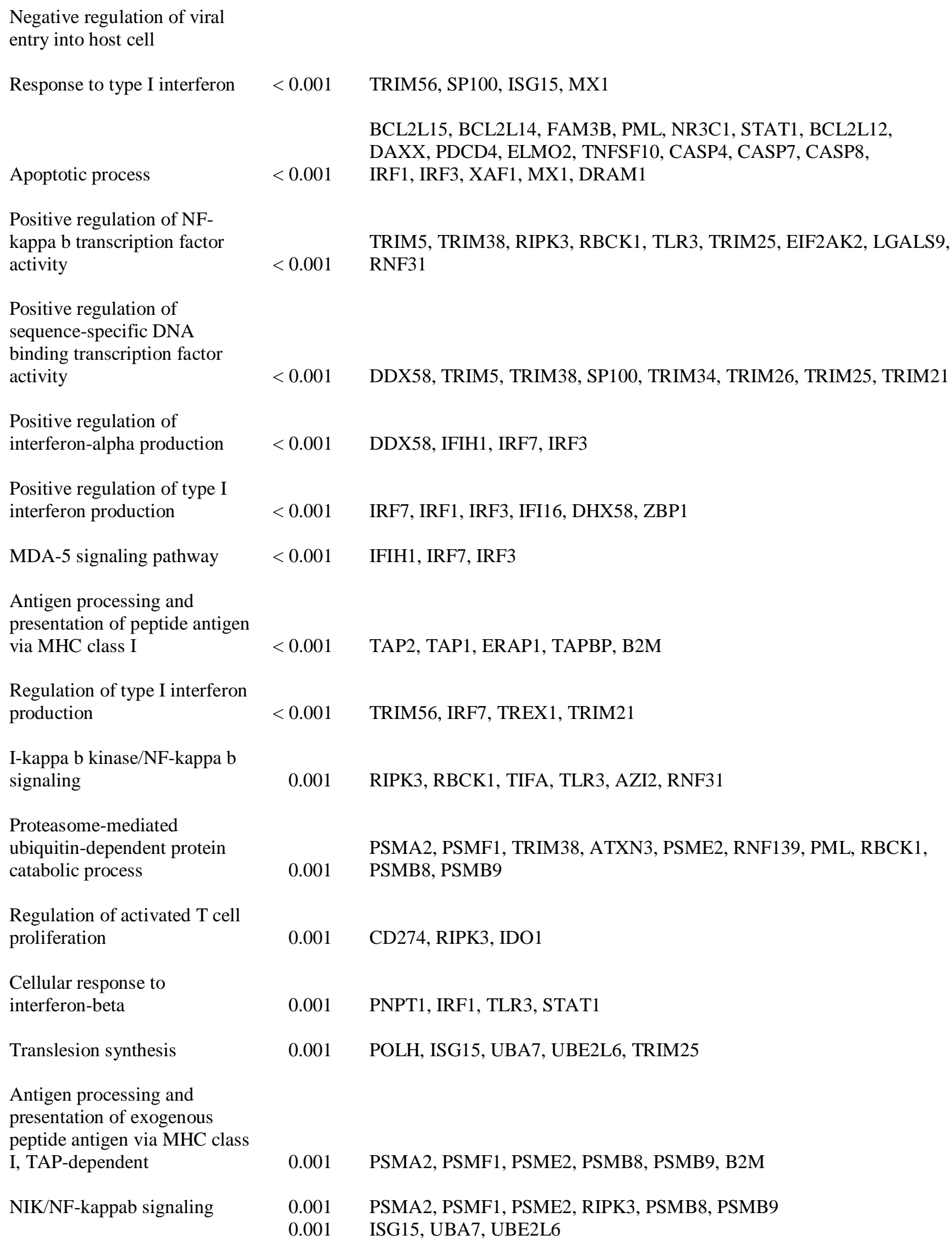

NIK/NF-kappab signaling

PSMA2, PSMF1, PSME2, PSMB8, PSMB9, B2M

PSMA2, PSMF1, PSME2, RIPK3, PSMB8, PSMB9

ISG15, UBA7, UBE2L6 
Modification-dependent

protein catabolic process

Detection of virus

0.001

Intracellular transport of viral

protein in host cell

0.001

Regulation of mRNA stability

0.001

RNA catabolic process

0.002

Regulation of adaptive

immune response

0.002

0.003

entry into host cell

Antigen processing and presentation of exogenous protein antigen via MHC class

Ib, TAP-dependent

Tumor necrosis factormediated signaling pathway

Regulation of cellular amino acid metabolic process

Response to cytokine

Positive regulation of extrinsic apoptotic signaling pathway

TRIF-dependent toll-like receptor signaling pathway

Protein trimerization

Positive regulation of type I interferon-mediated signaling pathway

RNA processing

Ubiquitin-dependent protein catabolic process

JAK-STAT cascade

Negative regulation of innate immune response

T cell receptor signaling pathway

0.003

0.003

0.003

0.004

0.004

0.005

0.005

0.006

0.006

0.006

0.007

0.009
DDX58, IFIH1, TLR3

IFIT1, TAP2, TAP1

PSMA2, PSMF1, XPO1, RNASEL, PSME2, PSMB8, PSMB9

PNPT1, OAS2, XRN2, ISG20

IRF7, RIPK3, IRF1

TRIM38, LGALS9, TRIM21

TAP2, TAP1, B2M

PSMA2, PSMF1, TNFSF13B, PSME2, STAT1, PSMB8, PSMB9

PSMA2, PSMF1, PSME2, PSMB8, PSMB9

IFI27, SP100, CD274, PML, STAT1

TNFSF10, BCL2L14, PML, RBCK1

IRF7, CASP8, TLR3, IRF3

TRIM5, TRIM34, TRIM21

NLRC5, IRF7, IRF3

PNPT1, RBMS2, YTHDC2, DUSP11, XRN2, ADAR

PSMA2, PSMF1, ATXN3, USP18, NUB1, CUL4B, USP25, RNF213

NMI, IL15RA, STAT1, STAT2

NMI, IFI16, DHX58
PSMA2, PSMF1, PSME2, RBCK1, PSMB8, PSMB9, RNF31 
Viral process

Regulation of innate immune response

Negative regulation of viral transcription

Negative regulation of ubiquitin-protein ligase activity involved in mitotic cell cycle

Immune response

Positive regulation of ubiquitin-protein ligase activity involved in regulation of mitotic cell cycle transition

Histone $\mathrm{H} 3$ acetylation

Anaphase-promoting complex-dependent catabolic process

Regulation of extrinsic apoptotic signaling pathway via death domain receptors

$\mathrm{T}$ cell activation

Necroptotic process

Proteolysis involved in cellular protein catabolic process

Defense response to protozoan

0.021

Regulation of myd88dependent toll-like receptor signaling pathway

0.024

Cytosol to ER transport

Organelle fission

Interferon-alpha production

Regulation of type III interferon production
KAT2A, XPO1, SP100, MORC3, RBCK1, SP110, DAXX, GTF2B, PSMB8, PSMB9

0.010 IRF1, ERAP1, DHX58

0.010 SP100, IFITM3, TRIM21

0.010 PSMA2, PSMF1, PSME2, PSMB8, PSMB9

GBP6, TNFSF10, TNFSF13B, IFITM3, CD274, IRF8, ACKR4, OAS2, GBP2, 0.013 IFI6, TAPBP, B2M

0.013 PSMA2, PSMF1, PSME2, PSMB8, PSMB9

0.015 KAT2A, JADE2, TRIM16, IRF4

0.015 PSMA2, PSMF1, PSME2, PSMB8, PSMB9

0.017 TNFSF10, SP100, CASP8

0.019 CASP8, IRF4, AZI2, HSH2D

0.019 RIPK3, TLR3, MLKL

PSMA2, CASP8, PSMB8, PSMB9

BATF2, IRF8, IRF4

0.024 TAP2, TAP1

$0.024 \quad \mathrm{MX} 1, \mathrm{MX} 2$

0.024 IRF7, AZI2

0.024 DDX58, IFIH1

$0.024 \quad$ XRN2, ISG20 
DNA catabolic process, exonucleolytic

Wnt signaling pathway, planar cell polarity pathway

0.025

Positive regulation of NF-

kappa b import into nucleus

0.026

Cellular response to

interferon-gamma

Myeloid cell differentiation

Protein K48-linked

deubiquitination

Regulation of interferon-

gamma production

Cytoplasmic pattern

recognition receptor signaling

pathway in response to virus

Zonula adherens maintenance

0.035

Interferon-beta production

0.035

Response to tumor necrosis

factor

0.036

Positive regulation of interleukin-12 production

Protein ubiquitination involved in ubiquitindependent protein catabolic process

0.037

Stimulatory C-type lectin receptor signaling pathway

Positive regulation of viral genome replication

Regulation of type I

interferon-mediated signaling pathway

0.038

Inflammatory response

0.039

Cellular response to DNA damage stimulus
PSMA2, PSMF1, PSME2, PSMB8, PSMB9

RBCK1, TLR3, LGALS9

GBP6, GBP5, TLR3, LGALS9

IRF8, PML, IFI16

ATXN3, USP25, VCPIP1

ISG15, RIPK3

DDX58, IFIH1

PLEKHA7, KIFC3

TRIM56, IRF7

NUB1, CASP8, YTHDC2

IRF8, TLR3, IDO1

HERC6, HERC5, TRIM25, CUL4B, RNF19B, RBBP6

0.037 PSMA2, PSMF1, PSME2, PSMB8, PSMB9

0.038 TRIM38, IFIT1, ADAR

USP18, STAT1, STAT2

APOL3, NMI, CASP4, SP100, GBP5, ANXA1, TLR3, IFI16, PXK, LGALS9

0.039 CDKN2AIP, IRF7, DTX3L, IRF3, MASTL, RBBP6, CTC1

0.044 PNPT1, XRN2, ISG20 
RNA phosphodiester bond hydrolysis, exonucleolytic

Double-strand break repair

Defense response

Negative regulation of canonical Wnt signaling pathway

Protein linear polyubiquitination

Positive regulation of interleukin-10 secretion

Type I interferon biosynthetic process

Regulation of tumor necrosis factor-mediated signaling pathway

KEGG Pathways

Influenza A

Herpes simplex infection

Hepatitis C

Measles

RIG-I-like receptor signaling

pathway

Cytosolic DNA-sensing pathway

Hepatitis B

Proteasome

Viral carcinogenesis

Pertussis

Antigen processing and

presentation

Toll-like receptor

signaling pathway
0.045 PARP9, DTX3L, PAPD7, MAD2L2

0.046 TAP1, MX1, MX2, SP140

0.047 PSMA2, PSMF1, PSME2, MAD2L2, PSMB8, PSMB9

$0.047 \quad$ RBCK1, RNF31

0.047 CD274, LGALS9

$0.047 \quad$ IRF7, IRF3

0.050 CASP8, RBCK1, RNF3

XPO1, IFIH1, RNASEL, PML, TLR3, RSAD2, TRIM25, OAS2, STAT1, < 0.001 STAT2, DDX58, IRF9, TNFSF10, IRF7, IRF3, EIF2AK2, MX1, ADAR

RNASEL, IFIH1, SP100, PML, TLR3, OAS2, STAT1, DAXX, STAT2, < 0.001 DDX58, IRF9, IFIT1, IRF7, TAP2, CASP8, TAP1, IRF3, EIF2AK2

DDX58, IRF9, RNASEL, IFIT1, IRF7, IRF1, TLR3, IRF3, OAS2, EIF2AK2, $<0.001 \quad$ STAT1, STAT2

DDX58, IRF9, IFIH1, TNFSF10, IRF7, IRF3, OAS2, EIF2AK2, MX1, $<0.001 \quad$ STAT1, STAT2, ADAR

< 0.001 DDX58, IFIH1, ISG15, IRF7, CASP8, TRIM25, IRF3, AZI2, DHX58

$<0.001$ DDX58, IRF7, RIPK3, TREX1, IRF3, ZBP1, ADAR

0.002 DDX58, IFIH1, IRF7, CASP8, TLR3, IRF3, STAT1, STAT2

0.002 PSMA2, PSMF1, PSME2, PSMB8, PSMB9

0.010 KAT2A, IRF9, SP100, IRF7, CASP8, IRF3, EIF2AK2, GTF2B

0.012 CASP7, IRF8, IRF1, IRF3, C2

0.012 PSME2, TAP2, TAP1, TAPBP, B2M

$0.036 \quad$ IRF7, CASP8, TLR3, IRF3, STAT1 
Table 3.5. Gene ontology (GO) Biological Process Direct for (70) genes up-regulated in bovine endometrial fibroblast cells treated with $100 \mathrm{ng}$ of oIFNT in 3D culture (II and III of Figure 2.2.).

\begin{tabular}{|c|c|c|}
\hline Term & P-Value & Genes \\
\hline \multicolumn{3}{|l|}{ GO Biological Process Direct } \\
\hline Defense response to virus & $<0.001$ & $\begin{array}{l}\text { RNASEL, ZC3HAV1, BST2, PML, HERC5, RSAD2, TRIM25, } \\
\text { IFI44L, OAS2, IFI16, IRF9, IFIT3, IFIT2, TRIM5, IFIT1, ISG15, } \\
\text { TRIM34, IFIT5, EIF2AK2, MX1, MX2, DHX58, GBP1, ADAR }\end{array}$ \\
\hline Type I interferon signaling pathway & $<0.001$ & $\begin{array}{l}\text { RNASEL, SP100, BST2, RSAD2, OAS2, IRF9, IFIT3, IFIT2, } \\
\text { IFIT1, IFI27, ISG15, IRF7, IRF4, XAF1, MX1, MX2, IFI6, ADAR }\end{array}$ \\
\hline Response to virus & $<0.001$ & $\begin{array}{l}\text { IFIH1, BST2, ZC3HAV1, RSAD2, IFI44, OAS2, DDX58, IFIT3, } \\
\text { IFIT2, IFIT1, IRF7, EIF2AK2, MX1, MX2, DHX58, ADAR }\end{array}$ \\
\hline $\begin{array}{l}\text { Negative regulation of viral genome } \\
\text { replication }\end{array}$ & $<0.001$ & $\begin{array}{l}\text { RNASEL, IFIT1, ISG15, ZC3HAV1, BST2, RSAD2, IFI16, } \\
\text { PARP10, EIF2AK2, MX1, ADAR }\end{array}$ \\
\hline $\begin{array}{l}\text { Interferon-gamma-mediated signaling } \\
\text { pathway }\end{array}$ & $<0.001$ & $\begin{array}{l}\text { IRF9, TRIM5, SP100, TRIM34, IRF7, PML, TRIM25, OAS2, IRF4, } \\
\text { TRIM21, GBP1 }\end{array}$ \\
\hline Innate immune response & $<0.001$ & $\begin{array}{l}\text { IFIH1, BST2, ZC3HAV1, PML, HERC5, TRIM25, IFI16, TRIM21, } \\
\text { DDX58, TRIM5, IFIT5, IRF7, EIF2AK2, MX1, MX2, DHX58, } \\
\text { ADAR, ZBP1 }\end{array}$ \\
\hline $\begin{array}{l}\text { Negative regulation of type I } \\
\text { interferon production }\end{array}$ & $<0.001$ & $\begin{array}{l}\text { DDX58, IFIH1, ISG15, HERC5, UBA7, UBE2L6, TRIM25, } \\
\text { DHX58 }\end{array}$ \\
\hline ISG15-protein conjugation & $<0.001$ & ISG15, HERC5, UBA7, UBE2L6 \\
\hline Response to interferon-alpha & $<0.001$ & BST2, EIF2AK2, MX2, ADAR \\
\hline $\begin{array}{l}\text { Positive regulation of interferon-alpha } \\
\text { production }\end{array}$ & $<0.001$ & DDX58, IFIH1, ZC3HAV1, IRF7 \\
\hline $\begin{array}{l}\text { Negative regulation of viral release } \\
\text { from host cell }\end{array}$ & $<0.001$ & TRIM5, PML, TRIM25, TRIM21 \\
\hline $\begin{array}{l}\text { Positive regulation of type I interferon } \\
\text { production }\end{array}$ & $<0.001$ & ZC3HAV1, IRF7, IFI16, DHX58, ZBP1 \\
\hline $\begin{array}{l}\text { Positive regulation of sequence- } \\
\text { specific DNA binding transcription } \\
\text { factor activity }\end{array}$ & $<0.001$ & DDX58, TRIM5, SP100, TRIM34, TRIM25, TRIM21 \\
\hline $\begin{array}{l}\text { Positive regulation of interferon-beta } \\
\text { production }\end{array}$ & $<0.001$ & DDX58, IFIH1, ZC3HAV1, IRF7 \\
\hline $\begin{array}{l}\text { Modification-dependent protein } \\
\text { catabolic process }\end{array}$ & $<0.001$ & ISG15, UBA7, UBE2L6 \\
\hline
\end{tabular}


Response to type I interferon

Positive regulation of I-kappa $b$ kinase/NF-kappa b signaling

Translesion synthesis

Protein trimerization

Defense response

Response to interferon-gamma

Protein polyubiquitination

Regulation of type III interferon production

Organelle fission

Cytoplasmic pattern recognition receptor signaling pathway in response to virus

MDA-5 signaling pathway

Positive regulation of NF-kappa $b$ transcription factor activity

Response to cytokine

Peptide transport

Detection of virus

Intracellular transport of viral protein in host cell

Positive regulation of viral entry into host cell

Positive regulation of RIG-I signaling pathway

Cellular response to interferon-alpha

Response to interferon-beta

Activation of innate immune response

Activation of cysteine-type

endopeptidase activity involved in apoptotic process

Negative regulation of innate immune response

Positive regulation of mRNA

catabolic process
$<0.001$

SP100, ISG15, MX1

< 0.001 TRIM5, TNFSF10, ZC3HAV1, BST2, TRIM25, LGALS9

$<0.001 \quad$ ISG15, UBA7, UBE2L6, TRIM25

$<0.001 \quad$ TRIM5, TRIM34, TRIM21

0.002 TAP1, MX1, MX2, SP140

$0.003 \quad$ SP100, BST2, TRIM21

0.004 DTX3L, HERC6, HERC5, RNF213, TRIM21

0.007 DDX58, IFIH1

$0.007 \quad$ MX1, MX2

0.011 DDX58, IFIH1

$0.011 \quad$ IFIH1, IRF7

0.013 TRIM5, TRIM25, EIF2AK2, LGALS9

0.015 IFI27, SP100, PML

0.018 TAP1, SLC15A3

0.018 DDX58, IFIH1

$0.018 \quad$ IFIT1, TAP1

0.025 LGALS9, TRIM21

0.029 ZC3HAV1, DHX58

0.032 IFIT3, IFIT2

0.032 BST2, XAF1

0.036 TRIM5, IFI16

0.037 IFI27, TNFSF10, PML

0.039 IFI16, DHX58

0.043 ZC3HAV1, PNPT1 


\begin{tabular}{|c|c|c|}
\hline $\begin{array}{l}\text { Regulation of type I interferon } \\
\text { production }\end{array}$ & 0.046 & IRF7, TRIM21 \\
\hline Cellular response to virus & 0.046 & LGALS9, ADAR \\
\hline $\begin{array}{l}\text { Cellular response to exogenous } \\
\text { dsRNA } \\
\text { Negative regulation of viral } \\
\text { transcription } \\
\text { KEGG Pathways }\end{array}$ & 0.046 & $\begin{array}{l}\text { IFIT1, ZC3HAV1 } \\
\text { SP100, TRIM21 }\end{array}$ \\
\hline Influenza A & $<0.001$ & $\begin{array}{l}\text { IFIH1, RNASEL, PML, RSAD2, TRIM25, OAS2, IRF9, DDX58, } \\
\text { TNFSF10, IRF7, EIF2AK2, MX1, ADAR } \\
\text { DDX58, IRF9, RNASEL, IFIT1, IFIH1, SP100, IRF7, TAP1, PML, }\end{array}$ \\
\hline Herpes simplex infection & $<0.001$ & $\mathrm{OAS} 2, \mathrm{EIF} 2 \mathrm{AK} 2$ \\
\hline Measles & $<0.001$ & $\begin{array}{l}\text { DDX58, IRF9, IFIH1, TNFSF10, IRF7, OAS2, EIF2AK2, MX1, } \\
\text { ADAR }\end{array}$ \\
\hline RIG-I-like receptor signaling pathway & $<0.001$ & DDX58, IFIH1, ISG15, IRF7, TRIM25, DHX58 \\
\hline Hepatitis C & $<0.001$ & DDX58, IRF9, RNASEL, IFIT1, IRF7, OAS2, EIF2AK2 \\
\hline Cytosolic DNA-sensing pathway & 0.002 & DDX58, IRF7, ZBP1, ADAR \\
\hline Viral carcinogenesis & 0.037 & IRF9, SP100, IRF7, EIF2AK2 \\
\hline
\end{tabular}


A.

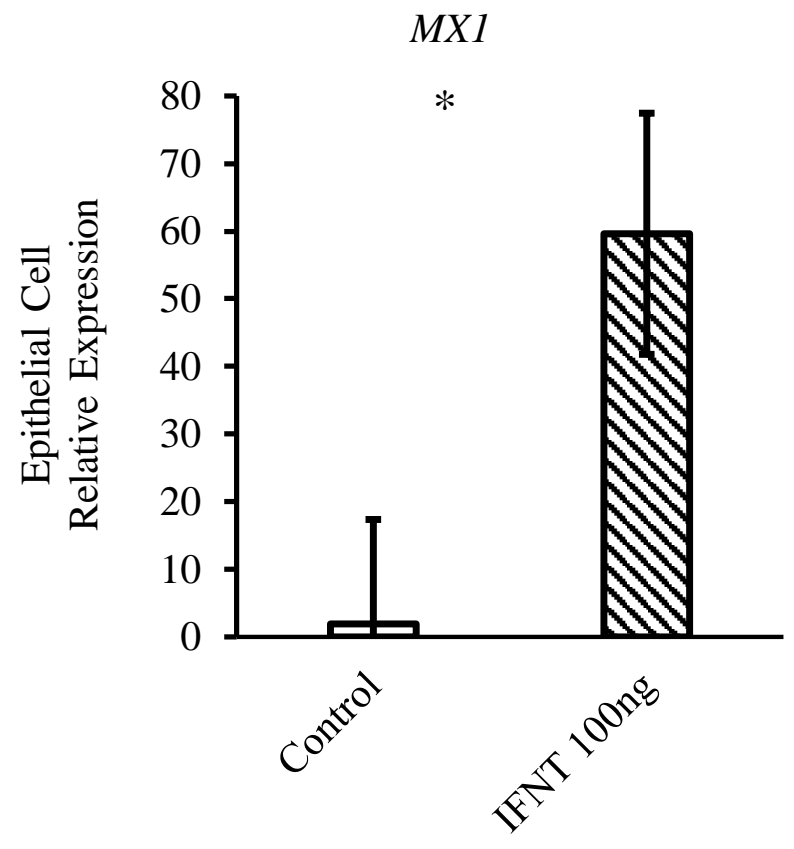

B.

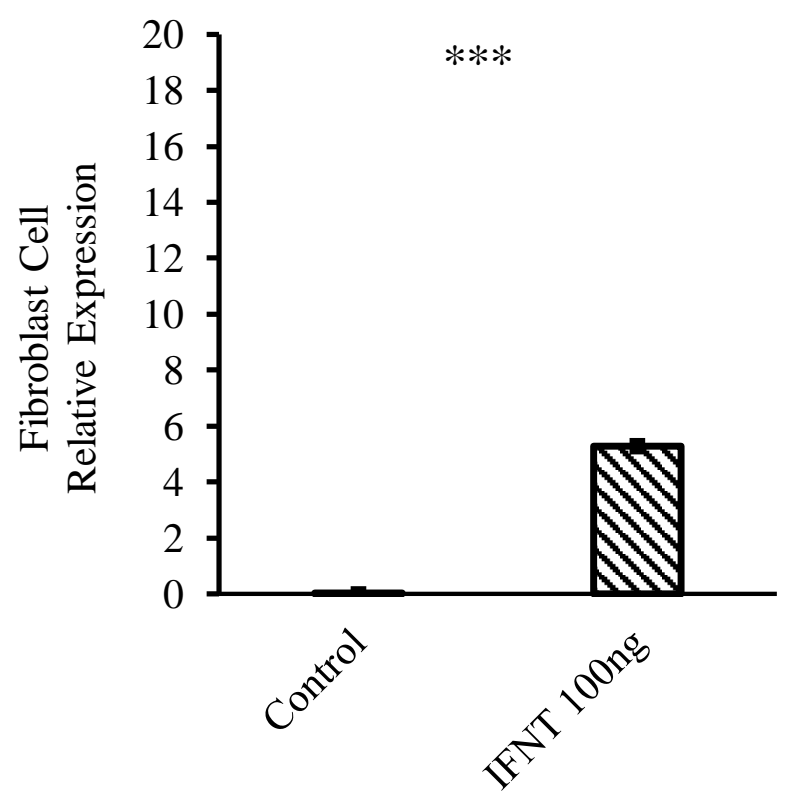

Figure 3.3. Quantitative real-time PCR analysis of $M X 1$ gene expression in bovine endometrial (A) epithelial and (B) fibroblast cells cultured in 3D treated with either treatment media only (Control; $\mathrm{n}=4)$ or $100 \mathrm{ng} / \mathrm{mL}$ of oIFNT $(\mathrm{n}=3)$. Relative expression data are normalized over the geometric mean of reference genes, RNF11 and SDHA. Data are presented as LSM \pm SEM. Relative expression of $M X 1$ was greater in epithelial and fibroblast cells treated with oIFNT $(* * * P<0.001 ; * * P<0.01 ; * P<0.05)$. 
$M X 2$

A.

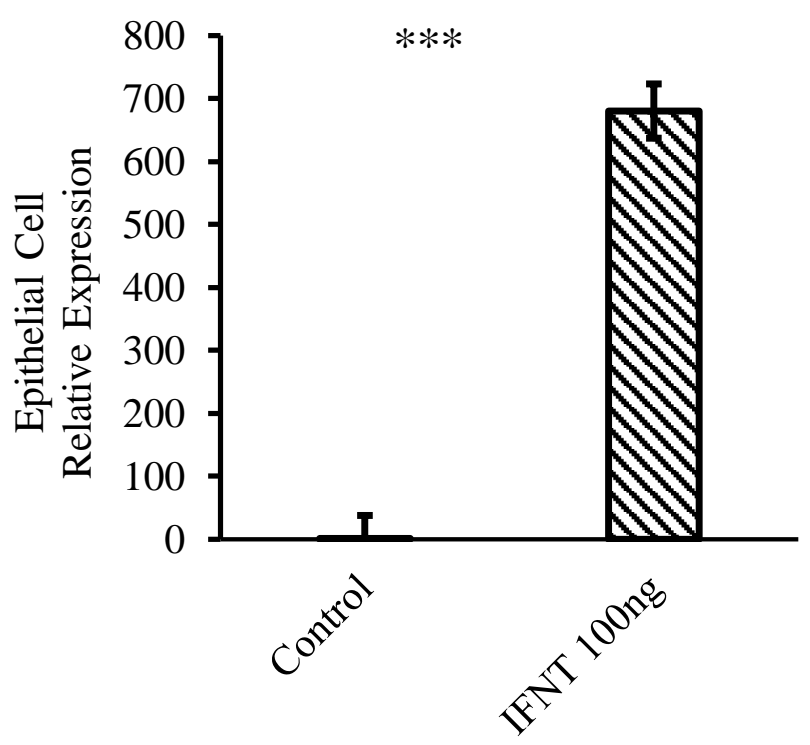

B.

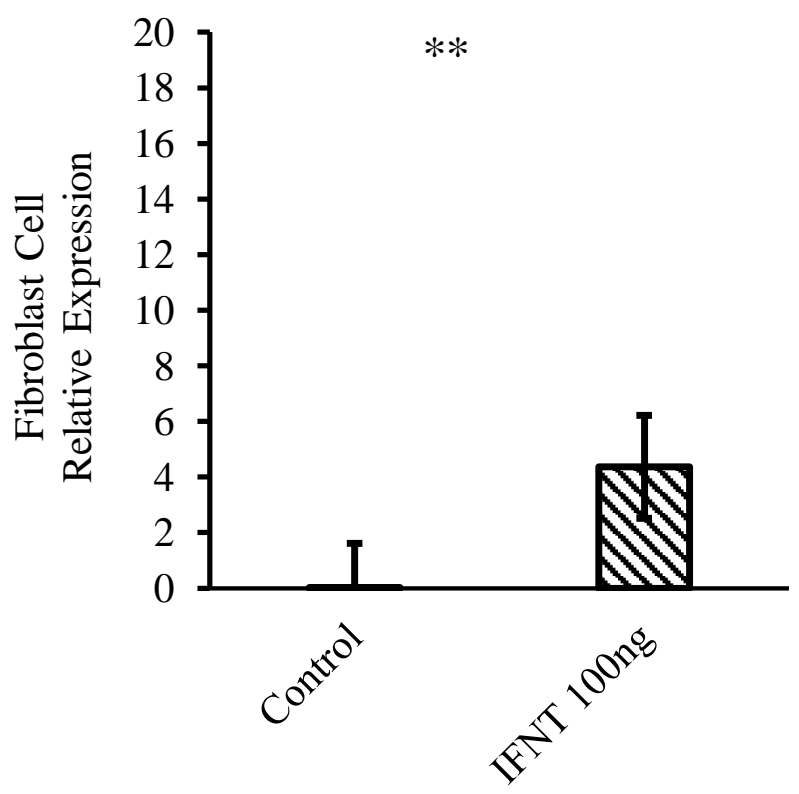

Figure 3.4. Quantitative real-time PCR analysis of $M X 2$ gene expression in bovine endometrial (A) epithelial and (B) fibroblast cells cultured in 3D treated with either treatment media only (Control; $\mathrm{n}=4)$ or $100 \mathrm{ng} / \mathrm{mL}$ of oIFNT $(\mathrm{n}=3)$. Relative expression data are normalized over the geometric mean of reference genes, RNF11 and SDHA. Data are presented as LSM \pm SEM. Relative expression of $M X 2$ was greater in epithelial and fibroblast cells treated with oIFNT $(* * * P<0.001 ; * * P<0.01 ; * P<0.05)$. 
OAS1

A.

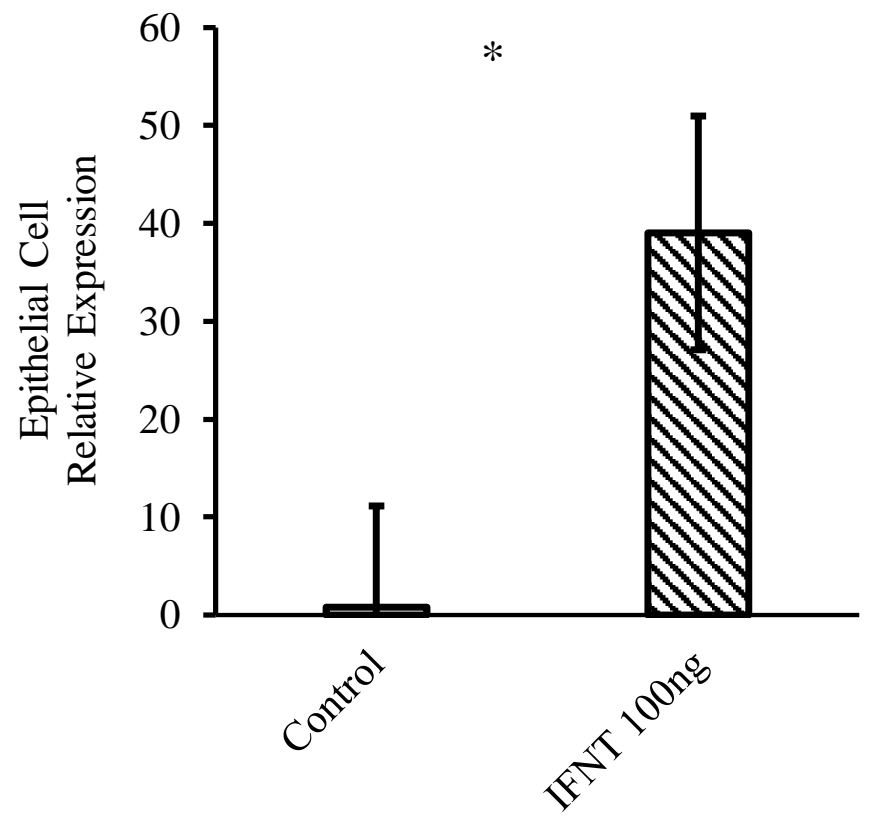

B.

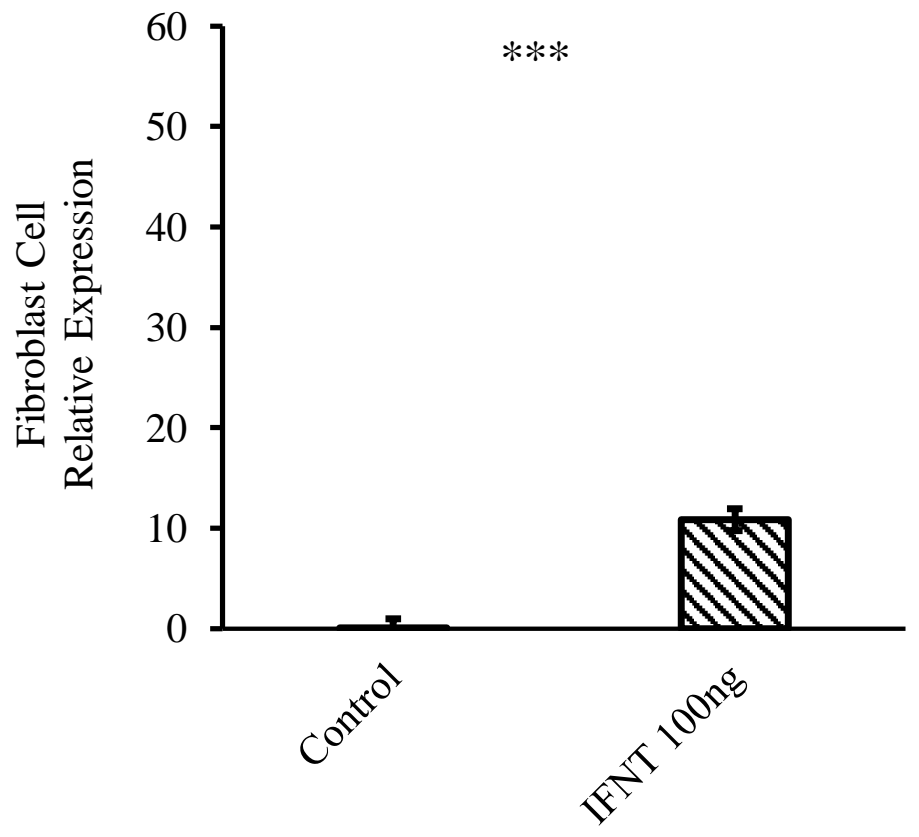

Figure 3.5. Quantitative real-time PCR analysis of OAS1 gene expression in bovine endometrial (A) epithelial and (B) fibroblast cells cultured in 3D treated with either treatment media only (Control; $\mathrm{n}=4$ ) or $100 \mathrm{n} \mathrm{ng} / \mathrm{mL}$ of oIFNT $(\mathrm{n}=3)$. Relative expression data are normalized over the geometric mean of reference genes, RNF11 and SDHA. Data are presented as LSM \pm SEM. Relative expression of $O A S 1$ was greater in epithelial and fibroblast cells treated with oIFNT $(* * * P<0.001 ; * * P<0.01 ; * P<0.05)$. 


\section{$L G A L S 3 B P$}

A.

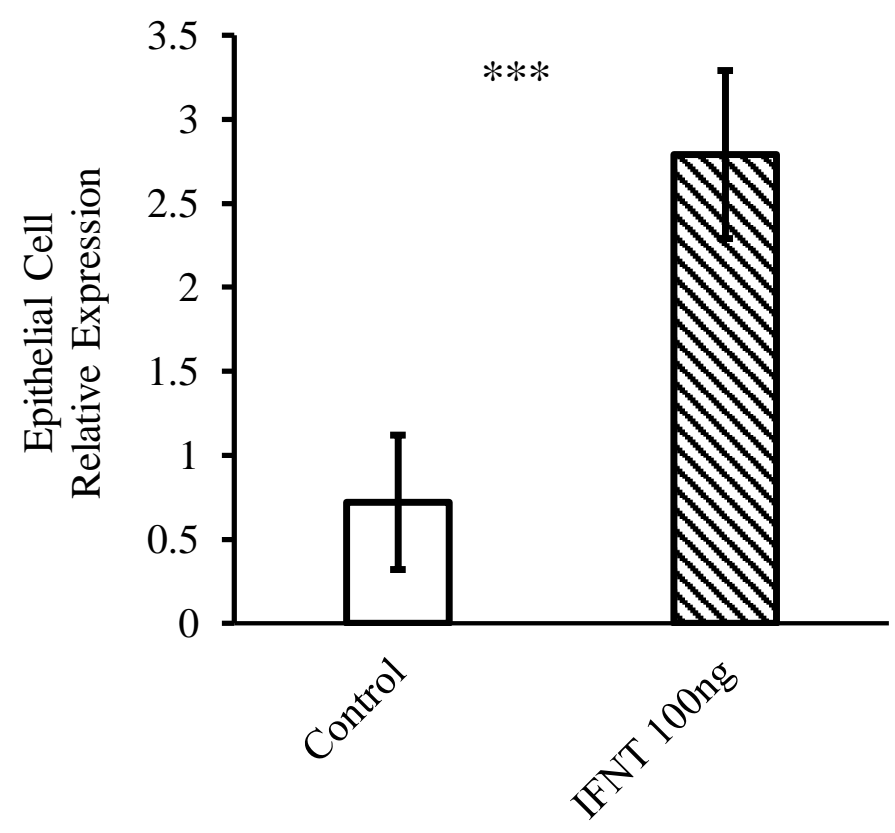

B.

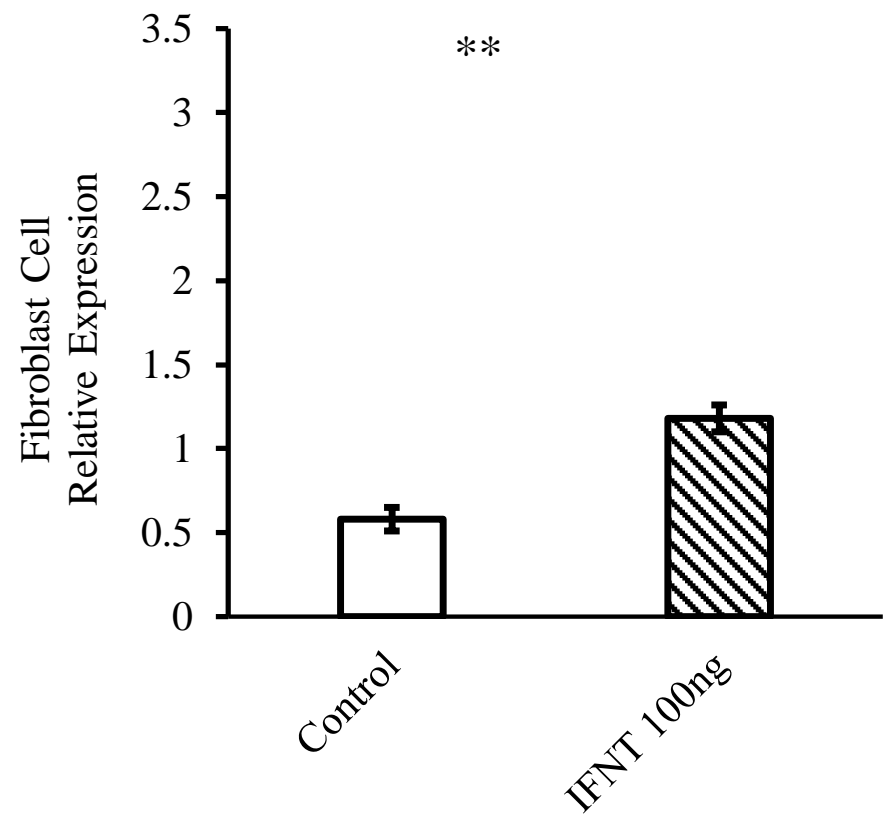

Figure 3.6. Quantitative real-time PCR analysis of LGALS3BP gene expression in bovine endometrial (A) epithelial and (B) fibroblast cells cultured in 3D treated with either treatment media only (Control; $\mathrm{n}=4$ ) or $100 \mathrm{ng} / \mathrm{mL}$ of oIFNT $(\mathrm{n}=3)$. Relative expression data are normalized over the geometric mean of reference genes, RNF11 and SDHA. Data are presented as $\mathrm{LSM} \pm$ SEM.Relative expression of $L G A L S 3 B P$ was greater in epithelial and fibroblast cells treated with oIFNT $(* * * P<0.001 ; * * P<0.01 ; * P<0.05)$. 
A.

LGALS9

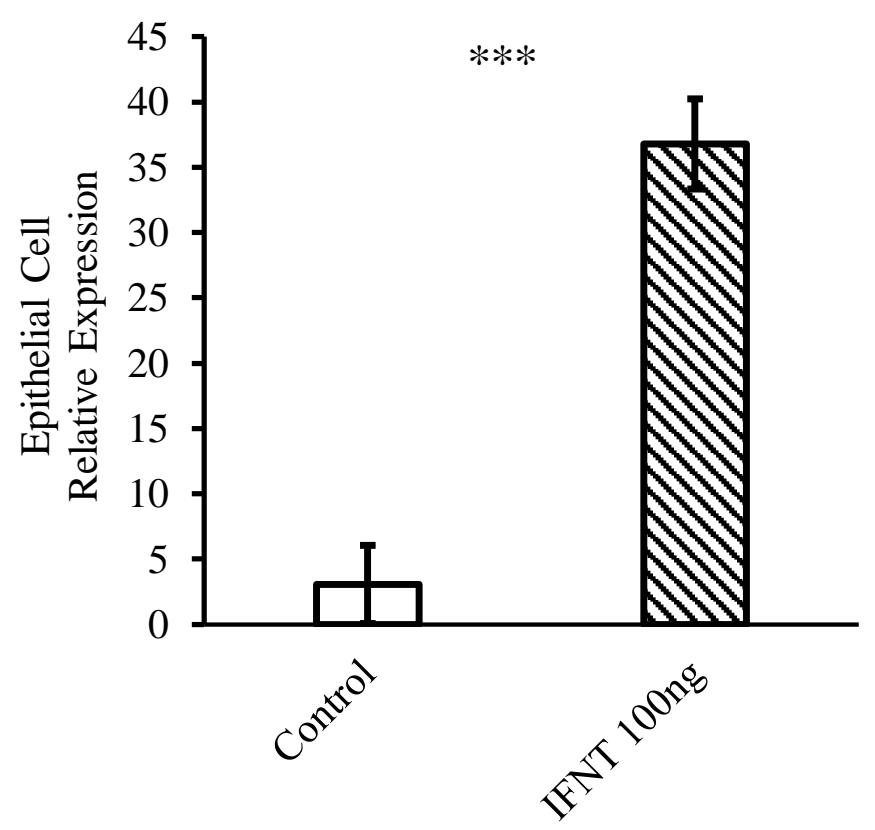

B.

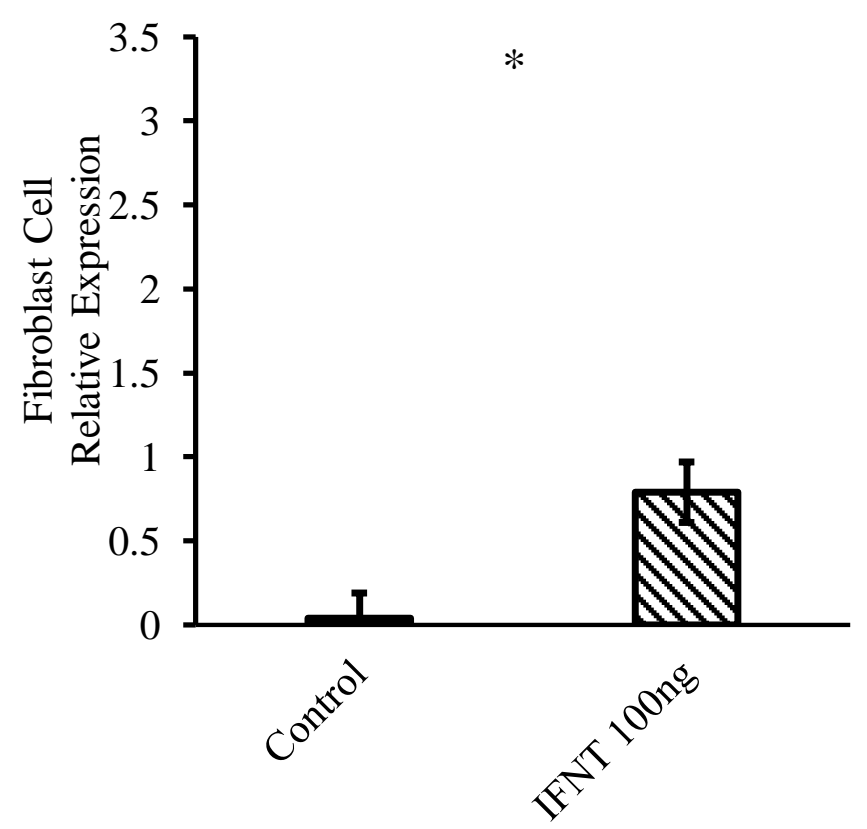

Figure 3.7. Quantitative real-time PCR analysis of LGALS9 gene expression in bovine endometrial (A) epithelial and (B) fibroblast cells cultured in 3D treated with either treatment media only (Control; $n=4)$ or $100 \mathrm{ng} / \mathrm{mL}$ of oIFNT $(\mathrm{n}=3)$. Relative expression data are normalized over the geometric mean of reference genes, RNF11 and SDHA. Data are presented as LSM \pm SEM. Relative expression of $L G A L S 9$ was greater in epithelial and fibroblast cells treated with oIFNT $(* * * P<0.001 ; * * P<0.01 ; * P<0.05)$. 


\section{OAS2}

A.

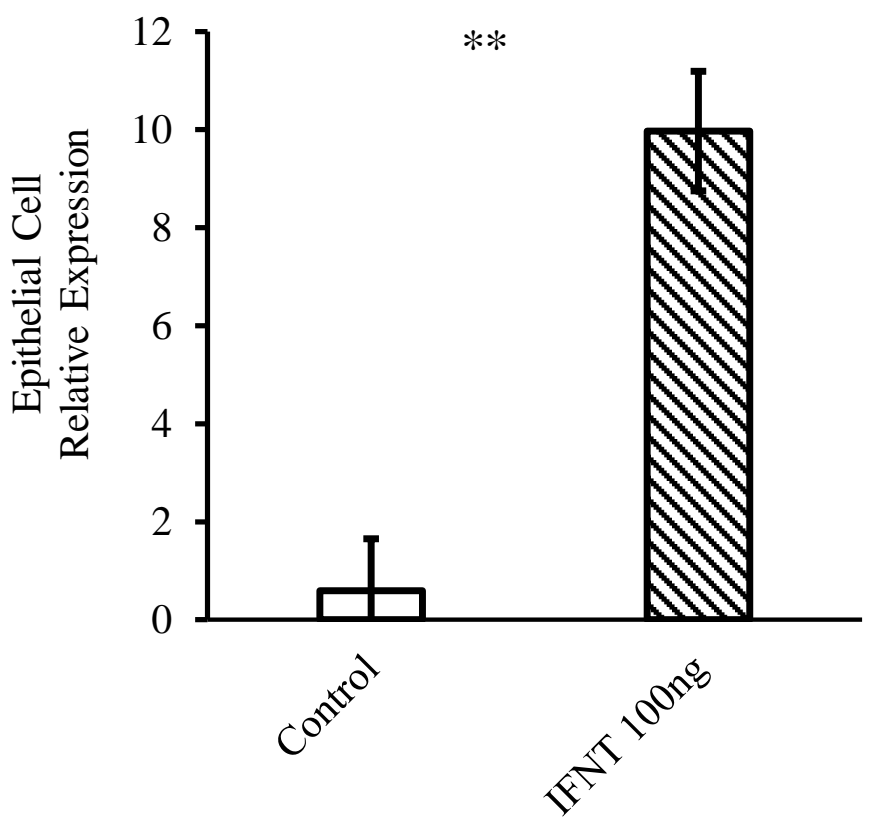

B.

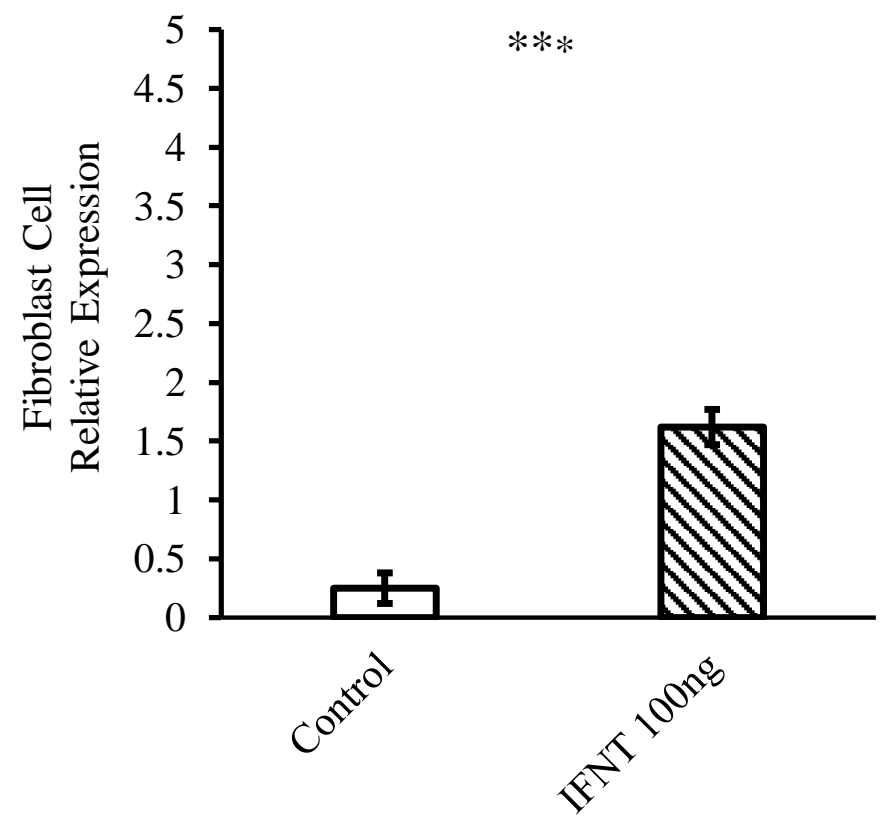

Figure 3.8. Quantitative real-time PCR analysis of OAS2 gene expression in bovine endometrial (A) epithelial and (B) fibroblast cells cultured in 3D treated with either treatment media only (Control; $\mathrm{n}=4)$ or $100 \mathrm{ng} / \mathrm{mL}$ of oIFNT $(\mathrm{n}=3)$. Relative expression data are normalized over the geometric mean of reference genes, RNF11 and SDHA. Data are presented as LSM \pm SEM. Relative expression of $O A S 2$ was greater in epithelial and fibroblast cells treated with oIFNT $(* * * P<0.001 ; * * P<0.01 ; * P<0.05)$. 


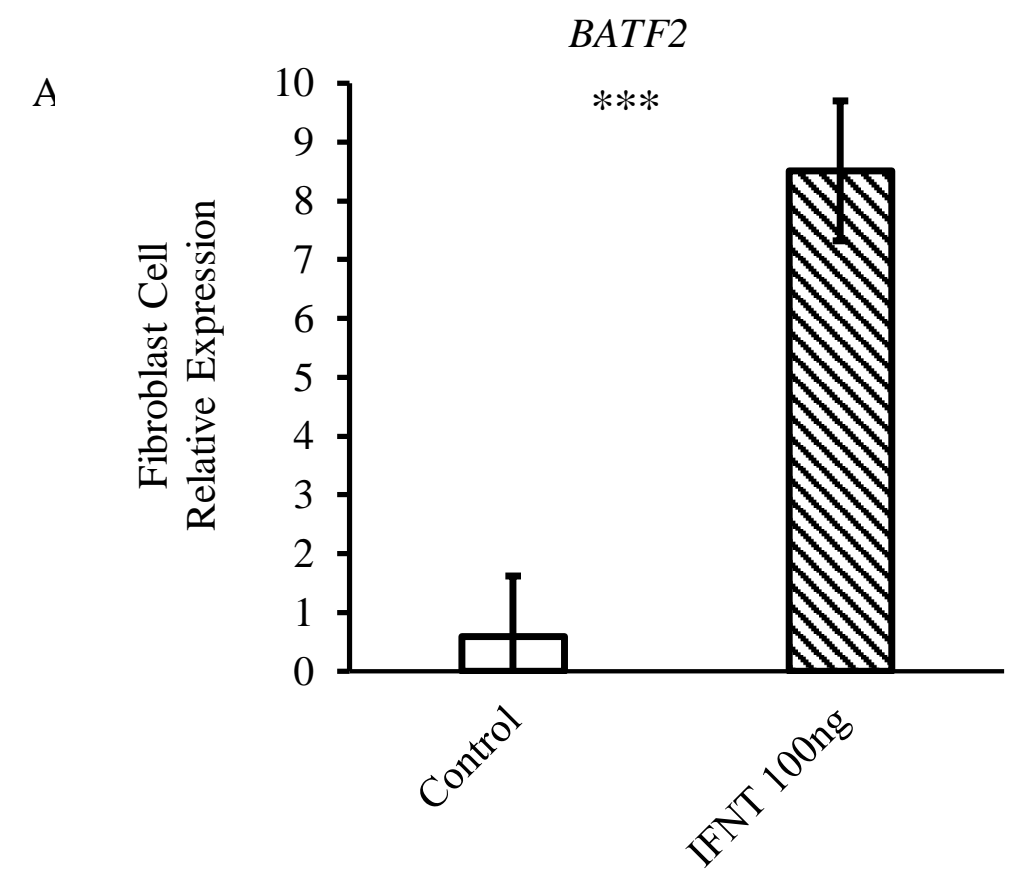

B.

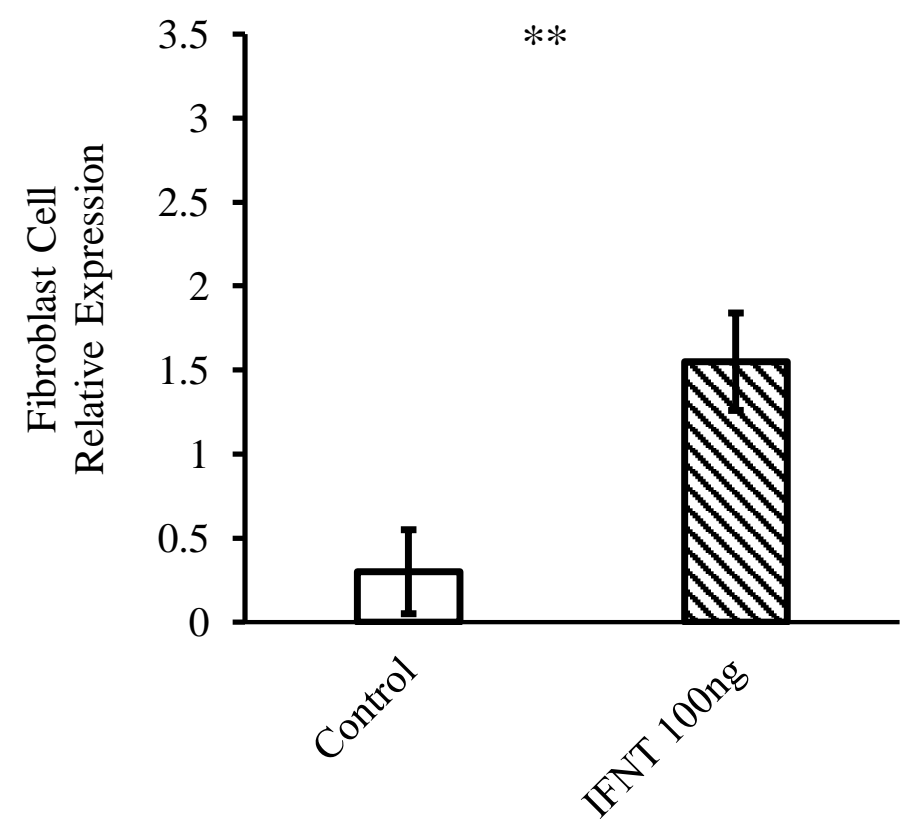

Figure 3.9. Quantitative real-time PCR analysis of BATF2 gene expression in bovine endometrial (A) epithelial and (B) fibroblast cells cultured in 3D treated with either treatment media only (Control; $\mathrm{n}=4)$ or $100 \mathrm{ng} / \mathrm{mL}$ of oIFNT $(\mathrm{n}=3)$. Relative expression data are normalized over the geometric mean of reference genes, RNF11 and SDHA. Data are presented as LSM \pm SEM. Relative expression of $B A T F 2$ was greater in epithelial and fibroblast cells treated with oIFNT $(* * * P<0.001 ; * * P<0.01 ; * P<0.05)$. 
A.

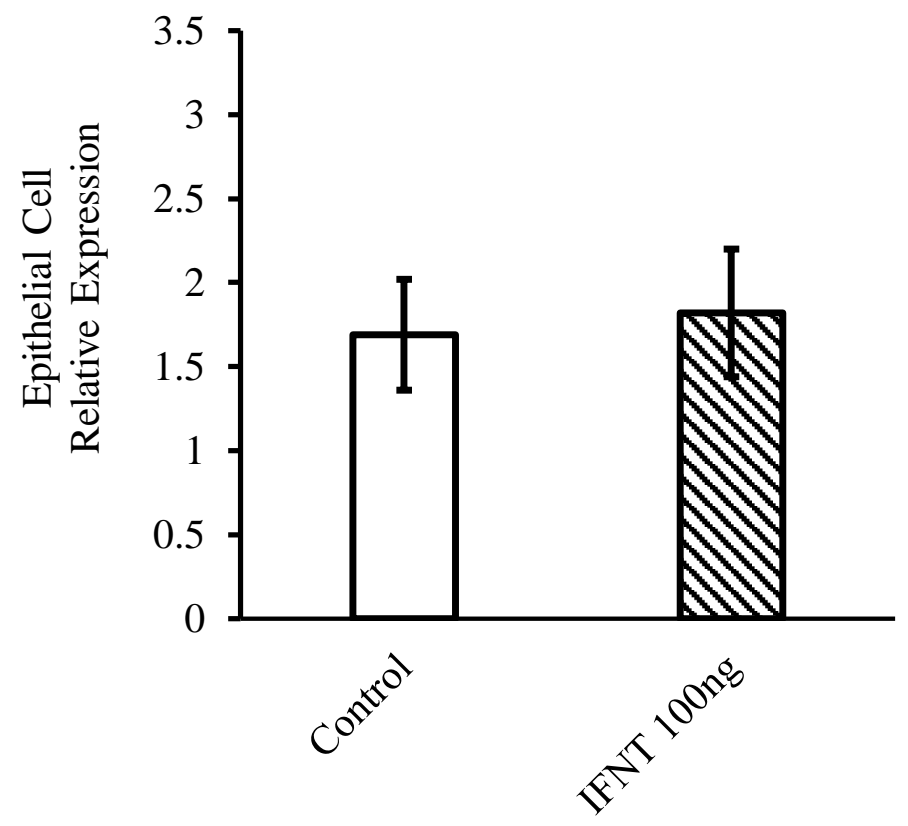

B.

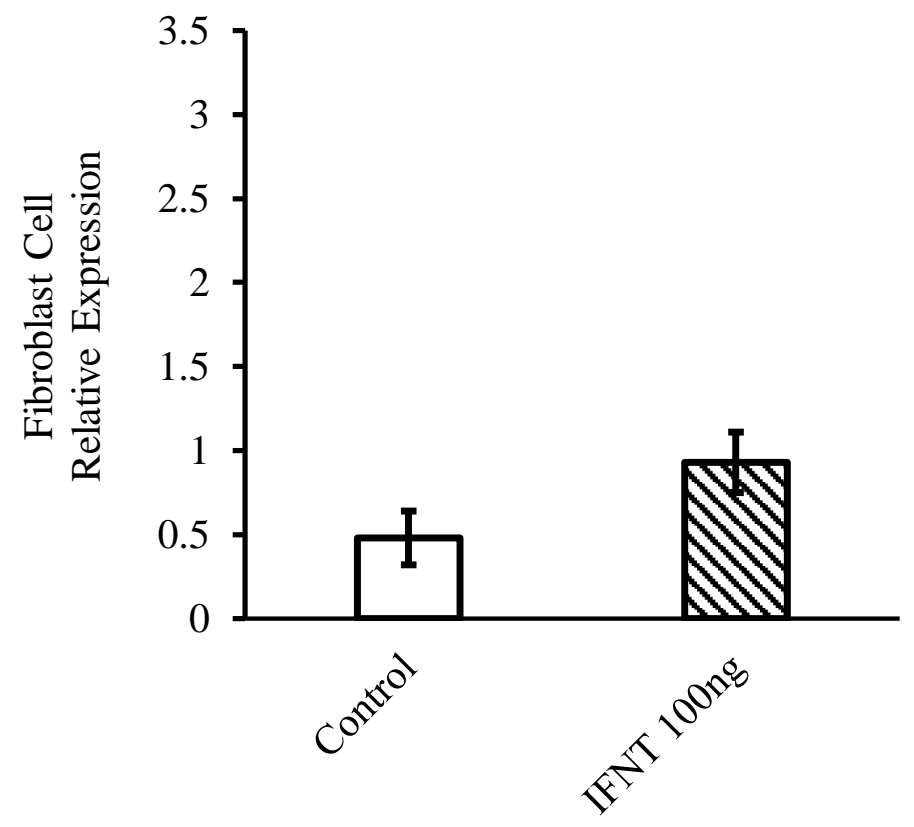

Figure 3.10. Quantitative real-time PCR analysis of IDOI gene expression in bovine endometrial (A) epithelial and (B) fibroblast cells cultured in 3D treated with either treatment media only (Control; $n=4)$ or $100 \mathrm{ng} / \mathrm{mL}$ of oIFNT $(\mathrm{n}=3)$. Relative expression data are normalized over the geometric mean of reference genes, RNF11 and SDHA. Data are presented as LSM \pm SEM. Expression of IDOI was not significantly elevated in oIFNT treated epithelial and fibroblast cells $(P>0.05)$. 
A.

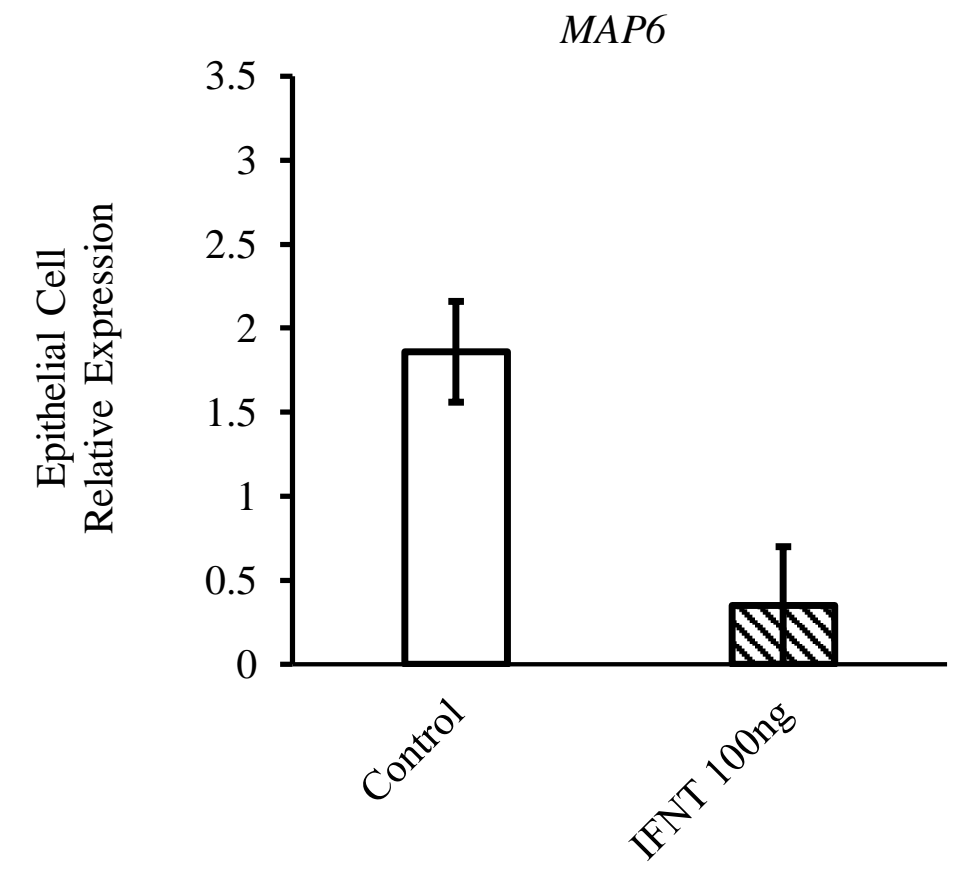

B.

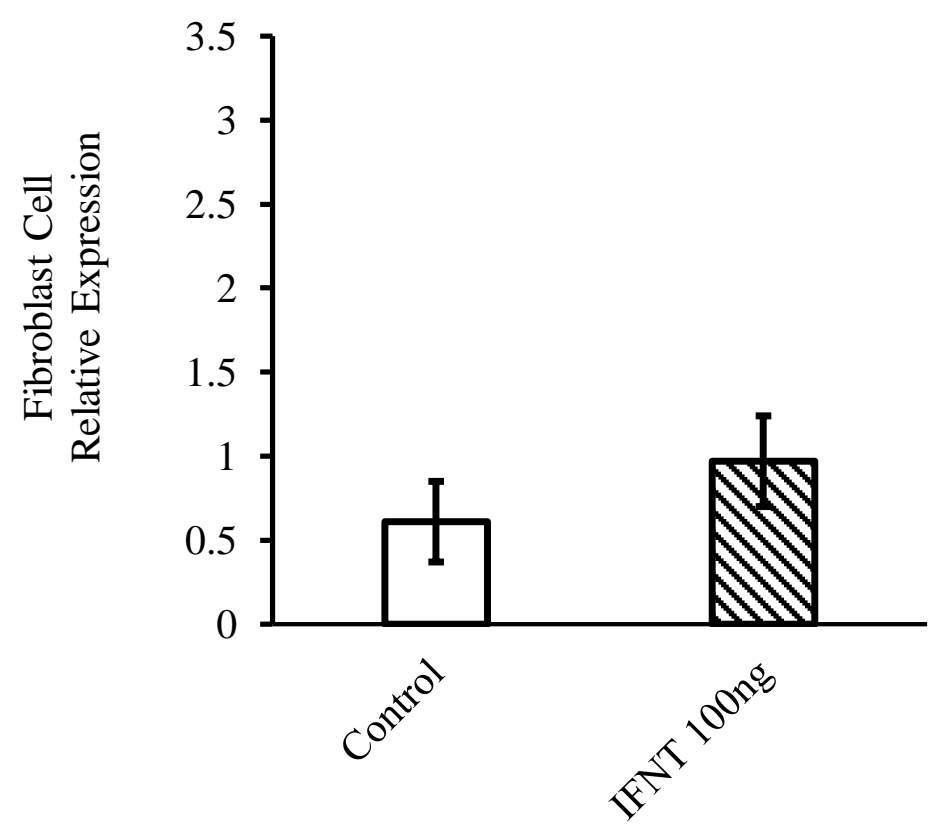

Figure 3.11. Quantitative real-time PCR analysis of MAP6 gene expression in bovine endometrial (A) epithelial and (B) fibroblast cells cultured in 3D treated with either treatment media only (Control; $\mathrm{n}=4)$ or $100 \mathrm{ng} / \mathrm{mL}$ of oIFNT $(\mathrm{n}=3)$. Relative expression data are normalized over the geometric mean of reference genes, RNF11 and SDHA. Data are presented as LSM \pm SEM. Expression of MAP6 decreated in oIFNT treated epithelial cells, however, not statistically $(P>0.05)$. In the fibroblast cells, there was not a trend $(P$ $>0.05)$. 


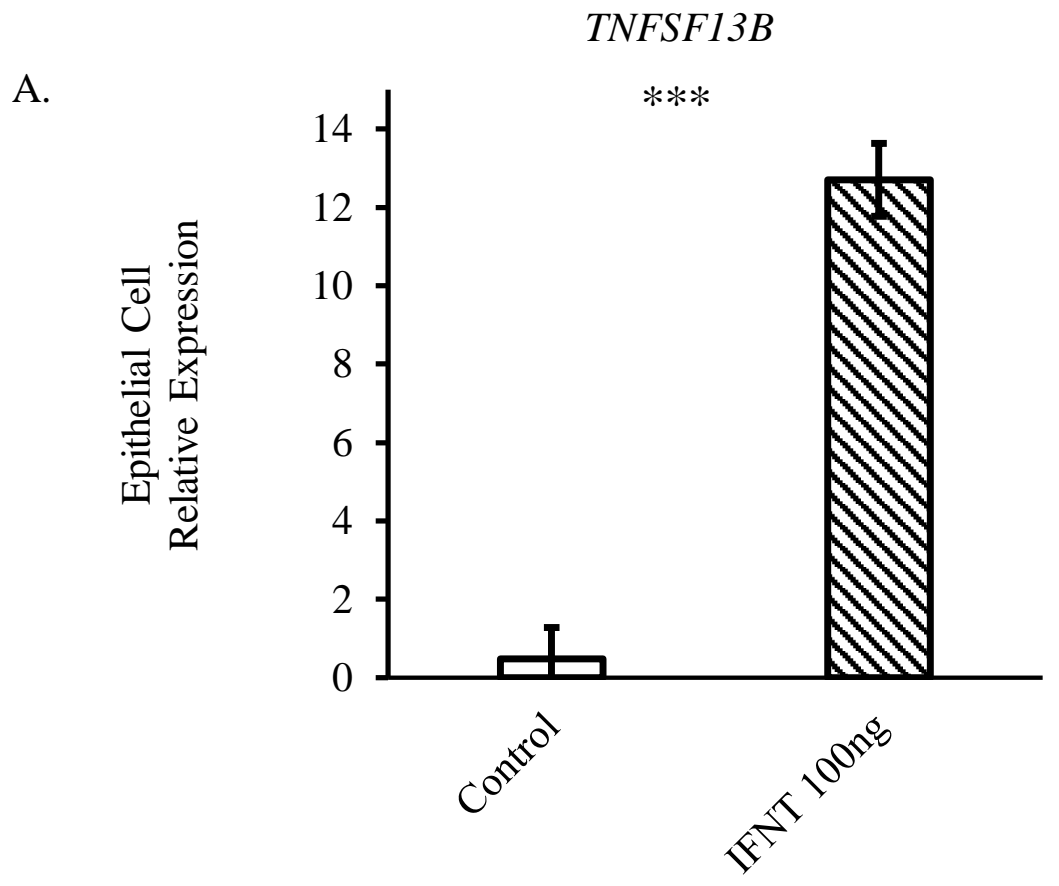

B.

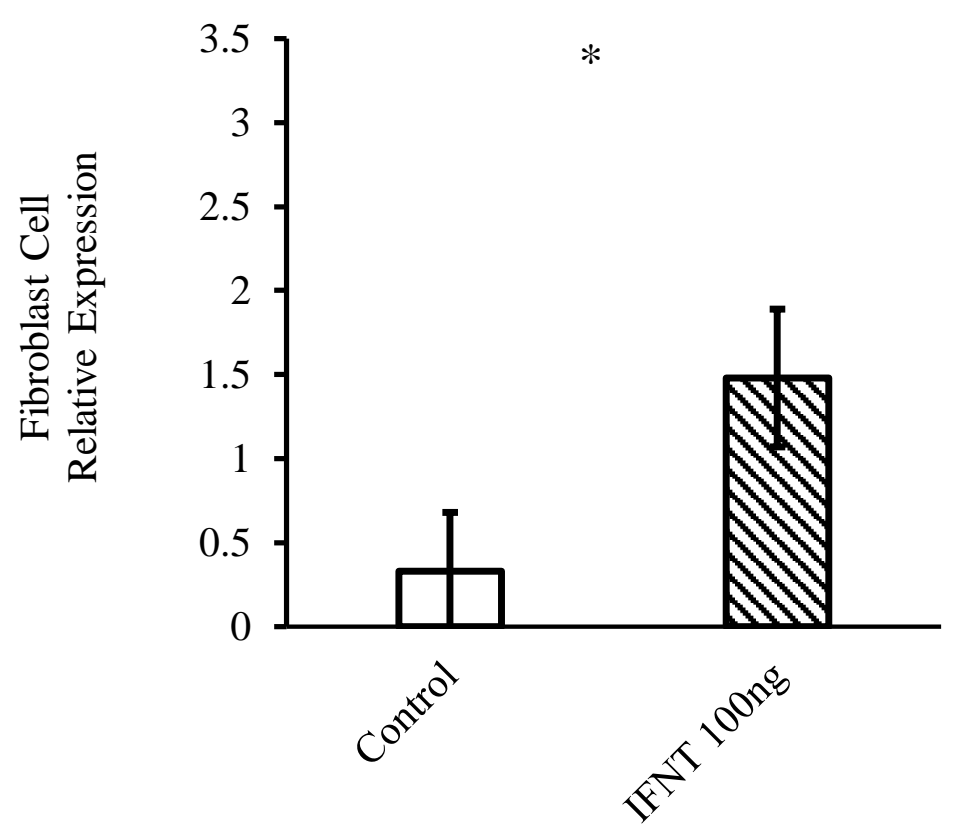

Figure 3.12. Quantitative real-time PCR analysis of TNFSF13B gene expression in bovine (A) epithelial and (B) fibroblast cells cultured in 3D treated with either treatment media only (Control; $\mathrm{n}=4)$ or $100 \mathrm{ng} / \mathrm{mL}$ of oIFNT (n=3). Relative expression data are normalized over the geometric mean of reference genes, RNF11 and SDHA. Data are presented as LSM \pm SEM. Relative expression of TNFSF13B was greater in epithelial and fibroblast cells treated with oIFNT $(* * * P<0.001 ; * * P<0.01 ; * P<0.05)$. 


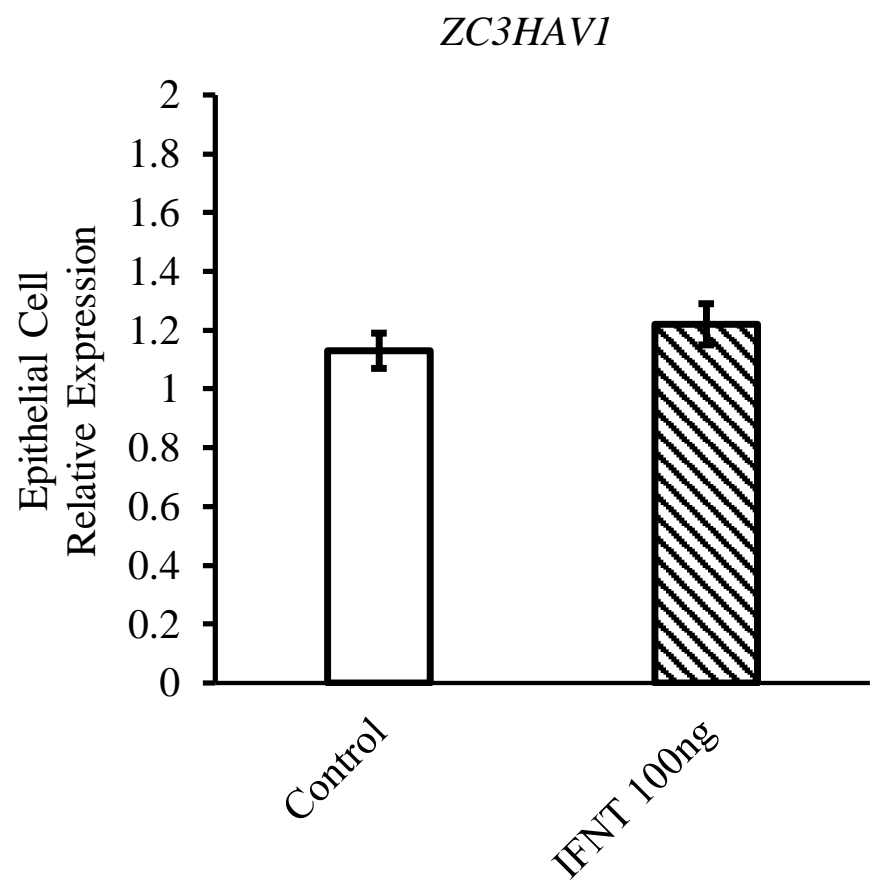

B.

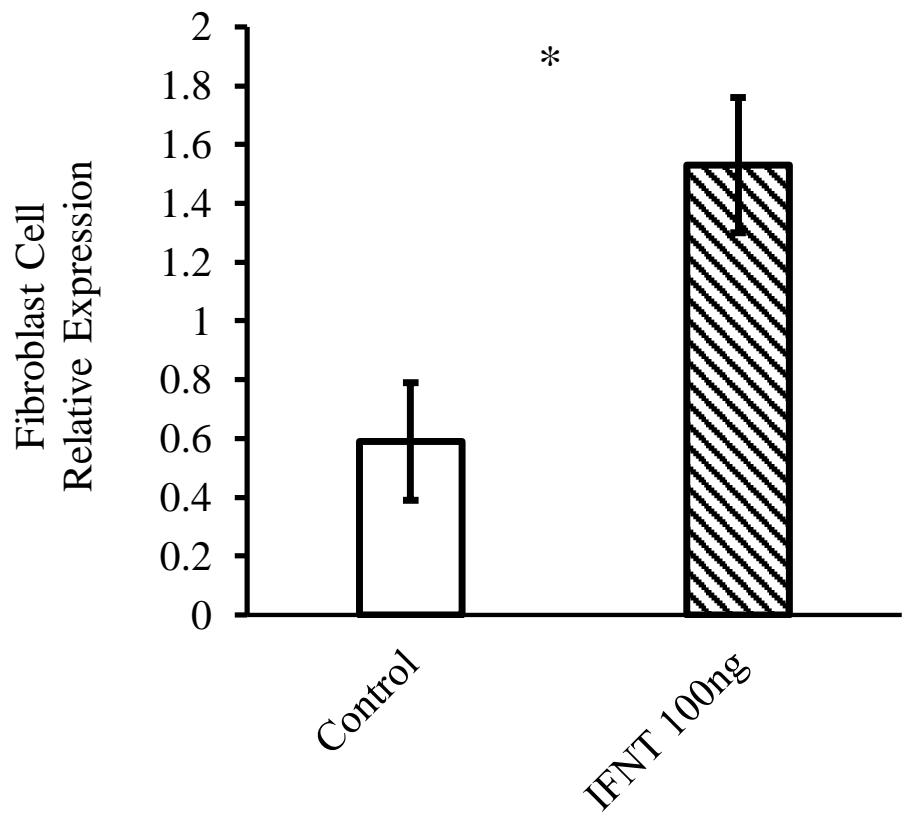

Figure 3.13. Quantitative real-time PCR analysis of ZC3HAVI gene expression in bovine endometrial (A) epithelial and (B) fibroblast cells cultured in 3D treated with either treatment media only (Control; $\mathrm{n}=4$ ) or $100 \mathrm{ng} / \mathrm{mL}$ of oIFNT $(\mathrm{n}=3)$. Relative expression data are normalized over the geometric mean of reference genes, RNF11 and SDHA. Data are presented as LSM \pm SEM. The treatment of endometrial cells with oIFNT significantly increased ZC3HAVI expression exclusively in the fibroblast cells in comparison to the control-treated cells. Expression of ZC3HAVI was not different in epithelial cells $(P>0.05)$ $(* * * P<0.001 ; * * P<0.01 ; * P<0.05)$. 
Table 3.6. Quantitative real-time PCR analysis of the effect of 100 or $1000 \mathrm{ng}$ of recombinant mouse LGALS3 protein on 3D cultured epithelial and fibroblast cells. The effect of flush fluid of a d14 pregnant ewe (FF) on epithelial and fibroblast cells gene expression was also examined. Control cells received treatment media only. Relative expression data are normalized over the geometric mean of reference genes, PPIA and SDHA. Data are presented as LSM $\pm \mathrm{SEM}$.

\begin{tabular}{|c|c|c|c|c|c|c|c|}
\hline Gene & $\begin{array}{l}\text { Cell } \\
\text { Type }\end{array}$ & Control & $\mathrm{FF}$ & $\begin{array}{c}\text { LGALS3 } \\
\text { (100 ng) }\end{array}$ & $\begin{array}{l}\text { LGALS3 } \\
(1000 \mathrm{ng})\end{array}$ & Trt. & Contrast \\
\hline \multirow[t]{2}{*}{$R P L 23 A$} & Epi. & $1.44 \pm 0.11$ & $0.93 \pm 0.12$ & $1.04 \pm 0.11$ & $0.99 \pm 0.11$ & NS & NS \\
\hline & Fib. & $1.07 \pm 0.10$ & $1.20 \pm 0.11$ & $1.02 \pm 0.10$ & $0.83 \pm 0.10$ & NS & NS \\
\hline \multirow[t]{2}{*}{ CXCR4 } & Epi. & $5.12 \pm 0.98^{a}$ & $9.50 \pm 1.10^{\mathrm{b}}$ & $4.89 \pm 0.98^{a}$ & $4.56 \pm 0.98^{a}$ & $<0.05$ & NS \\
\hline & Fib. & $0.19 \pm 0.10$ & $0.41 \pm 0.11$ & $0.16 \pm 0.20$ & $0.17 \pm 0.10$ & NS & NS \\
\hline \multirow[t]{2}{*}{ DMRTAI } & Epi. & $1.80 \pm 0.38$ & $1.12 \pm 0.42$ & $1.70 \pm 0.38$ & $1.33 \pm 0.38$ & NS & NS \\
\hline & Fib. & $1.78 \pm 0.45$ & $1.38 \pm 0.50$ & $1.28 \pm 0.45$ & $1.41 \pm 0.45$ & NS & NS \\
\hline \multirow[t]{2}{*}{$I S G 15$} & Epi. & $0.50 \pm 5.31^{\mathrm{a}}$ & $130.27 \pm 5.94^{b}$ & $0.60 \pm 5.31^{\mathrm{a}}$ & $0.55 \pm 5.31^{\mathrm{a}}$ & $<0.001$ & NS \\
\hline & Fib. & $0.27 \pm 7.70^{\mathrm{a}}$ & $58.40 \pm 8.61^{\mathrm{b}}$ & $0.23 \pm 7.70^{\mathrm{a}}$ & $0.19 \pm 7.70^{\mathrm{a}}$ & $<0.001$ & NS \\
\hline \multirow[t]{2}{*}{$L G A L S 3 B P$} & Epi. & $0.98 \pm 0.16^{\mathrm{a}}$ & $4.12 \pm 0.18^{\mathrm{b}}$ & $1.05 \pm 0.16^{\mathrm{a}}$ & $1.02 \pm 0.16^{\mathrm{a}}$ & $<0.001$ & NS \\
\hline & Fib. & $0.73 \pm 0.21^{\mathrm{a}}$ & $1.77 \pm 0.23^{b}$ & $0.58 \pm 0.21^{\mathrm{a}}$ & $0.59 \pm 0.21^{\mathrm{a}}$ & $<0.01$ & NS \\
\hline \multirow[t]{2}{*}{$L I F$} & Epi. & $4.27 \pm 0.77^{\mathrm{a}}$ & $7.11 \pm 0.86^{\mathrm{b}}$ & $4.89 \pm 0.77^{\mathrm{a}}$ & $4.56 \pm 0.77^{\mathrm{a}}$ & NS & NS \\
\hline & Fib. & $0.27 \pm 0.09$ & $0.27 \pm 0.10$ & $0.24 \pm 0.09$ & $0.23 \pm 0.09$ & NS & NS \\
\hline \multirow[t]{2}{*}{ PRRT3 } & Epi. & $0.62 \pm 0.09$ & $0.47 \pm 0.10$ & $0.62 \pm 0.09$ & $0.57 \pm 0.09$ & NS & NS \\
\hline & Fib. & $2.62 \pm 0.83$ & $2.49 \pm 0.93$ & $2.08 \pm 0.83$ & $1.87 \pm 0.83$ & NS & NS \\
\hline
\end{tabular}




\begin{tabular}{cc}
\hline \multicolumn{2}{c}{ IFNT Responsive } \\
\multicolumn{2}{c}{ Endometrial ISGs } \\
\hline LE & Stroma \\
\hline$B A T F 2$ & OAS2 \\
$M X 2$ & $I F I 44 L$ \\
$I F I 44$ & $R S A D 2$ \\
$I F I T 1$ & ZBP1 \\
OAS2 & $M X 2$ \\
PLAC8 & $M X 1$ \\
KIF5C & $P L A C 8$ \\
ZBP1 & $I F I 44$ \\
RSAD2 & $T N F S F 10$ \\
IFIT3 & $S A M D 9$ \\
\hline
\end{tabular}

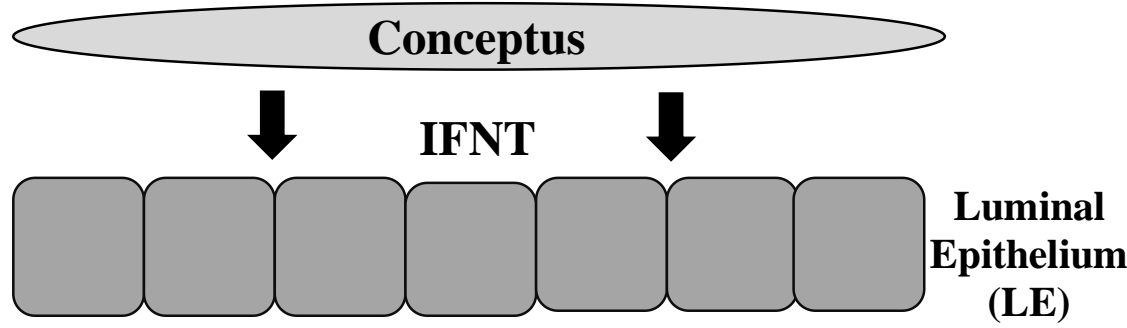

Figure 3.14. Model for IFNT regulation of classical and non-classical up-regulated ISGs in the bovine endometrium during early pregnancy. The conceptus secretes IFNT which results in the differential expression of endometrial ISGs. The genes listed were the top 10 genes up-regulated in response to oIFNT treatment to epithelial and fibroblast cells and were also up-regulated in endometrial explants in response a conceptus and IFNT [143]. 


\section{REFERENCES}

1. Geary T. Management Strategies to Reduce Embryonic Loss. In. Range Beef Cow Symposium; 2005: 36.

2. Humblot P. Use of pregnancy specific proteins and progesterone assays to monitor pregnancy and determine the timing, frequencies and sources of embryonic mortality in ruminants. Theriogenology 2001; 56:1417-1433.

3. Thatcher WW, Guzeloglu A, Mattos R, Binelli M, Hansen TR, Pru JK. Uterine-conceptus interactions and reproductive failure in cattle. Theriogenology 2001; 56:1435-1450.

4. Inskeep EK. Preovulatory, postovulatory, and postmaternal recognition effects of concentrations of progesterone on embryonic survival in the cow. J Anim Sci 2004; 82 ESuppl:E24-39.

5. Northey DL, French LR. Effect of embryo removal and intrauterine infusion of embryonic homogenates on the lifespan of the bovine corpus luteum. J Anim Sci 1980; 50:298-302.

6. Yang H, Lei C, Cheng C, Feng Y, Zhang W, Petracco RG, Sak S. The antiapoptotic effect of galectin-3 in human endometrial cells under the regulation of estrogen and progesterone. Biol Reprod 2012; 87:39.

7. Senger PL. Pathways to pregnancy \& parturition. Redmond, OR: Current Conceptions; 2012.

8. Sirois J, Fortune JE. Ovarian follicular dynamics during the estrous cycle in heifers monitored by real-time ultrasonography. Biol Reprod 1988; 39:308-317.

9. Spell AR, Beal WE, Corah LR, Lamb GC. Evaluating recipient and embryo factors that affect pregnancy rates of embryo transfer in beef cattle. Theriogenology 2001; 56:287297.

10. Ivell R, Brackett KH, Fields MJ, Richter D. Ovulation triggers oxytocin gene expression in the bovine ovary. FEBS Lett 1985; 190:263-267.

11. Knickerbocker JJ, Thatcher WW, Foster DB, Wolfenson D, Bartol FF, Caton D. Uterine prostaglandin and blood flow responses to estradiol-17 beta in cyclic cattle.

Prostaglandins 1986; 31:757-776.

12. Cushman RA, Allan MF, Snowder GD, Thallman RM, Echternkamp SE. Evaluation of ovulation rate and ovarian phenotype in puberal heifers from a cattle population selected for increased ovulation rate. J Anim Sci 2005; 83:1839-1844.

13. Karamishabankareh H, Hajarian H, Shahsavari M, Moradinejad R. In vivo and in vitro study of the function of the left and right bovine ovaries. Theriogenology 2015; 84:724731.

14. Hugentobler SA, Diskin MG, Leese HJ, Humpherson PG, Watson T, Sreenan JM, Morris DG. Amino acids in oviduct and uterine fluid and blood plasma during the estrous cycle in the bovine. Mol Reprod Dev 2007; 74:445-454.

15. Hugentobler SA, Humpherson PG, Leese HJ, Sreenan JM, Morris DG. Energy substrates in bovine oviduct and uterine fluid and blood plasma during the oestrous cycle. Mol Reprod Dev 2008; 75:496-503.

16. Hugentobler SA, Morris DG, Sreenan JM, Diskin MG. Ion concentrations in oviduct and uterine fluid and blood serum during the estrous cycle in the bovine. Theriogenology 2007; 68:538-548. 
17. Rexroad CE, Powell AM. Development of ovine embryos co-cultured on oviductal cells, embryonic fibroblasts, or STO cell monolayers. Biol Reprod 1993; 49:789-793.

18. Wiltbank MC, Baez GM, Garcia-Guerra A, Toledo MZ, Monteiro PL, Melo LF, Ochoa JC, Santos JE, Sartori R. Pivotal periods for pregnancy loss during the first trimester of gestation in lactating dairy cows. Theriogenology 2016; 86:239-253.

19. Betteridge KJ, Eaglesome MD, Randall GC, Mitchell D. Collection, description and transfer of embryos from cattle 10--16 days after oestrus. J Reprod Fertil 1980; 59:205216.

20. Spencer TE, Hansen TR. Implantation and Establishment of Pregnancy in Ruminants. Adv Anat Embryol Cell Biol 2015; 216:105-135.

21. Berg DK, van Leeuwen J, Beaumont S, Berg M, Pfeffer PL. Embryo loss in cattle between Days 7 and 16 of pregnancy. Theriogenology 2010; 73:250-260.

22. Degrelle SA, Campion E, Cabau C, Piumi F, Reinaud P, Richard C, Renard JP, Hue I. Molecular evidence for a critical period in mural trophoblast development in bovine blastocysts. Dev Biol 2005; 288:448-460.

23. Clemente M, de La Fuente J, Fair T, Al Naib A, Gutierrez-Adan A, Roche JF, Rizos D, Lonergan P. Progesterone and conceptus elongation in cattle: a direct effect on the embryo or an indirect effect via the endometrium? Reproduction 2009; 138:507-517.

24. Gao H, Wu G, Spencer TE, Johnson GA, Bazer FW. Select nutrients in the ovine uterine lumen. ii. glucose transporters in the uterus and peri-implantation conceptuses. Biol Reprod 2009; 80:94-104.

25. Gao H, Wu G, Spencer TE, Johnson GA, Bazer FW. Select nutrients in the ovine uterine lumen. III. Cationic amino acid transporters in the ovine uterus and peri-implantation conceptuses. Biol Reprod 2009; 80:602-609.

26. Gao H, Wu G, Spencer TE, Johnson GA, Bazer FW. Select nutrients in the ovine uterine lumen. IV. Expression of neutral and acidic amino acid transporters in ovine uteri and peri-implantation conceptuses. Biol Reprod 2009; 80:1196-1208.

27. Gao H, Wu G, Spencer TE, Johnson GA, Li X, Bazer FW. Select nutrients in the ovine uterine lumen. I. Amino acids, glucose, and ions in uterine lumenal flushings of cyclic and pregnant ewes. Biol Reprod 2009; 80:86-93.

28. Wrenzycki C, Herrmann D, Carnwath JW, Niemann H. Expression of the gap junction gene connexin43 (Cx43) in preimplantation bovine embryos derived in vitro or in vivo. $\mathrm{J}$ Reprod Fertil 1996; 108:17-24.

29. Rizos D, Ward F, Duffy P, Boland MP, Lonergan P. Consequences of bovine oocyte maturation, fertilization or early embryo development in vitro versus in vivo: implications for blastocyst yield and blastocyst quality. Mol Reprod Dev 2002; 61:234248.

30. Gray CA, Burghardt RC, Johnson GA, Bazer FW, Spencer TE. Evidence that absence of endometrial gland secretions in uterine gland knockout ewes compromises conceptus survival and elongation. Reproduction 2002; 124:289-300.

31. Spencer TE, Gray CA. Sheep uterine gland knockout (UGKO) model. Methods Mol Med 2006; 121:85-94.

32. Lonergan P. Influence of progesterone on oocyte quality and embryo development in cows. Theriogenology 2011; 76:1594-1601.

33. Bazer FW, Spencer TE, Johnson GA. Interferons and uterine receptivity. Semin Reprod Med 2009; 27:90-102. 
34. Wooding FB, Wathes DC. Binucleate cell migration in the bovine placentome. J Reprod Fertil 1980; 59:425-430.

35. Bazer FW, Burghardt RC, Johnson GA, Spencer TE, Wu G. Interferons and progesterone for establishment and maintenance of pregnancy: interactions among novel cell signaling pathways. Reprod Biol 2008; 8:179-211.

36. Spencer TE, Bazer FW. Biology of progesterone action during pregnancy recognition and maintenance of pregnancy. Front Biosci 2002; 7:d1879-1898.

37. Ulbrich SE, Schulke K, Groebner AE, Reichenbach HD, Angioni C, Geisslinger G, Meyer HH. Quantitative characterization of prostaglandins in the uterus of early pregnant cattle. Reproduction 2009; 138:371-382.

38. Spencer TE, Forde N, Dorniak P, Hansen TR, Romero JJ, Lonergan P. Conceptusderived prostaglandins regulate gene expression in the endometrium prior to pregnancy recognition in ruminants. Reproduction 2013; 146:377-387.

39. Psychoyos A, Nikas G, Gravanis A. The role of prostaglandins in blastocyst implantation. Hum Reprod 1995; 10 Suppl 2:30-42.

40. González-Navajas JM, Lee J, David M, Raz E. Immunomodulatory functions of type I interferons. Nat Rev Immunol 2012; 12:125-135.

41. Kim S, Choi Y, Bazer FW, Spencer TE. Identification of genes in the ovine endometrium regulated by interferon tau independent of signal transducer and activator of transcription 1. Endocrinology 2003; 144:5203-5214.

42. Spencer TE, Sandra O, Wolf E. Genes involved in conceptus-endometrial interactions in ruminants: insights from reductionism and thoughts on holistic approaches. Reproduction 2008; 135:165-179.

43. Mathew DJ, Lucy MC, D Geisert R. Interleukins, interferons, and establishment of pregnancy in pigs. Reproduction 2016; 151:R111-122.

44. Stark GR. How cells respond to interferons revisited: from early history to current complexity. Cytokine Growth Factor Rev 2007; 18:419-423.

45. Choi Y, Johnson GA, Burghardt RC, Berghman LR, Joyce MM, Taylor KM, Stewart $\mathrm{MD}$, Bazer FW, Spencer TE. Interferon regulatory factor-two restricts expression of interferon-stimulated genes to the endometrial stroma and glandular epithelium of the ovine uterus. Biol Reprod 2001; 65:1038-1049.

46. Geisert R, Bazer F. Regulation of Implantation and Establishment of Pregnancy in Mammals: Tribute to 45 Year Anniversary of Roger V. Short's Maternal Recognition of Pregnancy. Regulation of Implantation and Establishment of Pregnancy in Mammals: Tribute To 45 Year Anniversary of Roger V. Short's Maternal Recognition of Pregnancy 2015; 216:1-270.

47. Patel OV, Yamada O, Kizaki K, Takahashi T, Imai K, Takahashi S, Izaike Y, Schuler LA, Takezawa T, Hashizume K. Expression of trophoblast cell-specific pregnancyrelated genes in somatic cell-cloned bovine pregnancies. Biol Reprod 2004; 70:11141120.

48. Austin KJ, King CP, Vierk JE, Sasser RG, Hansen TR. Pregnancy-specific protein B induces release of an alpha chemokine in bovine endometrium. Endocrinology 1999; 140:542-545.

49. Anthony RV, Liang R, Kayl EP, Pratt SL. The growth hormone/prolactin gene family in ruminant placentae. J Reprod Fertil Suppl 1995; 49:83-95. 
50. Soares MJ, Müller H, Orwig KE, Peters TJ, Dai G. The uteroplacental prolactin family and pregnancy. Biol Reprod 1998; 58:273-284.

51. Schlafer DH, Fisher PJ, Davies CJ. The bovine placenta before and after birth: placental development and function in health and disease. Anim Reprod Sci 2000; 60-61:145-160.

52. Ushizawa K, Takahashi T, Hosoe M, Kizaki K, Hashizume K. Characterization and expression analysis of SOLD1, a novel member of the retrotransposon-derived Ly-6 superfamily, in bovine placental villi. PLoS One 2009; 4:e5814.

53. Ushizawa K, Takahashi T, Hosoe M, Kizaki K, Hashizume K. Cloning and expression of SOLD1 in ovine and caprine placenta, and their expected roles during the development of placentomes. BMC Dev Biol 2010; 10:9.

54. Peippo J, Machaty Z, Peter A. Terminologies for the pre-attachment bovine embryo. Theriogenology 2011; 76:1373-1379.

55. Tveden-Nyborg PY, Alexopoulos NI, Cooney MA, French AJ, Tecirlioglu RT, Holland MK, Thomsen PD, D'Cruz NT. Analysis of the expression of putatively imprinted genes in bovine peri-implantation embryos. Theriogenology 2008; 70:1119-1128.

56. Mamo S, Rizos D, Lonergan P. Transcriptomic changes in the bovine conceptus between the blastocyst stage and initiation of implantation. Anim Reprod Sci 2012; 134:56-63.

57. Bauersachs $\mathrm{S}$, Wolf E. Transcriptome analyses of bovine, porcine and equine endometrium during the pre-implantation phase. Anim Reprod Sci 2012; 134:84-94.

58. Guzeloglu-Kayisli O, Kayisli UA, Taylor HS. The role of growth factors and cytokines during implantation: endocrine and paracrine interactions. Semin Reprod Med 2009; 27:62-79.

59. Watson AJ, Hogan A, Hahnel A, Wiemer KE, Schultz GA. Expression of growth factor ligand and receptor genes in the preimplantation bovine embryo. Mol Reprod Dev 1992; 31:87-95.

60. Aplin AE, Howe A, Alahari SK, Juliano RL. Signal transduction and signal modulation by cell adhesion receptors: the role of integrins, cadherins, immunoglobulin-cell adhesion molecules, and selectins. Pharmacol Rev 1998; 50:197-263.

61. Bai R, Bai H, Kuse M, Ideta A, Aoyagi Y, Fujiwara H, Okuda K, Imakawa K, Sakurai T. Involvement of VCAM1 in the bovine conceptus adhesion to the uterine endometrium. Reproduction 2014; 148:119-127.

62. Akiyama SK. Integrins in cell adhesion and signaling. Hum Cell 1996; 9:181-186.

63. Nagaoka K, Nojima H, Watanabe F, Chang KT, Christenson RK, Sakai S, Imakawa K. Regulation of blastocyst migration, apposition, and initial adhesion by a chemokine, interferon gamma-inducible protein $10 \mathrm{kDa}$ (IP-10), during early gestation. J Biol Chem 2003; 278:29048-29056.

64. Farmer JL, Burghardt RC, Jousan FD, Hansen PJ, Bazer FW, Spencer TE. Galectin 15 (LGALS15) functions in trophectoderm migration and attachment. FASEB J 2008; 22:548-560.

65. Simmons RM, Erikson DW, Kim J, Burghardt RC, Bazer FW, Johnson GA, Spencer TE. Insulin-like growth factor binding protein-1 in the ruminant uterus: potential endometrial marker and regulator of conceptus elongation. Endocrinology 2009; 150:4295-4305.

66. Chen HL, Yang YP, Hu XL, Yelavarthi KK, Fishback JL, Hunt JS. Tumor necrosis factor alpha mRNA and protein are present in human placental and uterine cells at early and late stages of gestation. Am J Pathol 1991; 139:327-335. 
67. Correia-Álvarez E, Gómez E, Martín D, Carrocera S, Pérez S, Peynot N, Giraud-Delville C, Caamaño JN, Balseiro A, Sandra O, Duranthon V, Muñoz M. Early embryonic and endometrial regulation of tumor necrosis factor and tumor necrosis factor receptor 2 in the cattle uterus. Theriogenology 2015; 83:1028-1037.

68. Okuda K, Kasahara Y, Murakami S, Takahashi H, Woclawek-Potocka I, Skarzynski DJ. Interferon-tau blocks the stimulatory effect of tumor necrosis factor-alpha on prostaglandin F2alpha synthesis by bovine endometrial stromal cells. Biol Reprod 2004; 70:191-197.

69. Roussev RG, Coulam CB, Kaider BD, Yarkoni M, Leavis PC, Barnea ER. Embryonic origin of preimplantation factor (PIF): biological activity and partial characterization. Mol Hum Reprod 1996; 2:883-887.

70. Barnea ER, Simon J, Levine SP, Coulam CB, Taliadouros GS, Leavis PC. Progress in characterization of pre-implantation factor in embryo cultures and in vivo. Am J Reprod Immunol 1999; 42:95-99.

71. Stamatkin CW, Roussev RG, Stout M, Absalon-Medina V, Ramu S, Goodman C, Coulam CB, Gilbert RO, Godke RA, Barnea ER. PreImplantation Factor (PIF) correlates with early mammalian embryo development-bovine and murine models. Reprod Biol Endocrinol 2011; 9:63.

72. Paidas MJ, Krikun G, Huang SJ, Jones R, Romano M, Annunziato J, Barnea ER. A genomic and proteomic investigation of the impact of preimplantation factor on human decidual cells. Am J Obstet Gynecol 2010; 202:459.e451-458.

73. Ayalon N. A review of embryonic mortality in cattle. J Reprod Fertil 1978; 54:483-493.

74. Sreenan JM, Diskin MG. Early embryonic mortality in the cow: its relationship with progesterone concentration. Vet Rec 1983; 112:517-521.

75. Santos JE, Thatcher WW, Chebel RC, Cerri RL, Galvão KN. The effect of embryonic death rates in cattle on the efficacy of estrus synchronization programs. Anim Reprod Sci 2004; 82-83:513-535.

76. Ahmad N, Schrick FN, Butcher RL, Inskeep EK. Effect of persistent follicles on early embryonic losses in beef cows. Biol Reprod 1995; 52:1129-1135.

77. Diskin MG, Sreenan JM. Fertilization and embryonic mortality rates in beef heifers after artificial insemination. J Reprod Fertil 1980; 59:463-468.

78. Diskin MG, Morris DG. Embryonic and early foetal losses in cattle and other ruminants. Reprod Domest Anim 2008; 43 Suppl 2:260-267.

79. Ortega HH, Marelli BE, Rey F, Amweg AN, Díaz PU, Stangaferro ML, Salvetti NR. Molecular aspects of bovine cystic ovarian disease pathogenesis. Reproduction 2015; 149:R251-264.

80. Salvetti NR, Alfaro NS, Velázquez MM, Amweg AN, Matiller V, Díaz PU, Ortega HH. Alteration in localization of steroid hormone receptors and coregulatory proteins in follicles from cows with induced ovarian follicular cysts. Reproduction 2012; 144:723735.

81. Marelli BE, Diaz PU, Salvetti NR, Rey F, Ortega HH. mRNA expression pattern of gonadotropin receptors in bovine follicular cysts. Reprod Biol 2014; 14:276-281.

82. Fradin C, Poulain D, Jouault T. beta-1,2-linked oligomannosides from Candida albicans bind to a 32-kilodalton macrophage membrane protein homologous to the mammalian lectin galectin-3. Infect Immun 2000; 68:4391-4398. 
83. Jung U, Ley K. Mice lacking two or all three selectins demonstrate overlapping and distinct functions for each selectin. J Immunol 1999; 162:6755-6762.

84. Johannes L, Jacob R, Leffler H. Galectins at a glance. J Cell Sci 2018; 131.

85. Barondes SH, Castronovo V, Cooper DN, Cummings RD, Drickamer K, Feizi T, Gitt MA, Hirabayashi J, Hughes C, Kasai K. Galectins: a family of animal beta-galactosidebinding lectins. Cell 1994; 76:597-598.

86. Liu FT, Rabinovich GA. Galectins as modulators of tumour progression. Nat Rev Cancer 2005; 5:29-41.

87. Dumic J, Dabelic S, Flögel M. Galectin-3: an open-ended story. Biochim Biophys Acta 2006; 1760:616-635.

88. Hirabayashi J, Kasai K. The family of metazoan metal-independent beta-galactosidebinding lectins: structure, function and molecular evolution. Glycobiology 1993; 3:297304.

89. Acosta-Rodríguez EV, Montes CL, Motrán CC, Zuniga EI, Liu FT, Rabinovich GA, Gruppi A. Galectin-3 mediates IL-4-induced survival and differentiation of B cells: functional cross-talk and implications during Trypanosoma cruzi infection. J Immunol 2004; 172:493-502.

90. Rabinovich GA, Baum LG, Tinari N, Paganelli R, Natoli C, Liu FT, Iacobelli S. Galectins and their ligands: amplifiers, silencers or tuners of the inflammatory response? Trends Immunol 2002; 23:313-320.

91. Ahmad N, Gabius HJ, André S, Kaltner H, Sabesan S, Roy R, Liu B, Macaluso F, Brewer CF. Galectin-3 precipitates as a pentamer with synthetic multivalent carbohydrates and forms heterogeneous cross-linked complexes. J Biol Chem 2004; 279:10841-10847.

92. Yang RY, Hsu DK, Liu FT. Expression of galectin-3 modulates T-cell growth and apoptosis. Proc Natl Acad Sci U S A 1996; 93:6737-6742.

93. Mehul B, Hughes RC. Plasma membrane targetting, vesicular budding and release of galectin 3 from the cytoplasm of mammalian cells during secretion. J Cell Sci 1997; 110 ( Pt 10):1169-1178.

94. Moutsatsos IK, Wade M, Schindler M, Wang JL. Endogenous lectins from cultured cells: nuclear localization of carbohydrate-binding protein 35 in proliferating $3 \mathrm{~T} 3$ fibroblasts. Proc Natl Acad Sci U S A 1987; 84:6452-6456.

95. Hughes RC. Secretion of the galectin family of mammalian carbohydrate-binding proteins. Biochim Biophys Acta 1999; 1473:172-185.

96. Nakahara S, Oka N, Raz A. On the role of galectin-3 in cancer apoptosis. Apoptosis 2005; 10:267-275.

97. Moon BK, Lee YJ, Battle P, Jessup JM, Raz A, Kim HR. Galectin-3 protects human breast carcinoma cells against nitric oxide-induced apoptosis: implication of galectin-3 function during metastasis. Am J Pathol 2001; 159:1055-1060.

98. Fukumori T, Takenaka Y, Yoshii T, Kim HR, Hogan V, Inohara H, Kagawa S, Raz A. CD29 and CD7 mediate galectin-3-induced type II T-cell apoptosis. Cancer Res 2003; 63:8302-8311.

99. Sharma UC, Pokharel S, van Brakel TJ, van Berlo JH, Cleutjens JP, Schroen B, André S, Crijns HJ, Gabius HJ, Maessen J, Pinto YM. Galectin-3 marks activated macrophages in failure-prone hypertrophied hearts and contributes to cardiac dysfunction. Circulation 2004; 110:3121-3128. 
100. de Oliveira FL, Gatto M, Bassi N, Luisetto R, Ghirardello A, Punzi L, Doria A. Galectin3 in autoimmunity and autoimmune diseases. Exp Biol Med (Maywood) 2015; 240:10191028.

101. Iurisci I, Tinari N, Natoli C, Angelucci D, Cianchetti E, Iacobelli S. Concentrations of galectin-3 in the sera of normal controls and cancer patients. Clin Cancer Res 2000; 6:1389-1393.

102. Castronovo V, Van Den Brûle FA, Jackers P, Clausse N, Liu FT, Gillet C, Sobel ME. Decreased expression of galectin-3 is associated with progression of human breast cancer. J Pathol 1996; 179:43-48.

103. Sanchez-Ruderisch H, Fischer C, Detjen KM, Welzel M, Wimmel A, Manning JC, André S, Gabius HJ. Tumor suppressor p16 INK4a: Downregulation of galectin-3, an endogenous competitor of the pro-anoikis effector galectin-1, in a pancreatic carcinoma model. FEBS J 2010; 277:3552-3563.

104. Song S, Ji B, Ramachandran V, Wang H, Hafley M, Logsdon C, Bresalier RS. Overexpressed galectin-3 in pancreatic cancer induces cell proliferation and invasion by binding Ras and activating Ras signaling. PLoS One 2012; 7:e42699.

105. Wang Y, Nangia-Makker P, Tait L, Balan V, Hogan V, Pienta KJ, Raz A. Regulation of prostate cancer progression by galectin-3. Am J Pathol 2009; 174:1515-1523.

106. Chung LY, Tang SJ, Sun GH, Chou TY, Yeh TS, Yu SL, Sun KH. Galectin-1 promotes lung cancer progression and chemoresistance by upregulating p38 MAPK, ERK, and cyclooxygenase-2. Clin Cancer Res 2012; 18:4037-4047.

107. Wang YG, Kim SJ, Baek JH, Lee HW, Jeong SY, Chun KH. Galectin-3 increases the motility of mouse melanoma cells by regulating matrix metalloproteinase-1 expression. Exp Mol Med 2012; 44:387-393.

108. Song S, Mazurek N, Liu C, Sun Y, Ding QQ, Liu K, Hung MC, Bresalier RS. Galectin-3 mediates nuclear beta-catenin accumulation and Wnt signaling in human colon cancer cells by regulation of glycogen synthase kinase-3beta activity. Cancer Res 2009; 69:1343-1349.

109. Shimura T, Takenaka Y, Fukumori T, Tsutsumi S, Okada K, Hogan V, Kikuchi A, Kuwano H, Raz A. Implication of galectin-3 in Wnt signaling. Cancer Res 2005; 65:3535-3537.

110. Shimura T, Takenaka Y, Tsutsumi S, Hogan V, Kikuchi A, Raz A. Galectin-3, a novel binding partner of beta-catenin. Cancer Res 2004; 64:6363-6367.

111. Ho JE, Liu C, Lyass A, Courchesne P, Pencina MJ, Vasan RS, Larson MG, Levy D. Galectin-3, a marker of cardiac fibrosis, predicts incident heart failure in the community. J Am Coll Cardiol 2012; 60:1249-1256.

112. de Boer RA, van der Velde AR, Mueller C, van Veldhuisen DJ, Anker SD, Peacock WF, Adams KF, Maisel A. Galectin-3: a modifiable risk factor in heart failure. Cardiovasc Drugs Ther 2014; 28:237-246.

113. Calvier L, Miana M, Reboul P, Cachofeiro V, Martinez-Martinez E, de Boer RA, Poirier F, Lacolley P, Zannad F, Rossignol P, López-Andrés N. Galectin-3 mediates aldosteroneinduced vascular fibrosis. Arterioscler Thromb Vasc Biol 2013; 33:67-75.

114. Kolatsi-Joannou M, Price KL, Winyard PJ, Long DA. Modified citrus pectin reduces galectin-3 expression and disease severity in experimental acute kidney injury. PLoS One 2011; 6:e18683. 
115. Lee VH, Lee AB, Phillips EB, Roberts JK, Weitlauf HM. Spatio-temporal pattern for expression of galectin-3 in the murine utero-placental complex: evidence for differential regulation. Biol Reprod 1998; 58:1277-1282.

116. Phillips B, Knisley K, Weitlauf KD, Dorsett J, Lee V, Weitlauf H. Differential expression of two beta-galactoside-binding lectins in the reproductive tracts of pregnant mice. Biol Reprod 1996; 55:548-558.

117. Kim M, Kim S, Kim H, Joo HG, Shin T. Immunohistochemical localization of galectin-3 in the reproductive organs of the cow. Acta Histochem 2008; 110:473-480.

118. Hashiba K, Sano M, Nio-Kobayashi J, Hojo T, Skarzynski DJ, Okuda K. Galectin-3 contributes to luteolysis by binding to Beta 1 integrin in the bovine corpus luteum. Biol Reprod 2014; 91:2.

119. Guzeloglu-Kayisli O, Basar M, Arici A. Basic aspects of implantation. Reprod Biomed Online 2007; 15:728-739.

120. Bao Q, Hughes RC. Galectin-3 expression and effects on cyst enlargement and tubulogenesis in kidney epithelial MDCK cells cultured in three-dimensional matrices in vitro. J Cell Sci 1995; 108 ( Pt 8):2791-2800.

121. Yang H, Yin J, Ficarrotta K, Hsu SH, Zhang W, Cheng C. Aberrant expression and hormonal regulation of Galectin-3 in endometriosis women with infertility. J Endocrinol Invest. 2016; 39:785-791.

122. Yang JT, Rayburn H, Hynes RO. Cell adhesion events mediated by alpha 4 integrins are essential in placental and cardiac development. Development 1995; 121:549-560.

123. Reddy KV, Mangale SS. Integrin receptors: the dynamic modulators of endometrial function. Tissue Cell 2003; 35:260-273.

124. Zhong X, Rescorla FJ. Cell surface adhesion molecules and adhesion-initiated signaling: understanding of anoikis resistance mechanisms and therapeutic opportunities. Cell Signal 2012; 24:393-401.

125. Frisch SM, Francis H. Disruption of epithelial cell-matrix interactions induces apoptosis. J Cell Biol 1994; 124:619-626.

126. Fortier MA, Guilbault LA, Grasso F. Specific properties of epithelial and stromal cells from the endometrium of cows. J Reprod Fertil 1988; 83:239-248.

127. MacKintosh SB, Schuberth HJ, Healy LL, Sheldon IM. Polarised bovine endometrial epithelial cells vectorially secrete prostaglandins and chemotactic factors under physiological and pathological conditions. Reproduction 2013; 145:57-72.

128. Wira CR, Grant-Tschudy KS, Crane-Godreau MA. Epithelial cells in the female reproductive tract: a central role as sentinels of immune protection. Am J Reprod Immunol 2005; 53:65-76.

129. González-Mariscal L, Tapia R, Chamorro D. Crosstalk of tight junction components with signaling pathways. Biochim Biophys Acta 2008; 1778:729-756.

130. Giepmans BN, van Ijzendoorn SC. Epithelial cell-cell junctions and plasma membrane domains. Biochim Biophys Acta 2009; 1788:820-831.

131. Fincher KB, Bazer FW, Hansen PJ, Thatcher WW, Roberts RM. Proteins secreted by the sheep conceptus suppress induction of uterine prostaglandin F-2 alpha release by oestradiol and oxytocin. J Reprod Fertil 1986; 76:425-433.

132. Bazer FW, Wu G, Spencer TE, Johnson GA, Burghardt RC, Bayless K. Novel pathways for implantation and establishment and maintenance of pregnancy in mammals. Mol Hum Reprod 2010; 16:135-152. 
133. Wells V, Mallucci L. Identification of an autocrine negative growth factor: mouse betagalactoside-binding protein is a cytostatic factor and cell growth regulator. Cell 1991; 64:91-97.

134. Than NG, Romero R, Balogh A, Karpati E, Mastrolia SA, Staretz-Chacham O, Hahn S, Erez O, Papp Z, Kim CJ. Galectins: Double-edged Swords in the Cross-roads of Pregnancy Complications and Female Reproductive Tract Inflammation and Neoplasia. J Pathol Transl Med 2015; 49:181-208.

135. Griffioen AW, Thijssen VL. Galectins in tumor angiogenesis. Ann Transl Med 2014; 2:90.

136. Noël JC, Chapron C, Borghese B, Fayt I, Anaf V. Galectin-3 is overexpressed in various forms of endometriosis. Appl Immunohistochem Mol Morphol 2011; 19:253-257.

137. Brinchmann MF, Patel DM, Iversen MH. The Role of Galectins as Modulators of Metabolism and Inflammation. Mediators Inflamm 2018; 2018:9186940.

138. Okumu LA, Fair T, Szekeres-Bartho J, O'Doherty AM, Crowe MA, Roche JF, Lonergan $\mathrm{P}$, Forde N. Endometrial expression of progesterone-induced blocking factor and galectins- $1,-3,-9$, and -3 binding protein in the luteal phase and early pregnancy in cattle. Physiol Genomics 2011; 43:903-910.

139. Larson JE, Lamb GC, Stevenson JS, Johnson SK, Day ML, Geary TW, Kesler DJ, DeJarnette JM, Schrick FN, DiCostanzo A, Arseneau JD. Synchronization of estrus in suckled beef cows for detected estrus and artificial insemination and timed artificial insemination using gonadotropin-releasing hormone, prostaglandin F2alpha, and progesterone. J Anim Sci 2006; 84:332-342.

140. Jackson C, Neville T, Mercadante V, Waters K, Lamb G, Dahlen C, Redden R. Efficacy of various five-day estrous synchronization protocols in sheep. Small Ruminant Research 2014; 120:100-107.

141. Hellemans J, Mortier G, De Paepe A, Speleman F, Vandesompele J. qBase relative quantification framework and software for management and automated analysis of realtime quantitative PCR data. Genome Biol 2007; 8:R19.

142. Vandesompele J, De Preter K, Pattyn F, Poppe B, Van Roy N, De Paepe A, Speleman F. Accurate normalization of real-time quantitative RT-PCR data by geometric averaging of multiple internal control genes. Genome Biol 2002; 3:RESEARCH0034.

143. Mathew DJ, Sánchez JM, Passaro C, Charpigny G, Behura SK, Spencer TE, Lonergan P. Interferon tau-dependent and independent effects of the bovine conceptus on the endometrial transcriptome $\dagger$. Biol Reprod 2019; 100:365-380.

144. Mohan M, Hurst AG, Malayer JR. Global gene expression analysis comparing bovine blastocysts flushed on day 7 or produced in vitro. Mol Reprod Dev 2004; 68:288-298.

145. Tirado-González I, Freitag N, Barrientos G, Shaikly V, Nagaeva O, Strand M, Kjellberg L, Klapp BF, Mincheva-Nilsson L, Cohen M, Blois SM. Galectin-1 influences trophoblast immune evasion and emerges as a predictive factor for the outcome of pregnancy. Mol Hum Reprod 2013; 19:43-53.

146. You JL, Wang W, Tang MY, Ye YH, Liu AX, Zhu YM. A potential role of galectin-1 in promoting mouse trophoblast stem cell differentiation. Mol Cell Endocrinol 2018; 470:228-239.

147. Than NG, Erez O, Wildman DE, Tarca AL, Edwin SS, Abbas A, Hotra J, Kusanovic JP, Gotsch F, Hassan SS, Espinoza J, Papp Z, et al. Severe preeclampsia is characterized by 
increased placental expression of galectin-1. J Matern Fetal Neonatal Med 2008; 21 :429442.

148. Menkhorst EM, Gamage T, Cuman C, Kaitu'u-Lino TJ, Tong S, Dimitriadis E. Galectin7 acts as an adhesion molecule during implantation and increased expression is associated with miscarriage. Placenta 2014; 35:195-201.

149. Menkhorst E, Koga K, Van Sinderen M, Dimitriadis E. Galectin-7 serum levels are altered prior to the onset of pre-eclampsia. Placenta 2014; 35:281-285.

150. Kolundžić N, Bojić-Trbojević Z, Radojčić L, Petronijević M, Vićovac L. Galectin-8 is expressed by villous and extravillous trophoblast of the human placenta. Placenta 2011; 32:909-911.

151. Shimizu Y, Kabir-Salmani M, Azadbakht M, Sugihara K, Sakai K, Iwashita M. Expression and localization of galectin-9 in the human uterodome. Endocr J 2008; 55:879-887.

152. Blois SM, Barrientos G. Galectin signature in normal pregnancy and preeclampsia. J Reprod Immunol 2014; 101-102:127-134.

153. Passaro C, Tutt D, Mathew DJ, Sanchez JM, Browne JA, Boe-Hansen GB, Fair T, Lonergan P. Blastocyst-induced changes in the bovine endometrial transcriptome. Reproduction 2018; 156:219-229.

154. Michael DD, Alvarez IM, Ocón OM, Powell AM, Talbot NC, Johnson SE, Ealy AD. Fibroblast growth factor- 2 is expressed by the bovine uterus and stimulates interferon-tau production in bovine trophectoderm. Endocrinology 2006; 147:3571-3579.

155. Spencer TE, Bazer FW. Ovine interferon tau suppresses transcription of the estrogen receptor and oxytocin receptor genes in the ovine endometrium. Endocrinology 1996; 137:1144-1147.

156. Stewart MD, Stewart DM, Johnson GA, Vyhlidal CA, Burghardt RC, Safe SH, Yu-Lee LY, Bazer FW, Spencer TE. Interferon-tau activates multiple signal transducer and activator of transcription proteins and has complex effects on interferon-responsive gene transcription in ovine endometrial epithelial cells. Endocrinology 2001; 142:98-107.

157. Johnson GA, Stewart MD, Gray CA, Choi Y, Burghardt RC, Yu-Lee LY, Bazer FW, Spencer TE. Effects of the estrous cycle, pregnancy, and interferon tau on 2',5'oligoadenylate synthetase expression in the ovine uterus. Biol Reprod 2001; 64:13921399.

158. Ireland JJ, Murphee RL, Coulson PB. Accuracy of predicting stages of bovine estrous cycle by gross appearance of the corpus luteum. J Dairy Sci 1980; 63:155-160.

159. Moraes JGN, Behura SK, Geary TW, Hansen PJ, Neibergs HL, Spencer TE. Uterine influences on conceptus development in fertility-classified animals. Proc Natl Acad Sci U S A 2018; 115:E1749-E1758.

160. Bolger AM, Lohse M, Usadel B. Trimmomatic: a flexible trimmer for Illumina sequence data. Bioinformatics 2014; 30:2114-2120.

161. Kim D, Langmead B, Salzberg SL. HISAT: a fast spliced aligner with low memory requirements. Nat Methods 2015; 12:357-360.

162. Liao Y, Smyth GK, Shi W. featureCounts: an efficient general purpose program for assigning sequence reads to genomic features. Bioinformatics 2014; 30:923-930.

163. Zhou X, Lindsay H, Robinson MD. Robustly detecting differential expression in RNA sequencing data using observation weights. Nucleic Acids Res 2014; 42:e91. 
164. Huang dW, Sherman BT, Lempicki RA. Systematic and integrative analysis of large gene lists using DAVID bioinformatics resources. Nat Protoc 2009; 4:44-57.

165. Klein C, Bauersachs S, Ulbrich SE, Einspanier R, Meyer HH, Schmidt SE, Reichenbach HD, Vermehren M, Sinowatz F, Blum H, Wolf E. Monozygotic twin model reveals novel embryo-induced transcriptome changes of bovine endometrium in the preattachment period. Biol Reprod 2006; 74:253-264.

166. Walker CG, Meier S, Littlejohn MD, Lehnert K, Roche JR, Mitchell MD. Modulation of the maternal immune system by the pre-implantation embryo. BMC Genomics 2010; 11:474.

167. Gray CA, Adelson DL, Bazer FW, Burghardt RC, Meeusen EN, Spencer TE. Discovery and characterization of an epithelial-specific galectin in the endometrium that forms crystals in the trophectoderm. Proc Natl Acad Sci U S A 2004; 101:7982-7987.

168. Forde N, Carter F, Spencer TE, Bazer FW, Sandra O, Mansouri-Attia N, Okumu LA, McGettigan PA, Mehta JP, McBride R, O'Gaora P, Roche JF, et al. Conceptus-induced changes in the endometrial transcriptome: how soon does the cow know she is pregnant? Biol Reprod 2011; 85:144-156.

169. Spencer TE, Forde N, Lonergan P. The role of progesterone and conceptus-derived factors in uterine biology during early pregnancy in ruminants. J Dairy Sci 2016; 99:5941-5950.

170. Stark GR, Kerr IM, Williams BR, Silverman RH, Schreiber RD. How cells respond to interferons. Annu Rev Biochem 1998; 67:227-264.

171. Romero JJ, Antoniazzi AQ, Nett TM, Ashley RL, Webb BT, Smirnova NP, Bott RC, Bruemmer JE, Bazer FW, Anthony RV, Hansen TR. Temporal Release, Paracrine and Endocrine Actions of Ovine Conceptus-Derived Interferon-Tau During Early Pregnancy. Biol Reprod 2015; 93:146.

172. Hansen TR, Henkes LK, Ashley RL, Bott RC, Antoniazzi AQ, Han H. Endocrine actions of interferon-tau in ruminants. Soc Reprod Fertil Suppl 2010; 67:325-340.

173. Yankey SJ, Hicks BA, Carnahan KG, Assiri AM, Sinor SJ, Kodali K, Stellflug JN, Ott TL. Expression of the antiviral protein $\mathrm{Mx}$ in peripheral blood mononuclear cells of pregnant and bred, non-pregnant ewes. J Endocrinol 2001; 170:R7-11.

174. Song G, Bazer FW, Spencer TE. Pregnancy and interferon tau regulate RSAD2 and IFIH1 expression in the ovine uterus. Reproduction 2007; 133:285-295.

175. Joyce MM, White FJ, Burghardt RC, Muñiz JJ, Spencer TE, Bazer FW, Johnson GA. Interferon stimulated gene 15 conjugates to endometrial cytosolic proteins and is expressed at the uterine-placental interface throughout pregnancy in sheep. Endocrinology 2005; 146:675-684.

176. Song G, Spencer TE, Bazer FW. Progesterone and interferon-tau regulate cystatin C in the endometrium. Endocrinology 2006; 147:3478-3483.

177. Lewis SK, Farmer JL, Burghardt RC, Newton GR, Johnson GA, Adelson DL, Bazer FW, Spencer TE. Galectin 15 (LGALS15): a gene uniquely expressed in the uteri of sheep and goats that functions in trophoblast attachment. Biol Reprod 2007; 77:1027-1036.

178. Forde N, Bazer FW, Spencer TE, Lonergan P. 'Conceptualizing' the Endometrium: Identification of Conceptus-Derived Proteins During Early Pregnancy in Cattle. Biol Reprod 2015; 92:156.

179. Inohara H, Akahani S, Koths K, Raz A. Interactions between galectin-3 and Mac-2binding protein mediate cell-cell adhesion. Cancer Res 1996; 56:4530-4534. 
180. Godkin JD, Smith SE, Johnson RD, Doré JJ. The role of trophoblast interferons in the maintenance of early pregnancy in ruminants. Am J Reprod Immunol 1997; 37:137-143.

181. Groebner AE, Rubio-Aliaga I, Schulke K, Reichenbach HD, Daniel H, Wolf E, Meyer $\mathrm{HH}$, Ulbrich SE. Increase of essential amino acids in the bovine uterine lumen during preimplantation development. Reproduction 2011; 141:685-695.

182. Gao G, Guo X, Goff SP. Inhibition of retroviral RNA production by ZAP, a CCCH-type zinc finger protein. Science 2002; 297:1703-1706.

183. Kerns JA, Emerman M, Malik HS. Positive selection and increased antiviral activity associated with the PARP-containing isoform of human zinc-finger antiviral protein. PLoS Genet 2008; 4:e21.

184. Cagliani R, Guerini FR, Fumagalli M, Riva S, Agliardi C, Galimberti D, Pozzoli U, Goris A, Dubois B, Fenoglio C, Forni D, Sanna S, et al. A trans-specific polymorphism in ZC3HAV1 is maintained by long-standing balancing selection and may confer susceptibility to multiple sclerosis. Mol Biol Evol 2012; 29:1599-1613.

185. Ozawa M, Sakatani M, Yao J, Shanker S, Yu F, Yamashita R, Wakabayashi S, Nakai K, Dobbs KB, Sudano MJ, Farmerie WG, Hansen PJ. Global gene expression of the inner cell mass and trophectoderm of the bovine blastocyst. BMC Dev Biol 2012; 12:33.

186. Weiner CM, Smirnova NP, Webb BT, Van Campen H, Hansen TR. Interferon stimulated genes, CXCR4 and immune cell responses in peripheral blood mononuclear cells infected with bovine viral diarrhea virus. Res Vet Sci 2012; 93:1081-1088. 